Supporting Information for:

\title{
Synthesis and Diels-Alder Reactivity of Substituted [4]Dendralenes
}

Mehmet F. Saglam, ${ }^{\dagger}$ Ali R. Alborzi,$^{\dagger}$ Alan D. Payne,$^{\dagger}$ Anthony C. Willis,,$^{\dagger \dagger}$ Michael N. PaddonRow $^{\S}$ and Michael S. Sherburn ${ }^{*} \dagger$

${ }^{\dagger}$ Research School of Chemistry, Australian National University, Canberra, ACT 2601, Australia.

${ }^{\S}$ School of Chemistry, The University of New South Wales, Sydney, NSW 2052, Australia.

*E-mail: michael.sherburn@anu.edu.au

\section{Table of Contents}

$\underline{\text { Page }}$

1. Experimental Section ..................................................................................................... S2

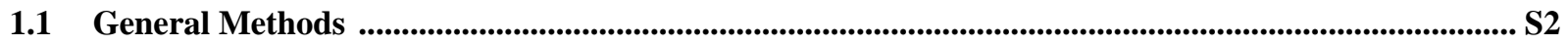

1.2 Diels-Alder Reaction Between [4]Dendralene (1) and $N$-Methylmaleimide (NMM) in Various Solvents

1.3 Competitive NMR Experiment for the Diels-Alder Reaction Between a 2:1 mixture of Isoprene (67) and 2,3-Dimethyl-1,3-butadiene (68) and $N$-Methylmaleimide (NMM) ................................................. S5

2. Crystallography Section........................................................................................................... S7

2.1 Crystallographic Data for $33,36,40,41,45,47,50,54,55,58,59$, and 60 . ...................................S7

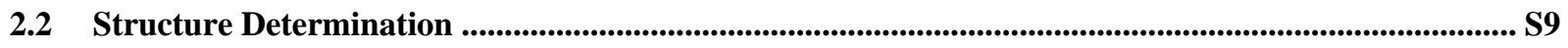

2.3 Anisotropic Displacement Ellipsoid Plots for 33, 36, 40, 41, 45, 47, 50, 54, 55, 58, 59, and 60. ........ S11

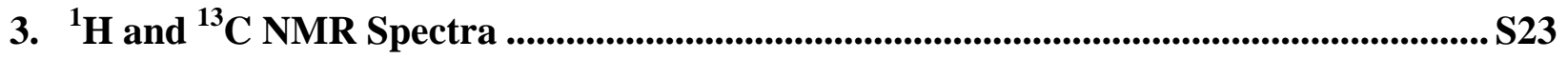

4. Stereochemical Assignments for 13, 14, 23, 24, 32, 37, 46, and 51................................ S85

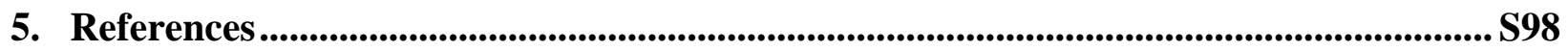

$\$$ Author to whom correspondence should be addressed regarding crystal structures. (willis@rsc.anu.edu.au). 


\section{Experimental Section}

\subsection{General Methods}

Reactions were performed under a positive pressure of dry nitrogen in oven or flame dried glassware, unless otherwise specified. Anhydrous THF was dried over sodium wire and distilled from sodium benzophenone ketyl. Other anhydrous solvents were dried using a solvent purification system outlined in the procedure by Grubbs et al. ${ }^{1}$ Commercially available chemicals were used as purchased or purified by standard procedures. ${ }^{2}$ Grignard reagents were titrated against salicylaldehyde phenylhydrazone according to the procedure of Love and Jones. ${ }^{3}$ Microwave reactions were performed using a CEM Discovery instrument.

\section{Chromatography}

Analytical thin-layer chromatography (TLC) was performed with silica gel plates, precoated with silica gel $60 \mathrm{~F}_{254}(0.2 \mathrm{~mm})$ on aluminium sheets and visualized using UV fluorescence $\left(\lambda_{\max }=\right.$ $254 \mathrm{~nm}$ ) and flash column chromatography employed using 230-400 mesh silica gel. Analytical high performance liquid chromatography (HPLC) was performed using on a $5 \mu \mathrm{m}, 4.6 \times 150 \mathrm{~mm}$, C18 column or a $5 \mu \mathrm{m}, 10 \times 250 \mathrm{~mm}, \mathrm{C} 18$ column.

\section{NMR Spectroscopy}

${ }^{1} \mathrm{H}$ and ${ }^{13} \mathrm{C}$ NMR spectra were recorded at $298 \mathrm{~K}$ using either 300,400 , or $800 \mathrm{MHz}$ spectrometers. Residual chloroform $\left(\mathrm{CHCl}_{3}\right.$ in $\left.\mathrm{CDCl}_{3}\right)(\delta=7.26 \mathrm{ppm})$ was used for ${ }^{1} \mathrm{H}$ NMR spectra and the central line of the deuterochloroform $\left(\mathrm{CDCl}_{3}\right)$ triplet $(\delta=77.1 \mathrm{ppm})$ was used for

${ }^{13} \mathrm{C}$ NMR spectra as an internal reference. Assignment of proton and carbon signals were assisted by DEPT, COSY, HSQC or HMBC experiments where necessary. 


\section{Infrared Spectroscopy}

Infrared spectra were recorded on a FT-IR spectrometer as neat films on $\mathrm{NaCl}$ plates for oils or as $\mathrm{KBr}$ disks for solids.

\section{Mass Spectroscopy}

Low resolution mass spectra (LRMS) and high resolution mass spectra (HRMS) were recorded on a magnetic sector mass spectrometer using electron impact $\left(\mathrm{EI}^{+}\right)$ionization mode at $70 \mathrm{eV}$. LRMS were reported with intensities quoted as percentages of the base peak.

\section{Melting Points}

Melting points were measured on a hot stage melting points apparatus and are uncorrected. 


\subsection{Diels-Alder Reaction Between [4]Dendralene (1) and $N$-Methylmaleimide (NMM) in Various Solvents}

The solvent dependence of the Diels-Alder reaction between parent [4]dendralene (1) and excess NMM (3 mol equiv) was examined. The product distribution obtained from reactions performed in THF, $\mathrm{CH}_{2} \mathrm{Cl}_{2}$ and $\mathrm{CDCl}_{3}$ were the same, demonstrating no significant solvent influence.

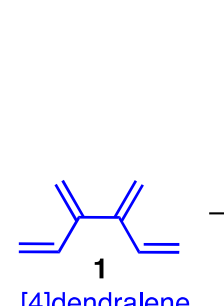

[4]dendralene

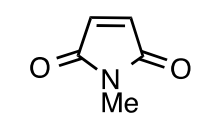

(3.0 mol equiv)

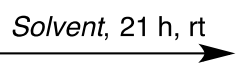

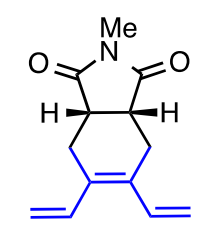

3
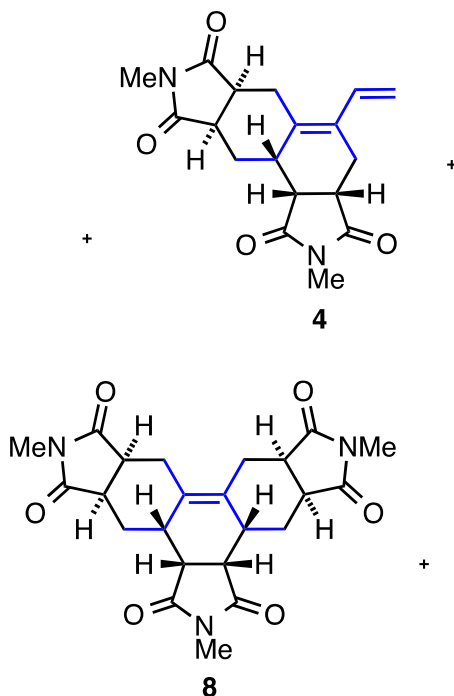

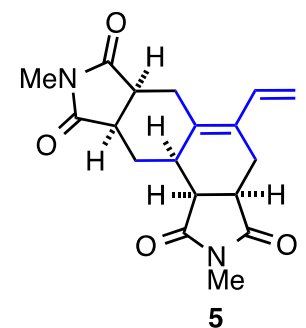

5

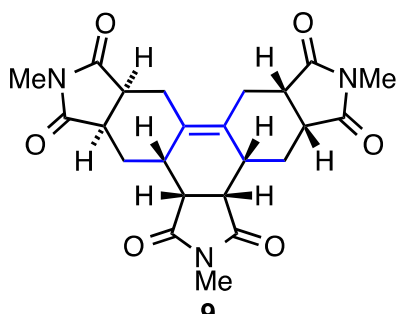

Scheme S1: Diels-Alder reaction between [4]dendralene (1) and excess NMM (3 mol equiv) in different solvents (THF, $\mathrm{CH}_{2} \mathrm{Cl}_{2}$ and $\mathrm{CDCl}_{3}$ ) at room temperature.

Experimental procedure: A reaction vessel was charged with [4]dendralene (1) (15 mg, 0.14 mmol, 1.0 mol equiv), solvent $(0.50 \mathrm{~mL})$, and NMM (47 mg, $0.42 \mathrm{mmol}, 3.0 \mathrm{~mol}$ equiv) and then capped. The reaction mixture was stirred for 21 hours at room temperature. The product composition was determined by analysis of the ${ }^{1} \mathrm{H}$ NMR spectra $\left(800 \mathrm{MHz}\right.$, at $25{ }^{\circ} \mathrm{C}$, in $\left.\mathrm{CDCl}_{3}\right)$ (Table S1). In the case of the $\mathrm{CDCl}_{3}$ reactions, direct analyses of the reaction mixtures by ${ }^{1} \mathrm{H}$ NMR spectroscopy was carried out. With runs in THF and $\mathrm{CH}_{2} \mathrm{Cl}_{2}$, the solvent was removed under reduced pressure before $\mathrm{CDCl}_{3}(0.5 \mathrm{~mL})$ was added and the ${ }^{1} \mathrm{H}$ NMR spectrum was recorded. 


\begin{tabular}{|c|c|c|c|c|c|}
\cline { 2 - 6 } \multicolumn{1}{c|}{} & \multicolumn{5}{c|}{ Product Ratio $^{(\boldsymbol{a})}$} \\
\hline Solvent & $\mathbf{3}$ & $\mathbf{4}$ & $\mathbf{5}$ & $\mathbf{8}$ & $\mathbf{9}$ \\
\hline $\mathrm{CDCl}_{3}{ }^{(\boldsymbol{b})}$ & 24 & 42 & 6 & 14 & 14 \\
\hline $\mathrm{CDCl}_{3}{ }^{(\boldsymbol{c})}$ & 26 & 42 & 6 & 13 & 13 \\
\hline $\mathrm{CH}_{2} \mathrm{Cl}_{2}$ & 24 & 44 & 6 & 13 & 13 \\
\hline $\mathrm{THF}$ & 21 & 49 & 7 & 11 & 12 \\
\hline
\end{tabular}

Table S1: Diels-Alder reaction between parent [4]dendralene (1) and excess (3 mol equiv) of NMM in different solvents at room temperature. (a) The crude product ratio was calculated based upon analysis of the crude ${ }^{1} \mathrm{H}$ NMR spectra $\left(800 \mathrm{MHz}\right.$, at $25^{\circ} \mathrm{C}$, in $\left.\mathrm{CDCl}_{3}\right),(\boldsymbol{b})$

Commercial $\mathrm{CDCl}_{3}$ was used directly as received. (c) $\mathrm{CDCl}_{3}$ was stored over $\mathrm{K}_{2} \mathrm{CO}_{3}$ and $3 \AA$ molecular sieves before use.

\subsection{Competition Experiment: Diels-Alder Reaction Between a 2:1 (Isoprene (67) : 2,3-Dimethyl-1,3-butadiene (68)) Mixture and $N$-Methylmaleimide (NMM)}

The outcome of the reaction between the parent [4]dendralene (1) and excess NMM is shown in Scheme 2 of the main manuscript. Of the five products formed, four are the result of addition to the mono-substituted diene site and the remaining one product results from addition to the disubstituted diene site. The mono-substituted diene site of [4]dendralene (1) is preferred over the di-substituted diene site in a ratio of 78:22 (Scheme S2, top). To test if this outcome is simply the result of a preference for addition to a 2-substituted diene over a 2,3-disubstituted diene, a competition experiment was performed in which NMM was treated with a 2:1 mixture of isoprene (67) and 2,3-dimethyl-1,3-butadiene (68). This experiment gave a slight preference for 
the more substituted diene (Scheme S2, bottom), demonstrating that [4]dendralene (1) does not behave as a simple mixtures of 1,3-butadienes.

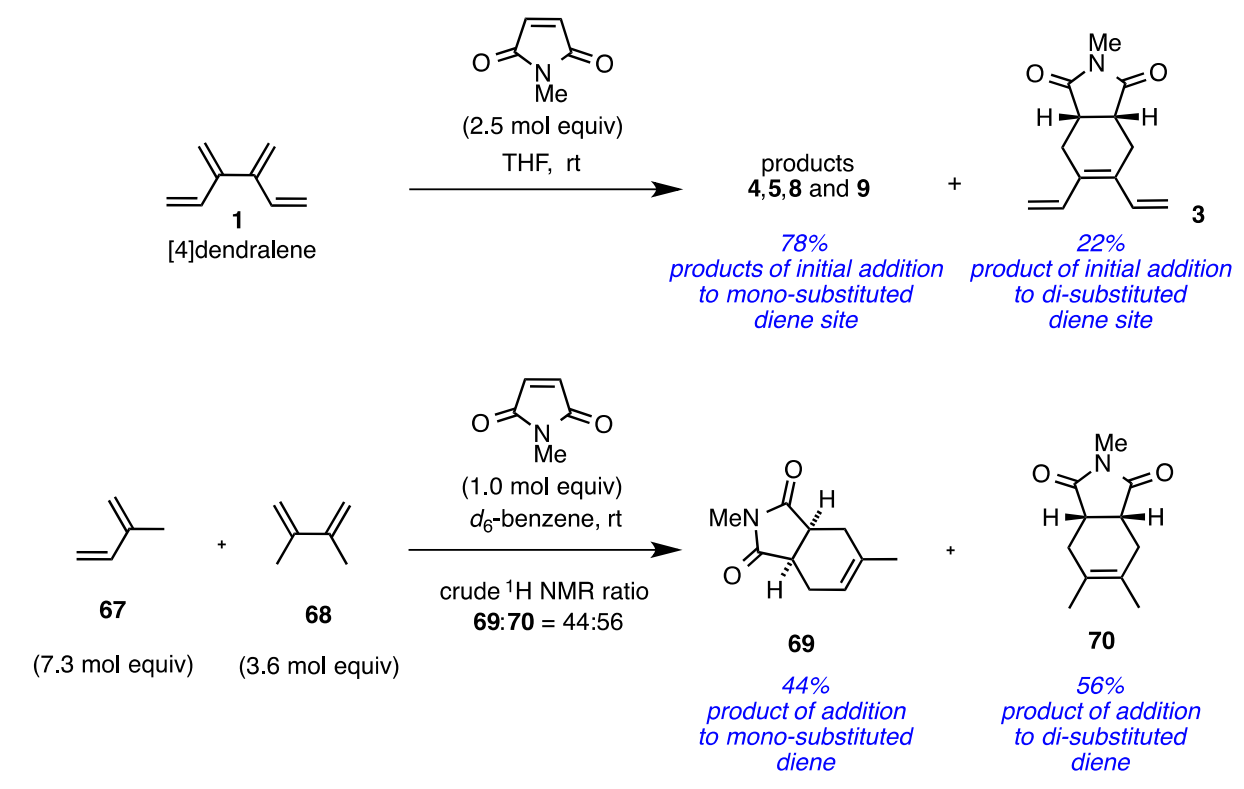

Scheme S2: A comparison of (top equation) the reactivity of [4]dendralene with NMM with (bottom equation) a 2:1 (isoprene (67) : 2,3-dimethyl-1,3-butadiene (68)) mixture with NMM.

Experimental procedure: An NMR tube was charged with a 2:1 mixture of isoprene (67) (38 mg, $0.56 \mathrm{mmol}, 7.3 \mathrm{~mol}$ equiv) and 2,3-dimethyl-1,3-butadiene (68) (23 mg, $0.28 \mathrm{mmol}, 3.6 \mathrm{~mol}$ equiv), anisole (internal standard, $19 \mathrm{mg}$ ) and $d_{6}$-benzene. To this was added a solution of $N$ methylmaleimide ( $8.6 \mathrm{mg}, 0.077 \mathrm{mmol}, 1.0 \mathrm{~mol}$ equiv) in $d_{6}$-benzene $(0.30 \mathrm{~mL})$. The resulting solution was allowed to stand for 16 hours at room temperature. The reaction progression was monitored by ${ }^{1} \mathrm{H}$ NMR spectroscopy and the reaction was deemed complete when NMM could no longer be observed. The ratio of the corresponding products $69^{4}$ and $\mathbf{7 0}^{5}$ (44:56) was obtained from integration of the ${ }^{1} \mathrm{H}$ NMR spectrum of the reaction mixture. 


\section{Crystallography Section}

\subsection{Crystallographic Data for $33,36,40,41,45,47,50,54,55,58,59$, and 60 .}

Compound 33: $\mathrm{C}_{19} \mathrm{H}_{22} \mathrm{~N}_{2} \mathrm{O}_{4}, M=342.39, T=200 \mathrm{~K}$, monoclinic, space group $P 2_{1}, Z=2, a=$ 9.2230(4), $b=10.8655(2), c=9.4767(3) \AA, \beta=115.290(2)^{\circ} ; V=858.67(6) \AA^{3}, D_{x}=1.324 \mathrm{~g}$ $\mathrm{cm}^{-3}, 2067$ unique data $\left(2 \theta_{\max }=55^{\circ}\right), R=0.041$ [for 1933 reflections with $I>2.0 \sigma(I)$ ]; $R w=$ 0.104 (all data), $S=1.01$.

Compound 36: $\mathrm{C}_{24} \mathrm{H}_{27} \mathrm{~N}_{3} \mathrm{O}_{6}, M=453.49, T=150 \mathrm{~K}$, monoclinic, space group $P 2_{1} / n, Z=12, a=$ $10.1654(2), b=23.4039(7), c=27.8440(7) \AA, \beta=97.1260(15)^{\circ} ; V=6573.2(3) \AA^{3}, D_{x}=1.375$ $\mathrm{g} \mathrm{cm}^{-3}, 11573$ unique data $\left(2 \theta_{\max }=50^{\circ}\right), R=0.076$ [for 6910 reflections with $I>2.0 \sigma(I)$ ]; $R w=$ 0.156 (all data), $S=1.03$.

Compound 40: $\mathrm{C}_{19} \mathrm{H}_{22} \mathrm{~N}_{2} \mathrm{O}_{4}, M=342.39, T=200 \mathrm{~K}$, monoclinic, space group $P 2_{1} / n, Z=12, a=$ 25.4459(4), $b=7.8587(1), c=26.2588(4) \AA, \beta=93.5300(7){ }^{\circ} ; V=5241.05(13) \AA^{3}, D_{x}=1.302$ $\mathrm{g} \mathrm{cm}^{-3}, 9266$ unique data $\left(2 \theta_{\max }=50^{\circ}\right), R=0.048$ [for 5989 reflections with $I>2.0 \sigma(I)$ ]; $R w=$ 0.120 (all data), $S=0.97$.

Compound 41: $\mathrm{C}_{19} \mathrm{H}_{22} \mathrm{~N}_{2} \mathrm{O}_{4}, M=342.39, T=200 \mathrm{~K}$, monoclinic, space group $P 2{ }_{1} / a, Z=4, a=$ 8.1469(2), $b=21.0989(6), c=10.1495(3) \AA, \beta=91.2076(17){ }^{\circ} ; V=1744.22(8) \AA^{3}, D_{x}=1.304$ $\mathrm{g} \mathrm{cm}^{-3}, 3999$ unique data $\left(2 \theta_{\max }=55^{\circ}\right), R=0.048$ [for 2569 reflections with $I>2.0 \sigma(I)$ ]; $R w=$ 0.115 (all data), $S=0.96$. 
Compound 45: $\mathrm{C}_{19} \mathrm{H}_{22} \mathrm{~N}_{2} \mathrm{O}_{4}, M=342.39, T=200 \mathrm{~K}$, monoclinic, space group $P 2_{1}, Z=2, a=$ 8.7713(4), $b=8.2519(3), c=12.8289(5) \AA, \beta=104.4285(19)^{\circ} ; V=899.27(6) \AA^{3}, D_{x}=1.264 \mathrm{~g}$ $\mathrm{cm}^{-3}, 2208$ unique data $\left(2 \theta_{\max }=55^{\circ}\right), R=0.035$ [for 2033 reflections with $\left.I>2.0 \sigma(I)\right] ; R w=$ 0.086 (all data), $S=1.01$.

Compound 47: $\mathrm{C}_{19} \mathrm{H}_{22} \mathrm{~N}_{2} \mathrm{O}_{4}, M=342.39, T=200 \mathrm{~K}$, monoclinic, space group $P 2{ }_{1} / n, Z=4, a=$ 6.5131(4), $b=15.578(1), c=17.3470(11) \AA, \beta=99.532(4)^{\circ} ; V=1735.75(19) \AA^{3}, D_{x}=1.310 \mathrm{~g}$ $\mathrm{cm}^{-3}, 3970$ unique data $\left(2 \theta_{\max }=55^{\circ}\right), R=0.060$ [for 2851 reflections with $\left.I>2.0 \sigma(I)\right] ; R w=$ 0.155 (all data), $S=1.05$.

Compound 50: $\mathrm{C}_{19} \mathrm{H}_{22} \mathrm{~N}_{2} \mathrm{O}_{4}, M=342.39, T=200 \mathrm{~K}$, monoclinic, space group $P 2{ }_{1} / a, Z=4, a=$ 8.1146(1), $b=15.1903(3), c=14.0567(3) \AA ̊ 丿, \beta=105.3616(10)^{\circ} ; V=1670.77(5) \AA^{3}, D_{x}=1.361$ $\mathrm{g} \mathrm{cm}^{-3}, 4873$ unique data $\left(2 \theta_{\max }=60^{\circ}\right), R=0.038$ [for 3534 reflections with $I>2.0 \sigma(I)$ ]; $R w=$ 0.106 (all data), $S=0.91$.

Compound 54: $\mathrm{C}_{19} \mathrm{H}_{22} \mathrm{~N}_{2} \mathrm{O}_{4}, M=342.39, T=200 \mathrm{~K}$, monoclinic, space group $P 2{ }_{1} / c, Z=4, a=$ 6.8438(2), $b=9.8978(2), c=24.5997(6) \AA, \beta=97.1851(10)^{\circ} ; V=1653.26(7) \AA^{3}, D_{x}=1.376 \mathrm{~g}$ $\mathrm{cm}^{-3}, 3752$ unique data $\left(2 \theta_{\max }=55^{\circ}\right), R=0.071$ [for 2980 reflections with $I>2.0 \sigma(I)$ ]; $R w=$ 0.216 (all data), $S=1.00$.

Compound 55: $\mathrm{C}_{19} \mathrm{H}_{22} \mathrm{~N}_{2} \mathrm{O}_{4} \cdot 0.5\left(\mathrm{CH}_{2} \mathrm{Cl}_{2}\right), M=384.86, T=200 \mathrm{~K}$, monoclinic, space group $P 2{ }_{1} / a, Z=4, a=8.6793(2), b=22.8503(4), c=9.6857(2) \AA, \beta=91.2144(9){ }^{\circ} ; V=1920.48(5)$ 
$\AA^{3}, D_{x}=1.331 \mathrm{~g} \mathrm{~cm}^{-3}, 4392$ unique data $\left(2 \theta_{\max }=55^{\circ}\right), R=0.049$ [for 2309 reflections with $I>$ $2.0 \sigma(I)] ; R w=0.133$ (all data), $S=0.81$.

Compound 58: $\mathrm{C}_{24} \mathrm{H}_{27} \mathrm{~N}_{3} \mathrm{O}_{6} \cdot \mathrm{CH}_{2} \mathrm{Cl}_{2}, M=538.43, T=200 \mathrm{~K}$, monoclinic, space group $P 2{ }_{1} / a, Z$ $=8, a=12.8137(1), b=20.3565(2), c=19.3212(2) \AA, \beta=94.2880(6)^{\circ} ; V=5025.67(8) \AA^{3}, D_{x}$ $=1.423 \mathrm{~g} \mathrm{~cm}^{-3}, 11540$ unique data $\left(2 \theta_{\max }=55^{\circ}\right), R=0.038$ [for 7015 reflections with $I>$ $2.0 \sigma(I)] ; R w=0.093$ (all data), $S=0.82$.

Compound 59: $\mathrm{C}_{24} \mathrm{H}_{27} \mathrm{~N}_{3} \mathrm{O}_{6} \cdot \mathrm{H}_{2} \mathrm{O}, M=471.51, T=200 \mathrm{~K}$, orthorhombic, space group $P 2{ }_{1} 2_{1} 2_{1}, Z$ $=4, a=7.6862(3), b=10.4995(5), c=28.4514(11) \AA ; V=2296.06(15) \AA^{3}, D_{x}=1.364 \mathrm{~g} \mathrm{~cm}^{-3}$, 2345 unique data $\left(2 \theta_{\max }=50^{\circ}\right), R=0.058$ [for 1644 reflections with $I>2.0 \sigma(I)$ ]; $R w=0.158$ (all data), $S=0.99$.

Compound 60: $\mathrm{C}_{24} \mathrm{H}_{27} \mathrm{~N}_{3} \mathrm{O}_{6} \cdot \mathrm{CHCl}_{3}, M=572.87, T=200 \mathrm{~K}$, monoclinic, space group $C c, Z=4$, $a=13.2299(2), b=13.6070(2), c=14.5131(3) \AA, \beta=91.0006(11)^{\circ} ; V=2612.24(8) \AA^{3}, D_{x}=$ $1.457 \mathrm{~g} \mathrm{~cm}^{-3}, 5906$ unique data $\left(2 \theta_{\max }=55^{\circ}\right), R=0.042$ [for 5203 reflections with $I>2.0 \sigma(I)$ ]; $R w=0.111$ (all data), $S=1.04$.

\subsection{Structure Determination}

Images were measured on a Nonius Kappa CCD diffractometer (MoK $\alpha$, graphite monochromator, $\lambda=0.71073 \AA$ ) and data extracted using the DENZO package. ${ }^{6}$ Structure solution was by direct methods (SIR92). ${ }^{7}$ The structures were refined using the CRYSTALS program package. $^{8}$ Atomic coordinates, bond lengths and angles, and displacement parameters 
for compounds $33,36,40,41,45,47,50,54,55,58,59$, and 60 have been deposited at the Cambridge Crystallographic Data Centre (CCDC nos. 1421657 - 1421668, respectively). These data can be obtained free-of-charge via www.ccdc.cam.ac.uk/data_request/cif, by emailing data_request@ccdc.cam.ac.uk, or by contacting The Cambridge Crystallographic Data Centre, 12 Union Road, Cambridge CB2 1EZ, UK; fax: +44 1223 336033. The CIFs are available as SI of this paper. The individual CIFs also contain details of refinement procedures used for that particular structure. 
2.3 Anisotropic Displacement Ellipsoid Plots for 33, 36, 40, 41, 45, 47, 50, 54, 55, 58,59 , and 60 .

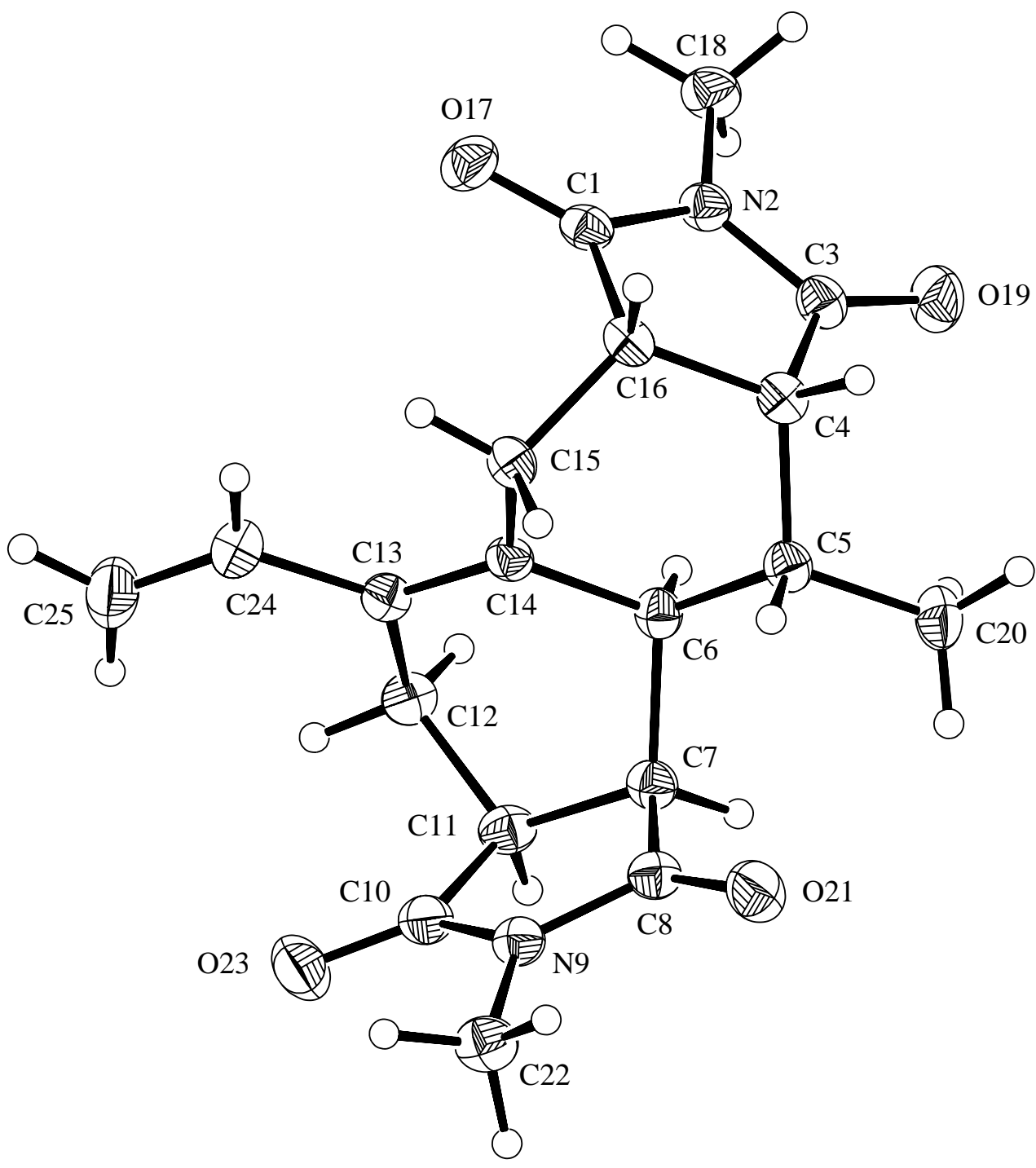

Figure S1: Molecular structure of $\mathbf{3 3}$ (CCDC 1421657) with labeling of selected atoms. Anisotropic displacement ellipsoids show $30 \%$ probability levels. $\mathrm{H}$ atoms are drawn as circles with small radii. 


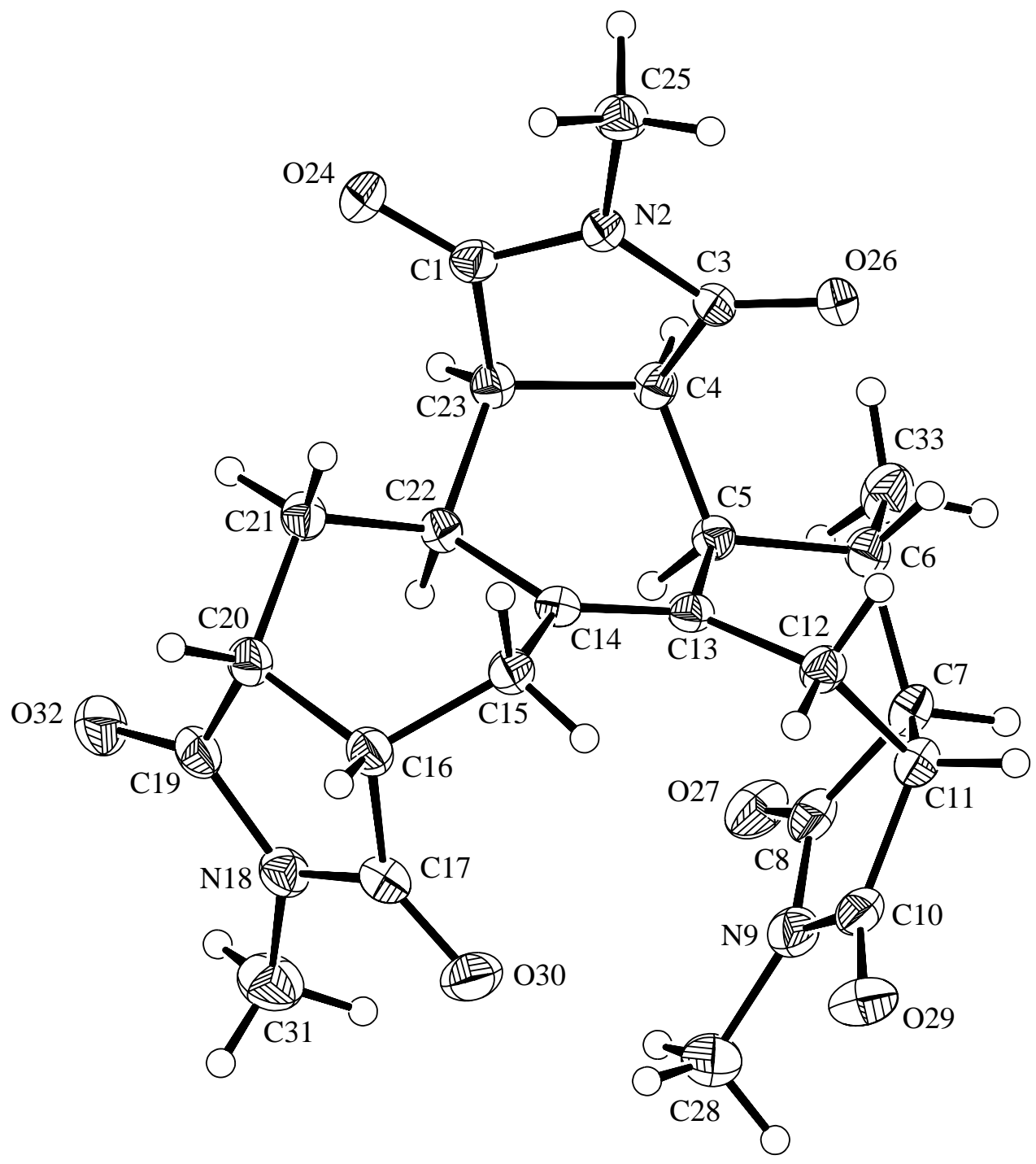

Figure S2: Molecular structure of 36 (CCDC 1421658) with labeling of selected atoms.

Anisotropic displacement ellipsoids show $30 \%$ probability levels. $\mathrm{H}$ atoms are drawn as circles with small radii. 


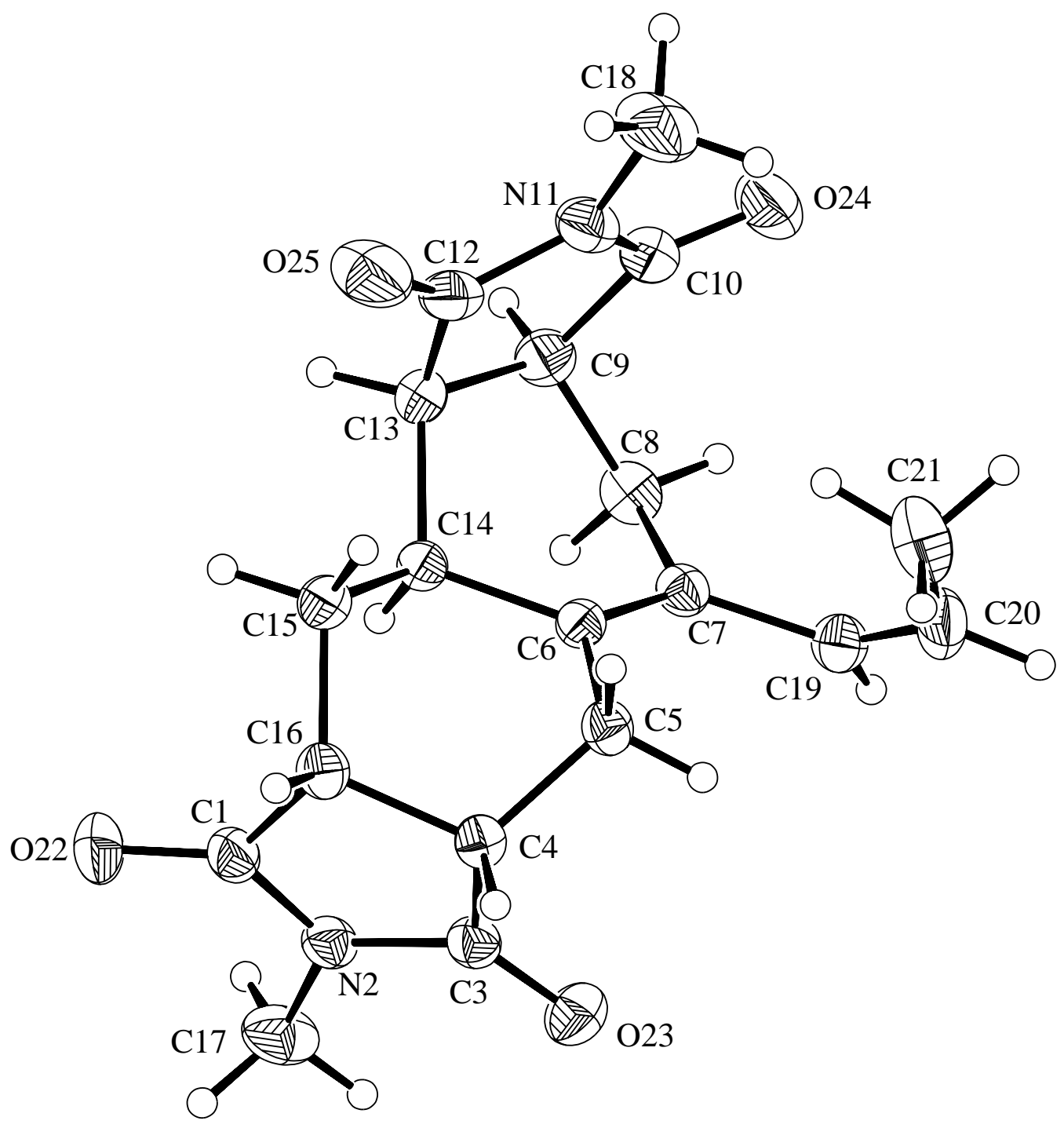

Figure S3: Molecular structure of 40 (CCDC 1421659) with labeling of selected atoms. Anisotropic displacement ellipsoids show $30 \%$ probability levels. $\mathrm{H}$ atoms are drawn as circles with small radii. 


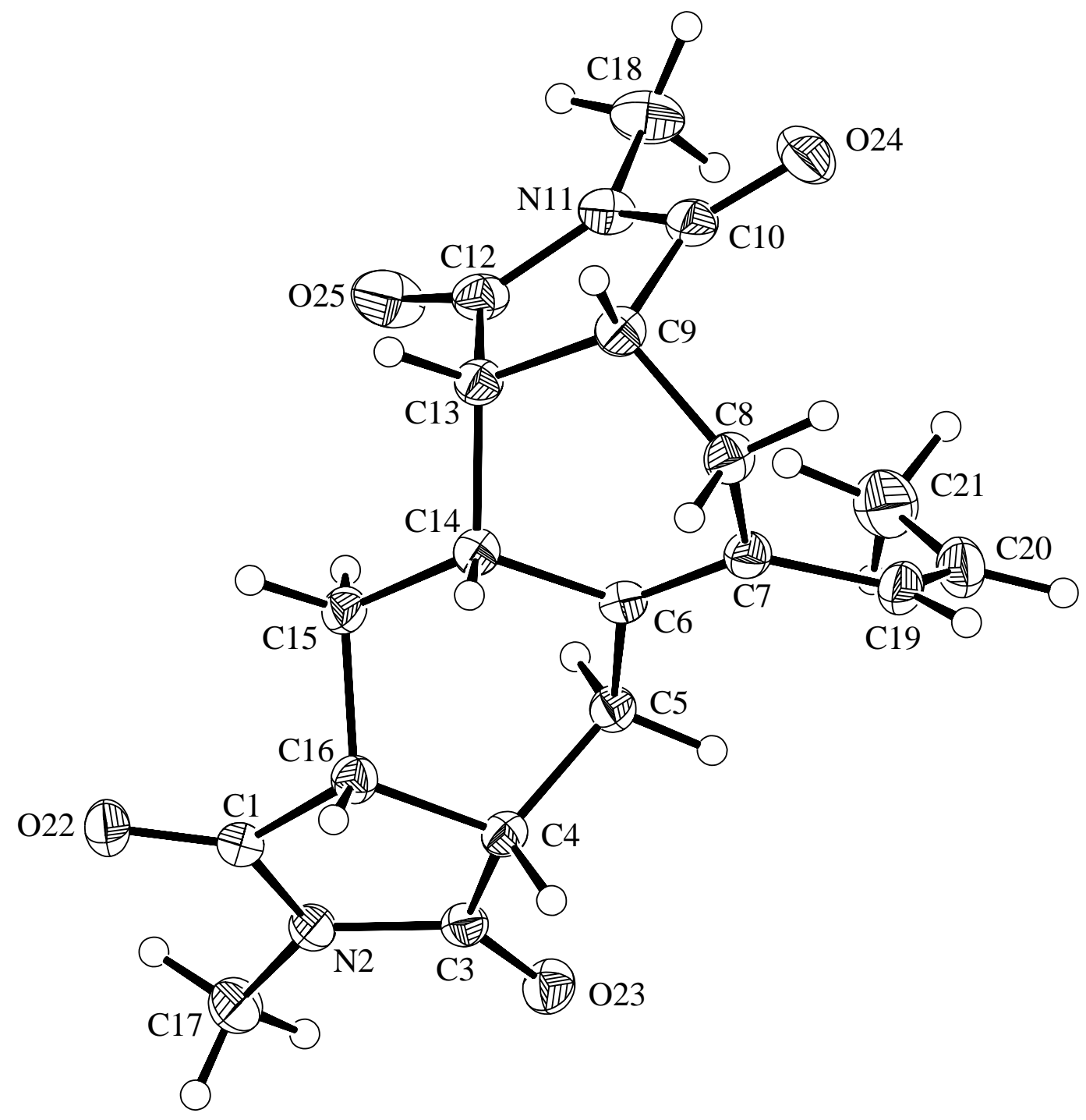

Figure S4: Molecular structure of 41 (CCDC 1421660) with labeling of selected atoms. Anisotropic displacement ellipsoids show $30 \%$ probability levels. $\mathrm{H}$ atoms are drawn as circles with small radii. 


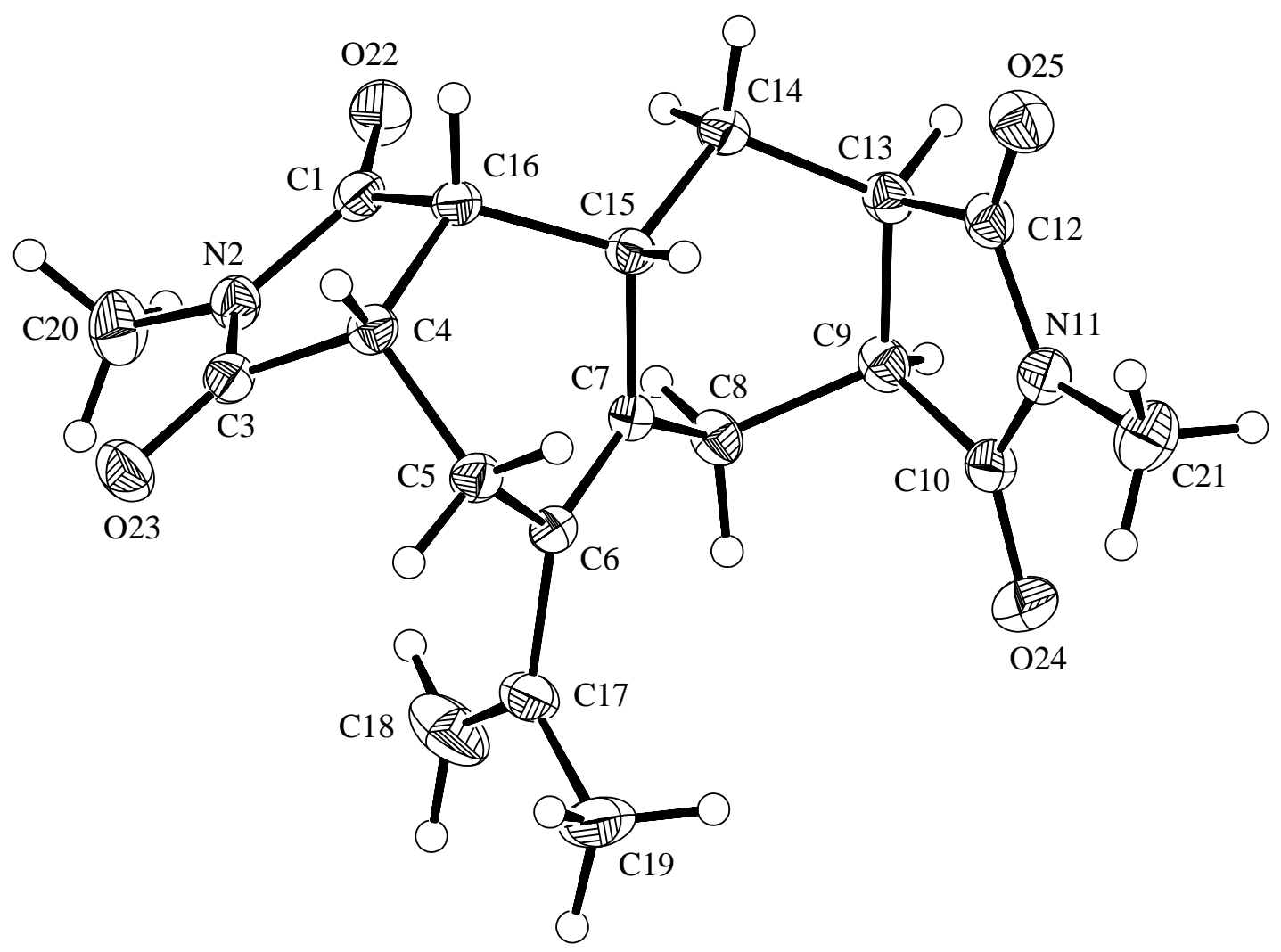

Figure S5: Molecular structure of 45 (CCDC 1421661) with labeling of selected atoms. Anisotropic displacement ellipsoids show $30 \%$ probability levels. H atoms are drawn as circles with small radii. 


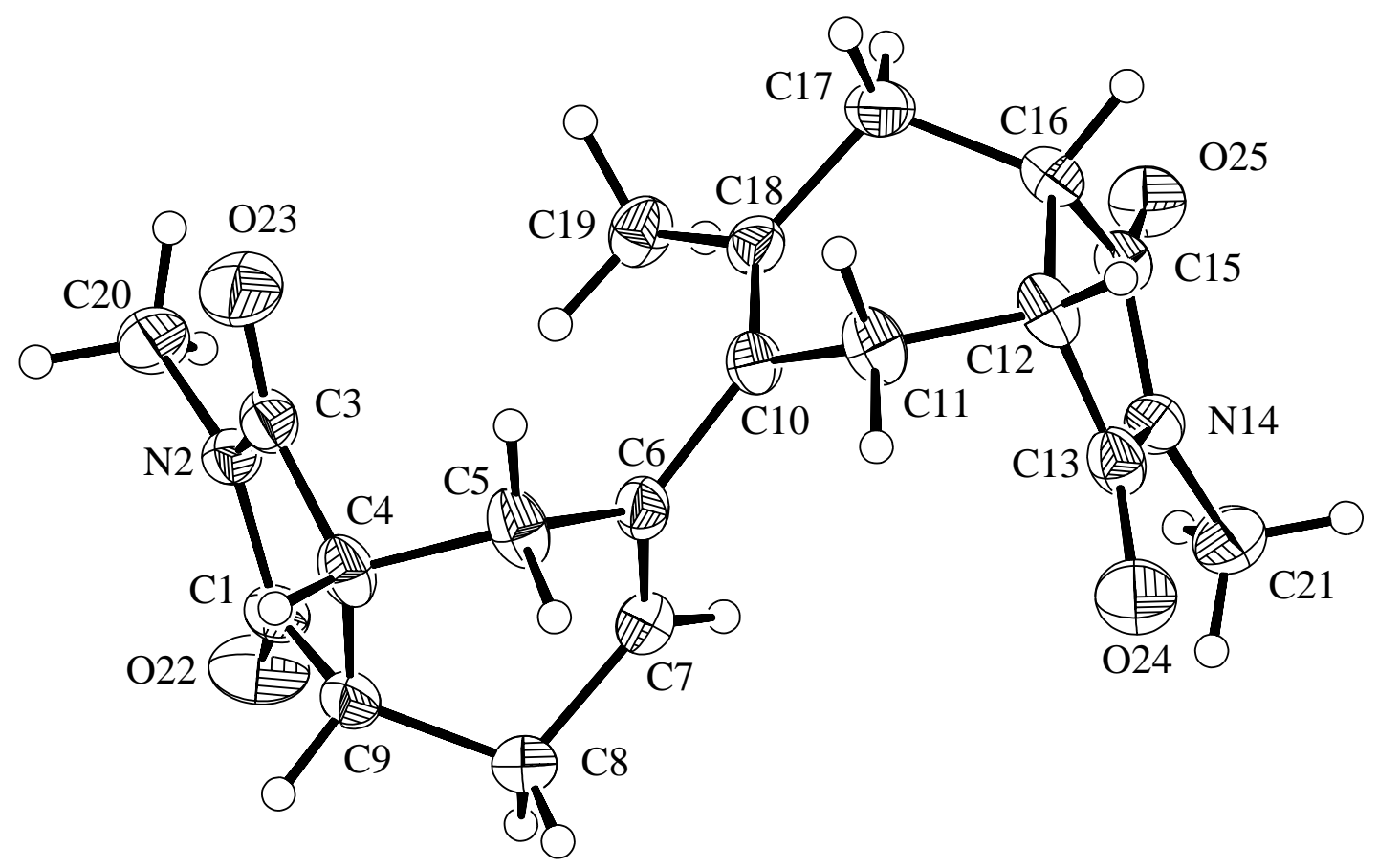

Figure S6: Molecular structure of 47 (CCDC 1421662) with labeling of selected atoms. Anisotropic displacement ellipsoids show 30\% probability levels. $\mathrm{H}$ atoms are drawn as circles with small radii. 


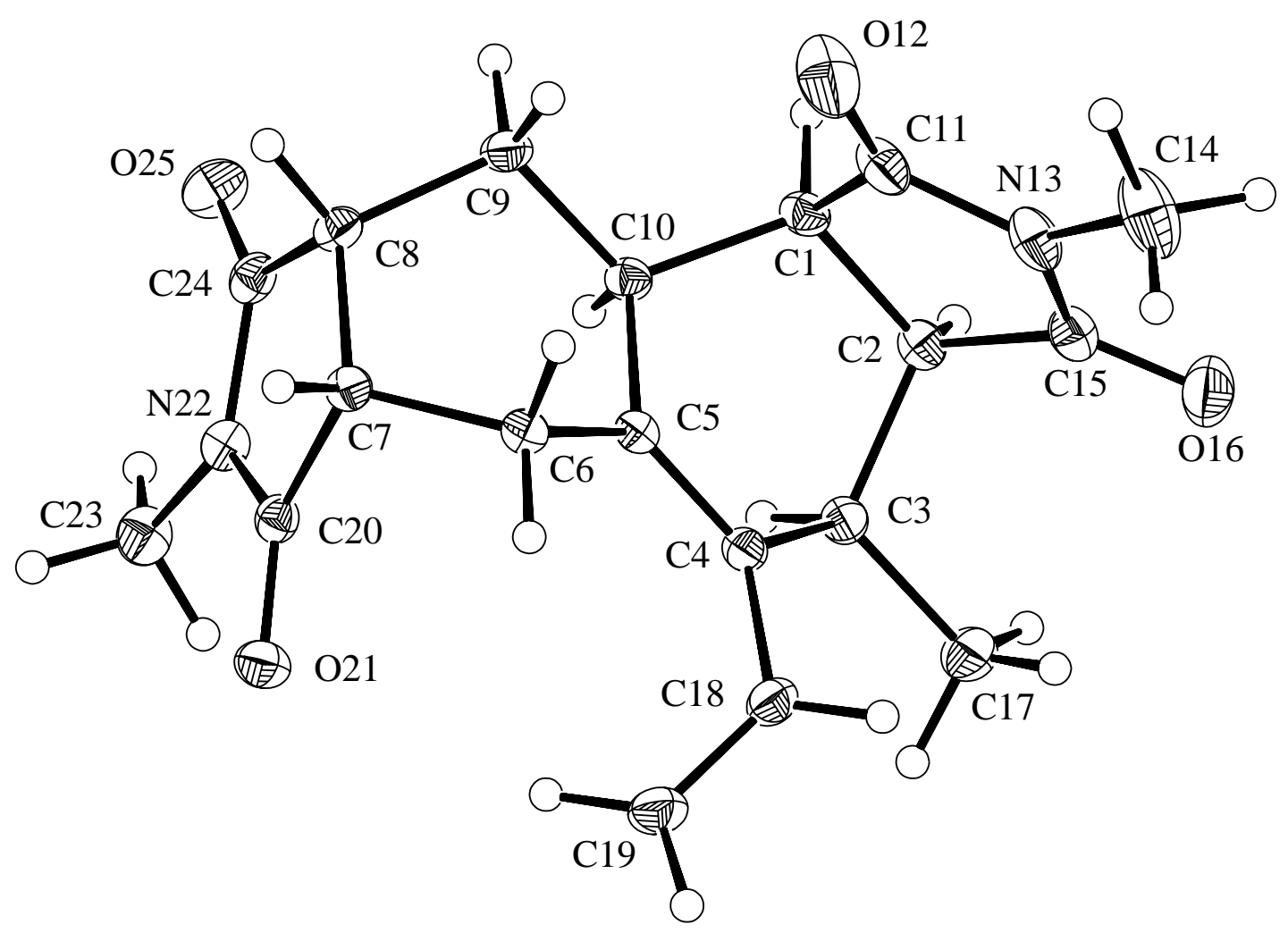

Figure S7: Molecular structure of $\mathbf{5 0}$ (CCDC 1421663) with labeling of selected atoms. Anisotropic displacement ellipsoids show $30 \%$ probability levels. $\mathrm{H}$ atoms are drawn as circles with small radii. 


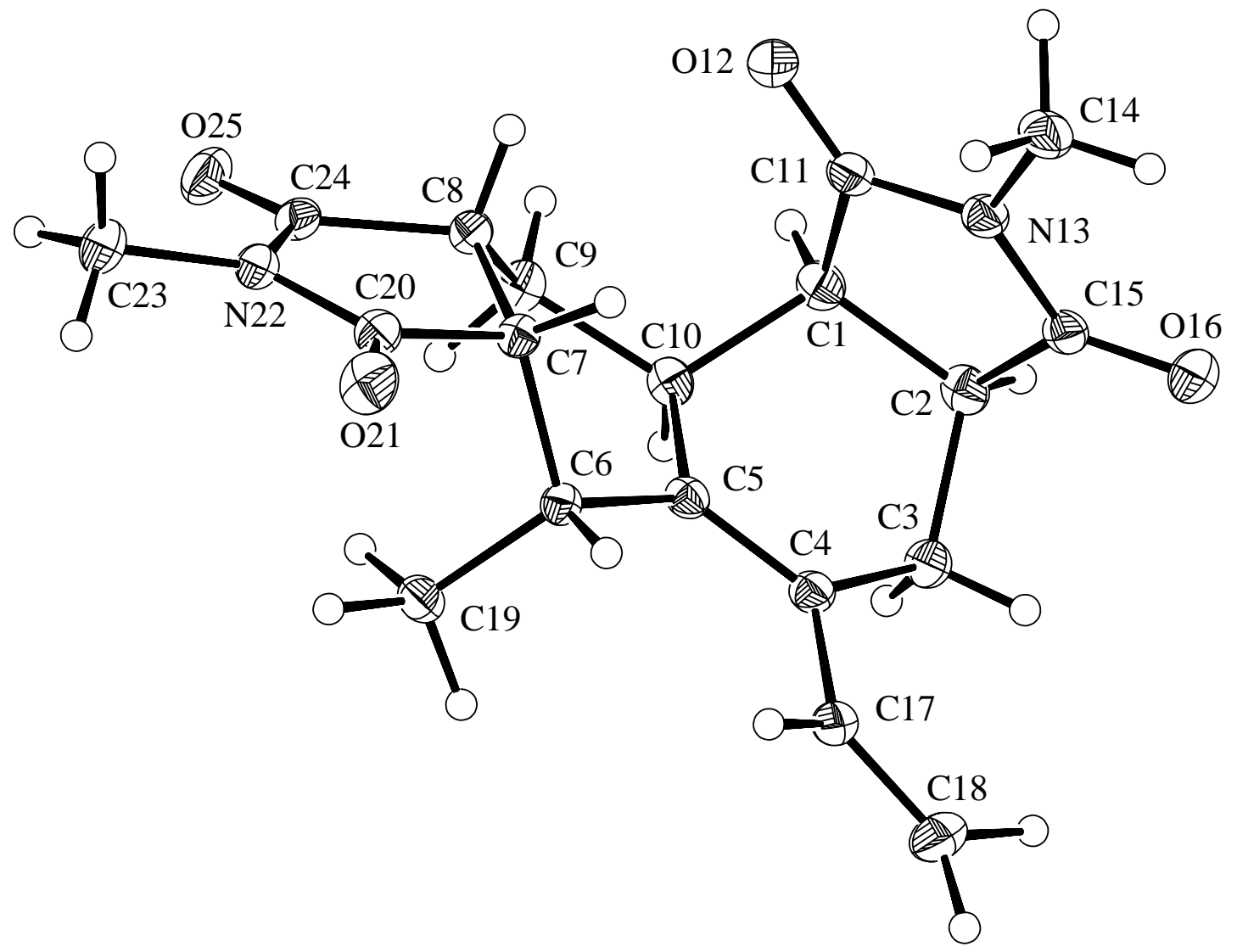

Figure S8: Molecular structure of 54 (CCDC 1421664) with labeling of selected atoms. Anisotropic displacement ellipsoids show $30 \%$ probability levels. $\mathrm{H}$ atoms are drawn as circles with small radii. 


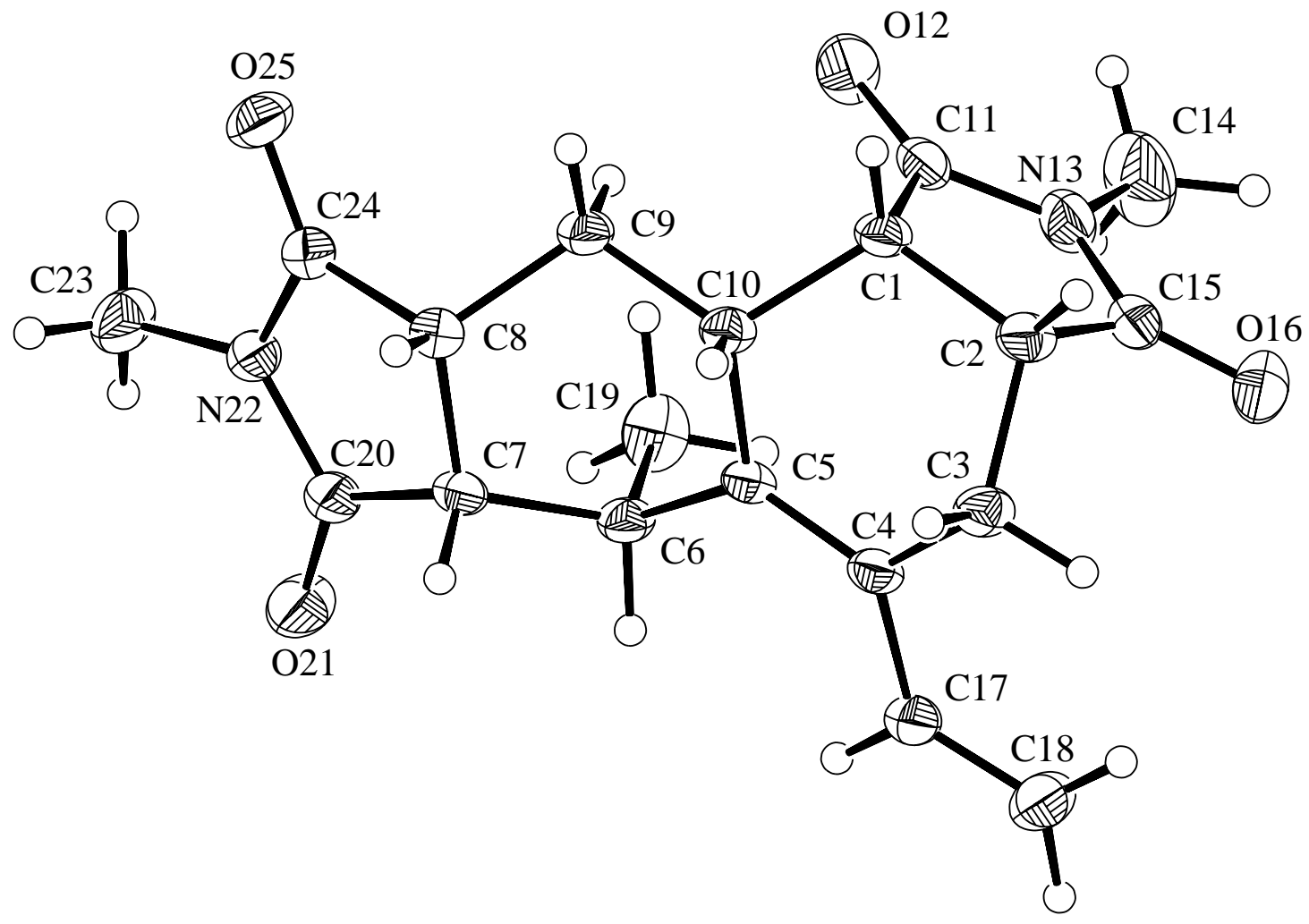

Figure S9: Molecular structure of 55 (CCDC 1421665) with labeling of selected atoms. Anisotropic displacement ellipsoids show 30\% probability levels. $\mathrm{H}$ atoms are drawn as circles with small radii. 


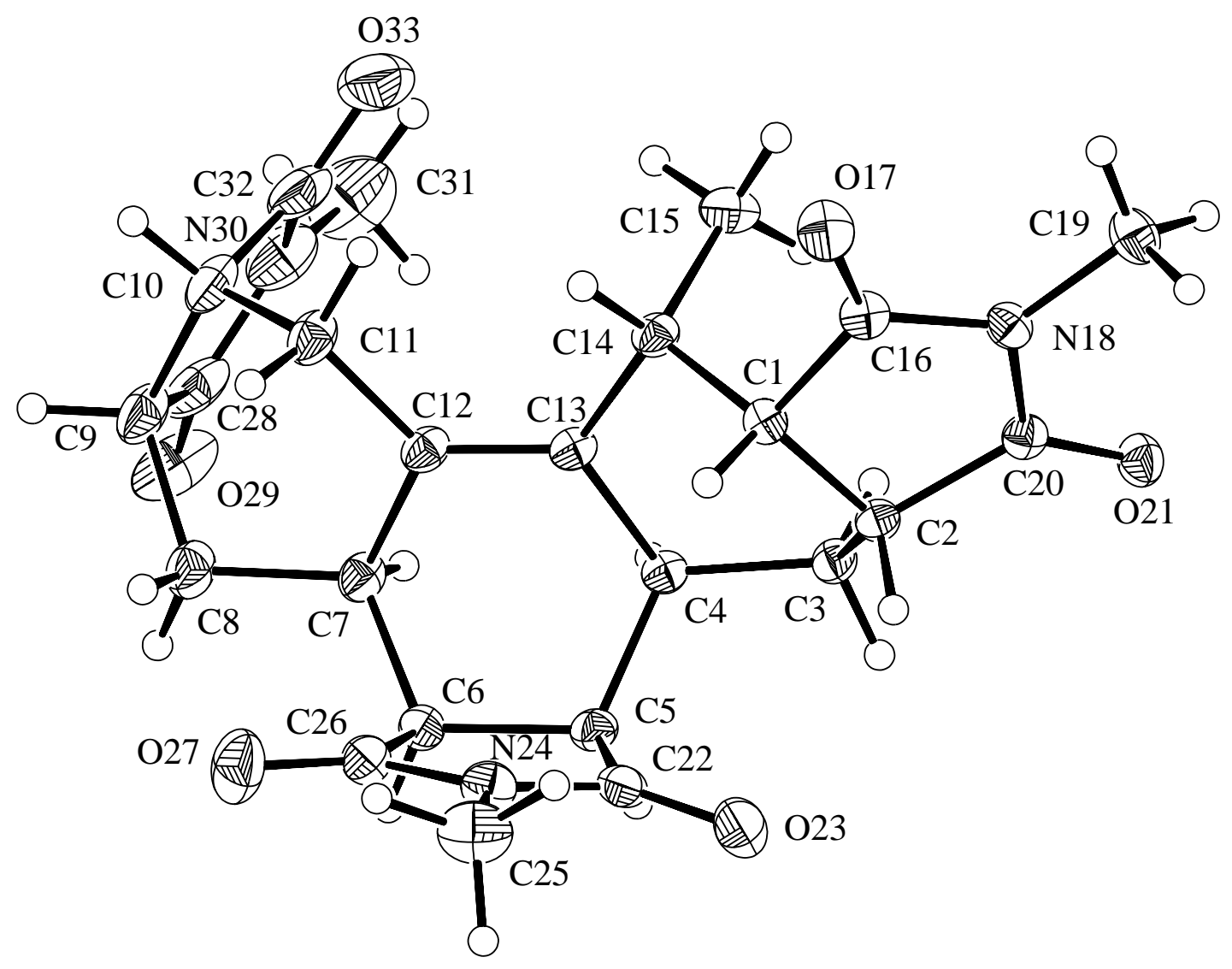

Figure S10: Molecular structure of 58 (CCDC 1421666) with labeling of selected atoms. Anisotropic displacement ellipsoids show $30 \%$ probability levels. $\mathrm{H}$ atoms are drawn as circles with small radii. 


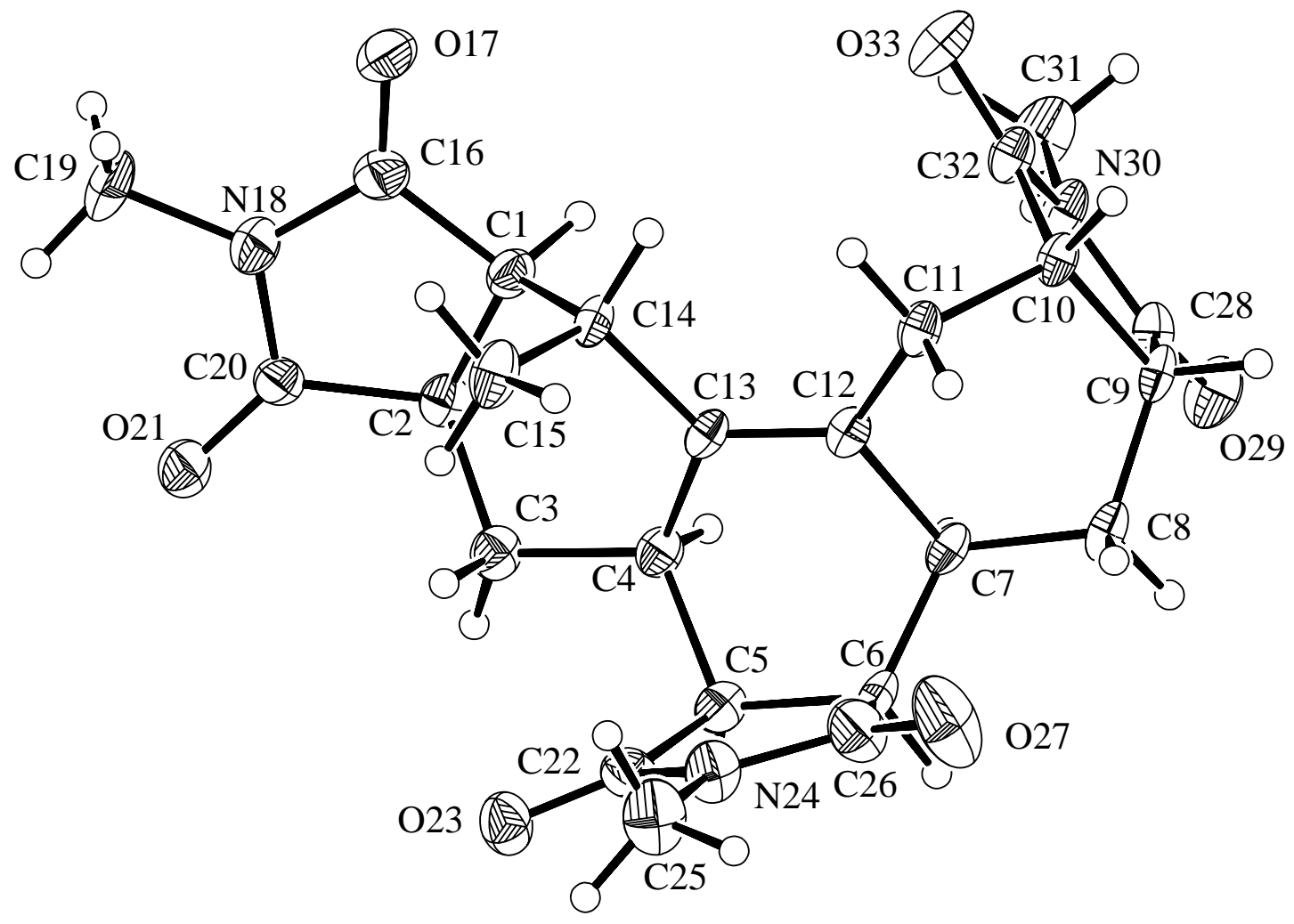

Figure S11: Molecular structure of 59 (CCDC 1421667) with labeling of selected atoms. Anisotropic displacement ellipsoids show $30 \%$ probability levels. $\mathrm{H}$ atoms are drawn as circles with small radii. 


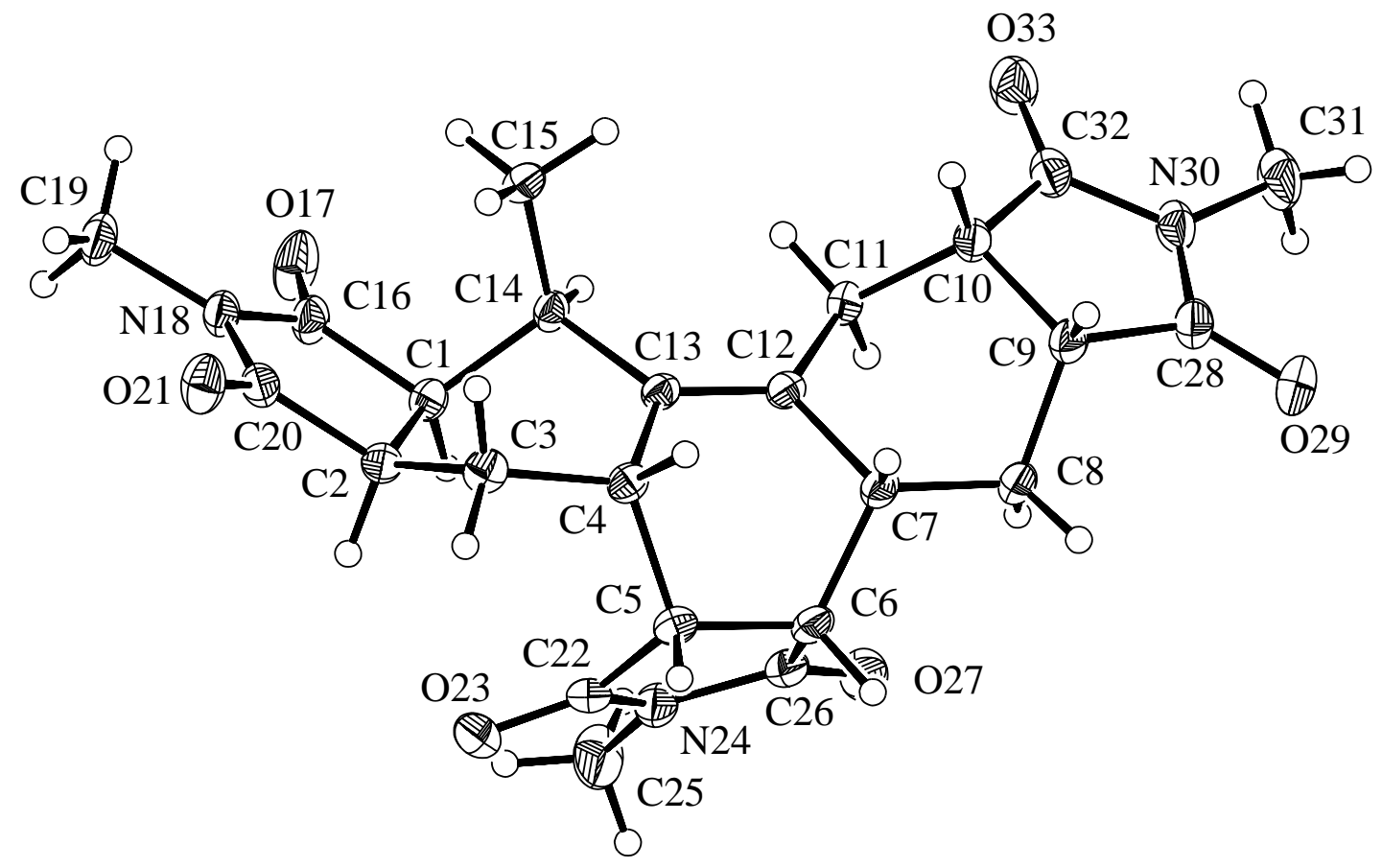

Figure S12: Molecular structure of $\mathbf{6 0}$ (CCDC 1421668) with labeling of selected atoms. Anisotropic displacement ellipsoids show $30 \%$ probability levels. $\mathrm{H}$ atoms are drawn as circles with small radii. 


\section{3. ${ }^{1} \mathrm{H}$ and ${ }^{13} \mathrm{C}$ NMR Spectra}

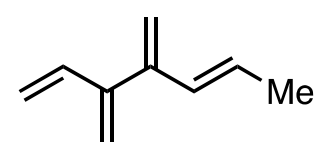

10

${ }^{1} \mathrm{H}$ NMR spectrum

$300 \mathrm{MHz}$, in $\mathrm{CDCl}_{3}$

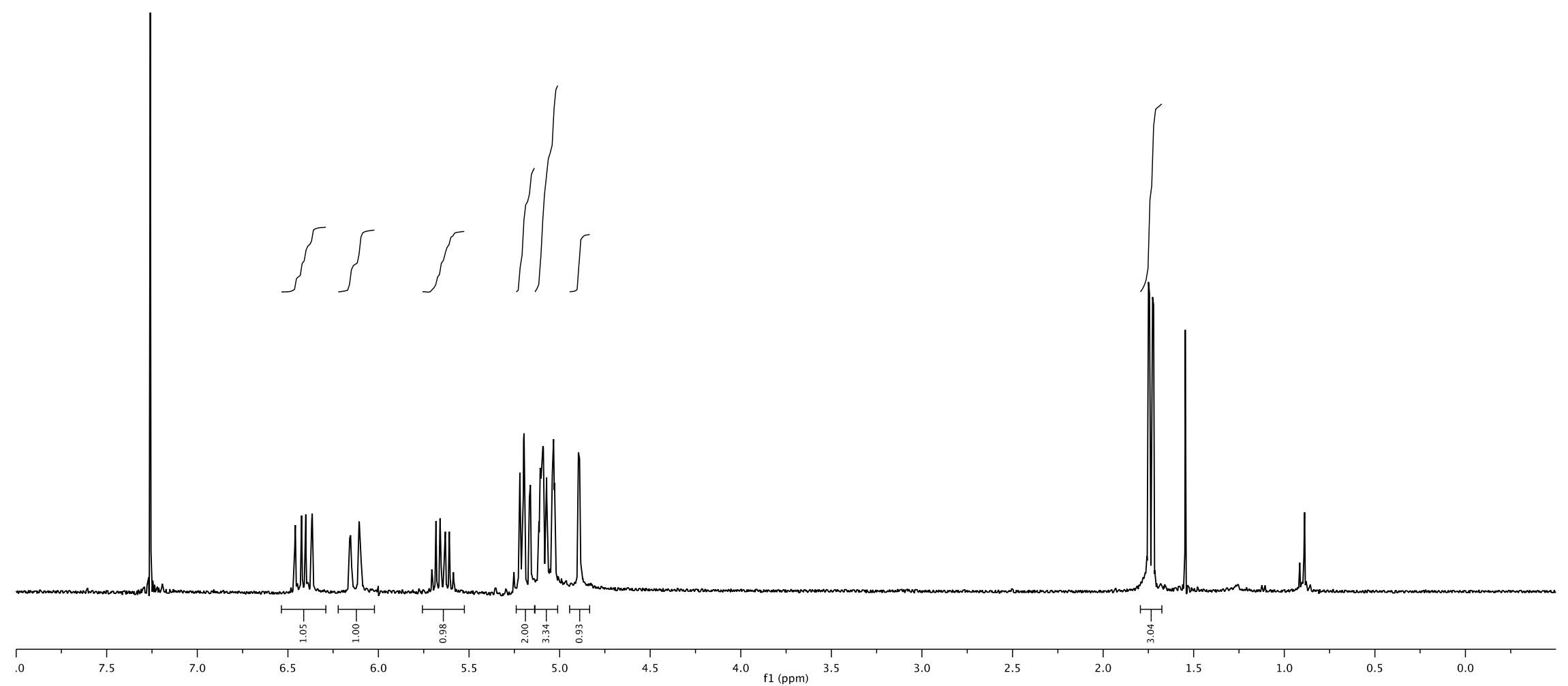




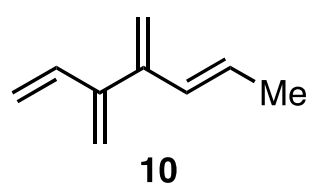

${ }^{13} \mathrm{C}$ NMR spectrum $75 \mathrm{MHz}$, in $\mathrm{CDCl}_{3}$

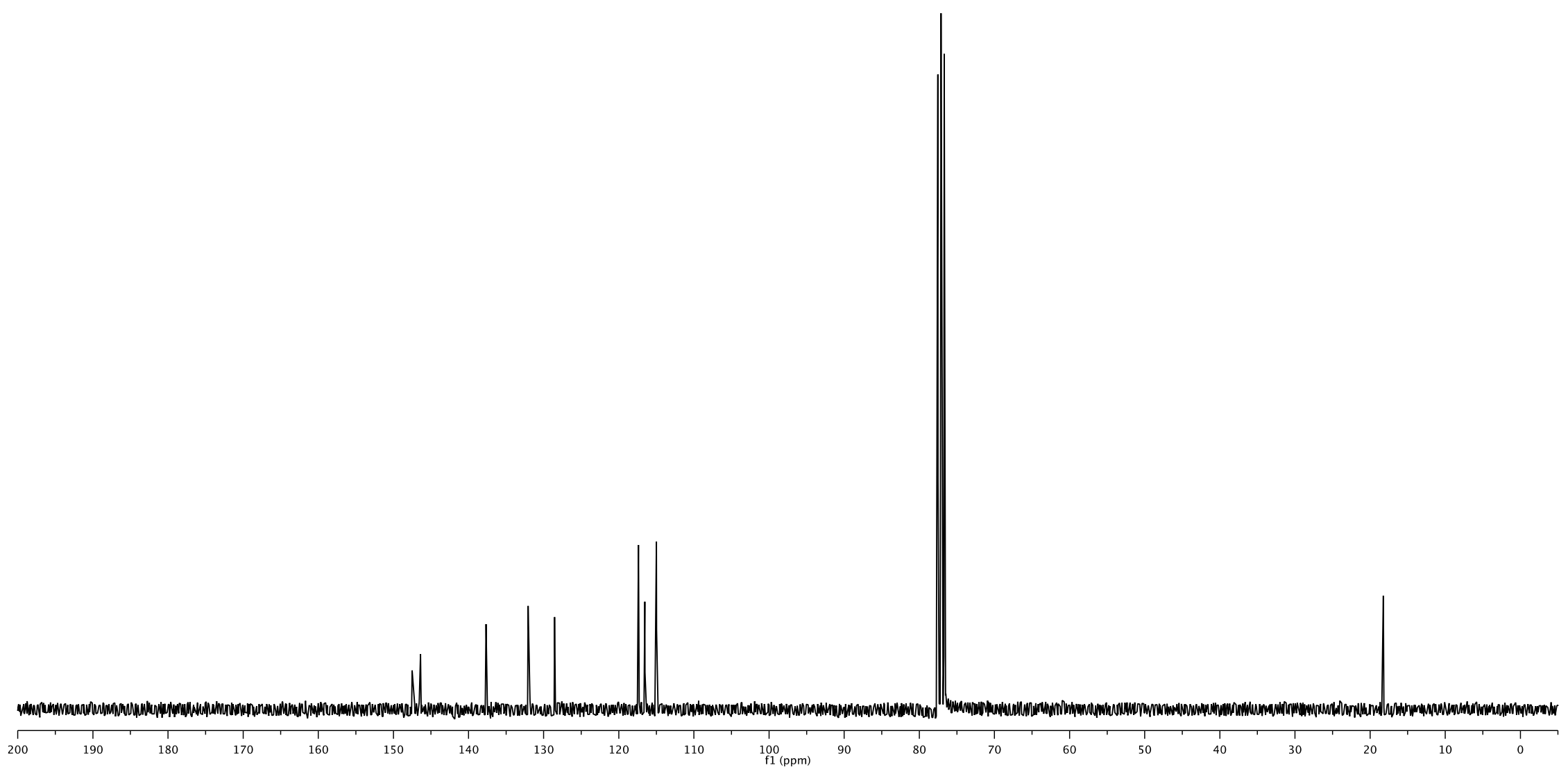

S24 


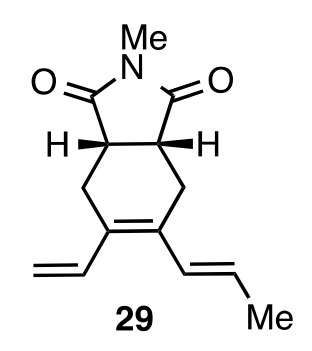

${ }^{1} \mathrm{H}$ NMR spectrum $300 \mathrm{MHz}$, in $\mathrm{CDCl}_{3}$

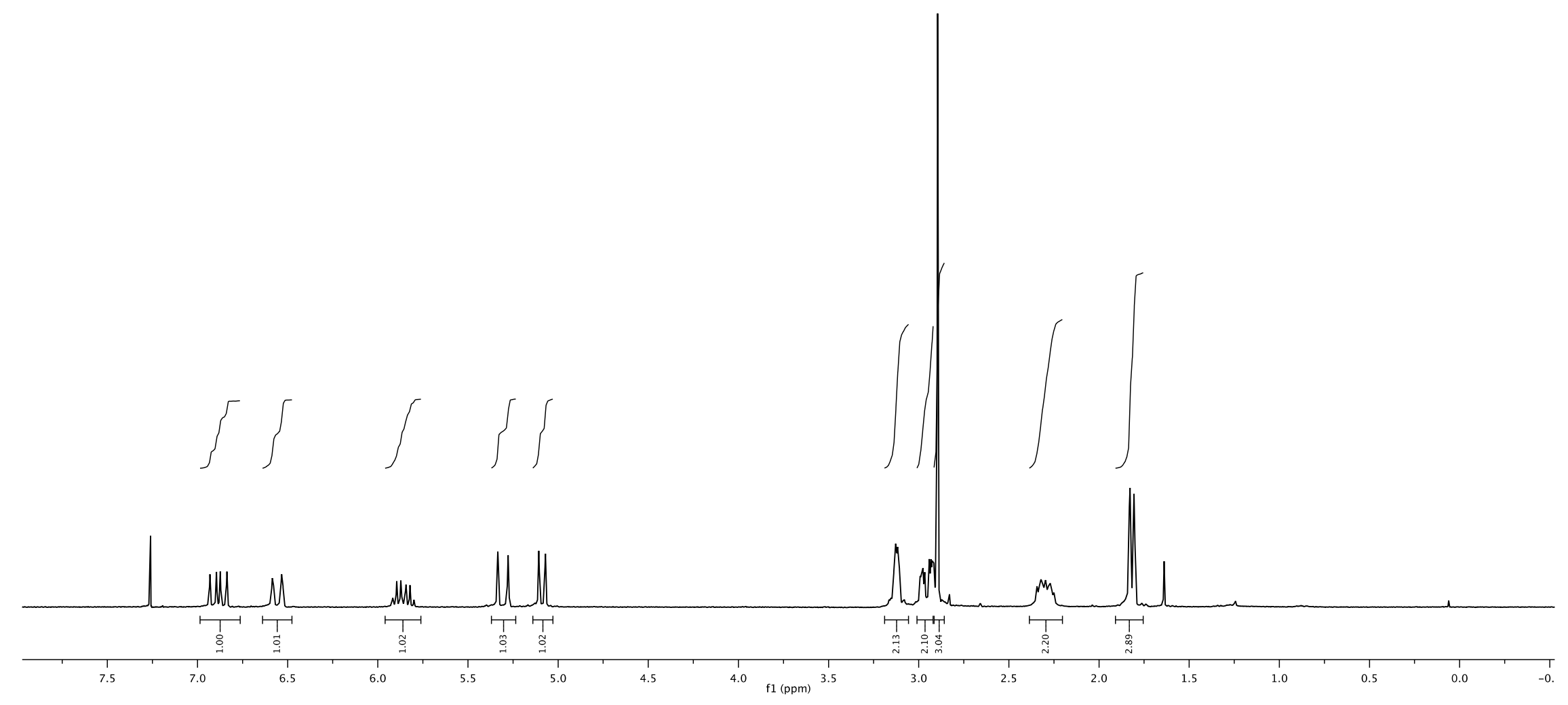




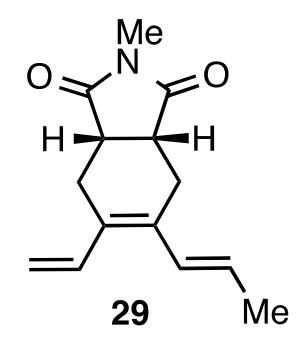

${ }^{13} \mathrm{C}$ NMR spectrum

$75 \mathrm{MHz}$, in $\mathrm{CDCl}_{3}$

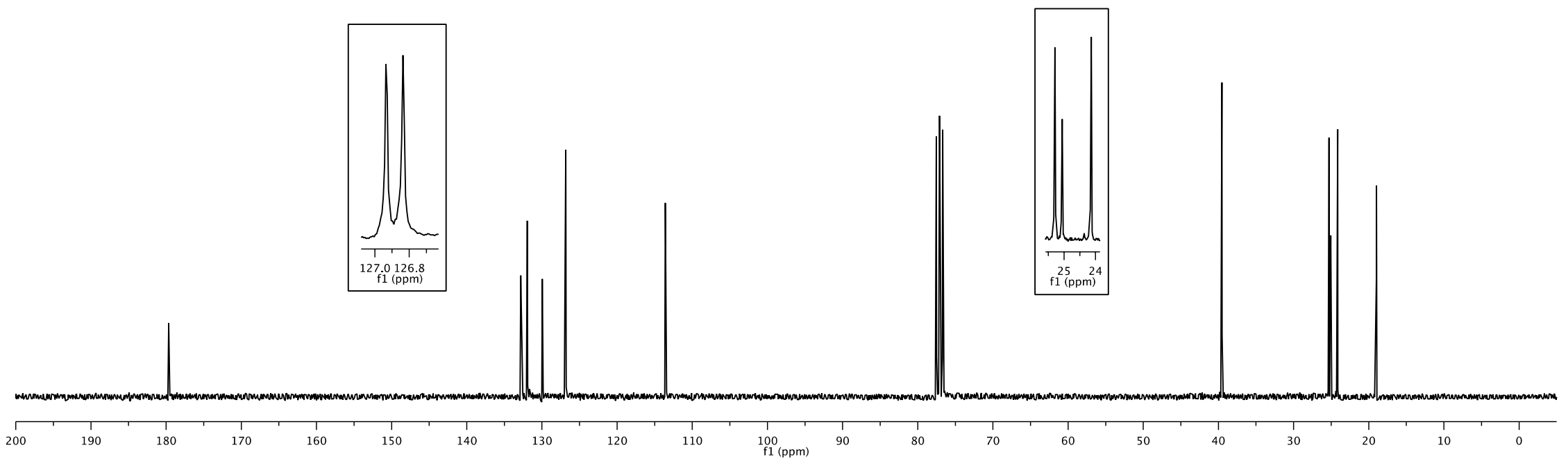




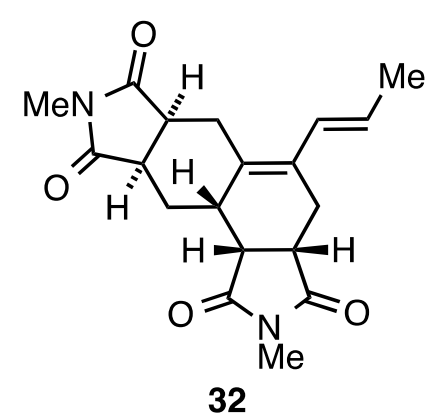

${ }^{1} \mathrm{H}$ NMR spectrum $800 \mathrm{MHz}$, in $\mathrm{CDCl}_{3}$

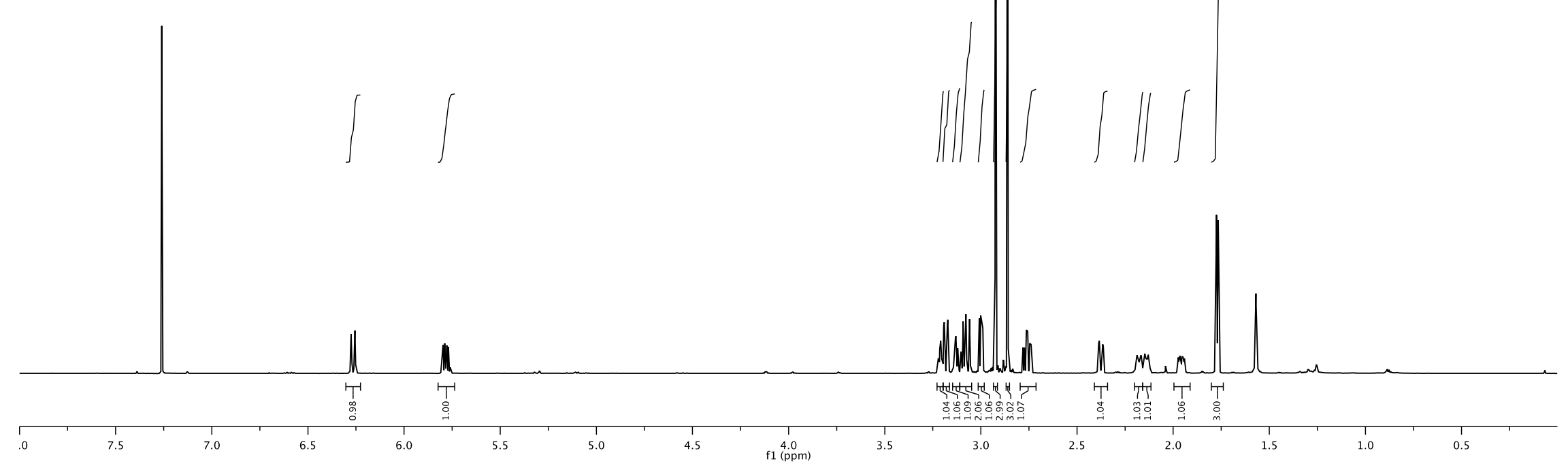




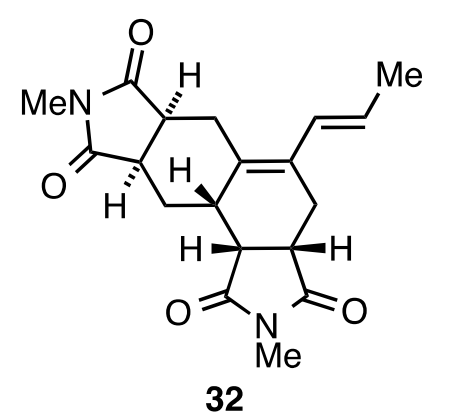

${ }^{13} \mathrm{C}$ NMR spectrum $200 \mathrm{MHz}$, in $\mathrm{CDCl}_{3}$
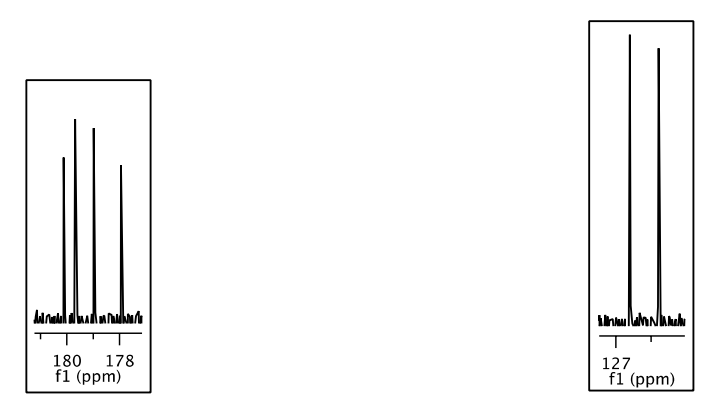
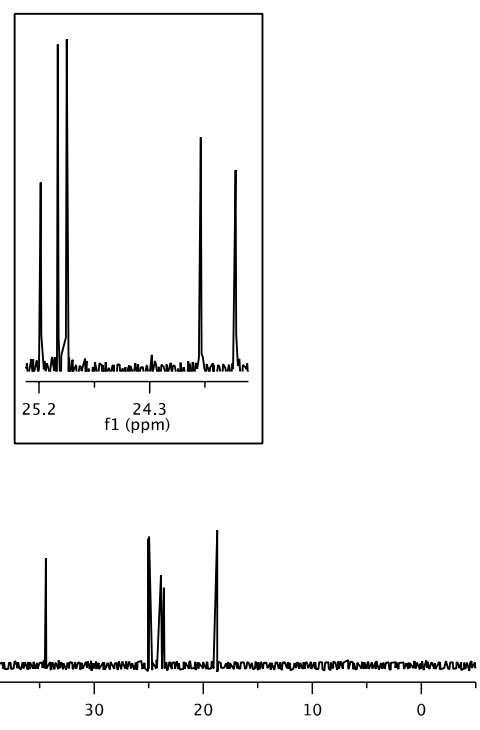


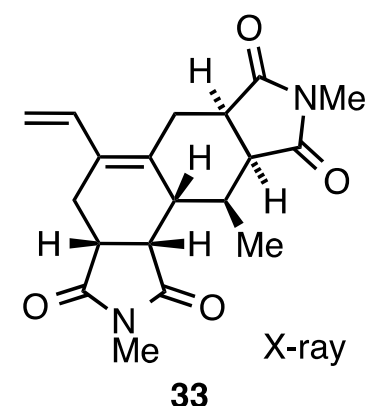

${ }^{1} \mathrm{H}$ NMR spectrum $300 \mathrm{MHz}$, in $\mathrm{CDCl}_{3}$

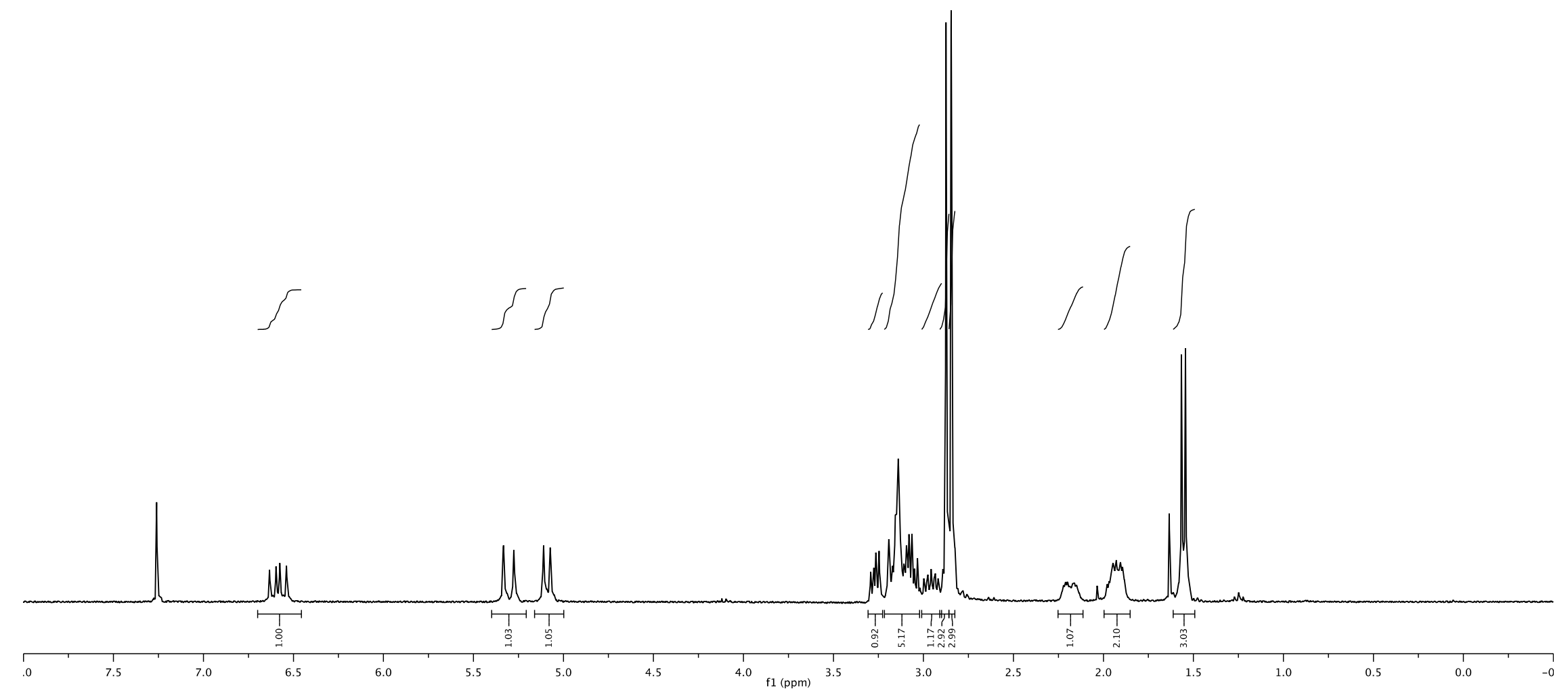




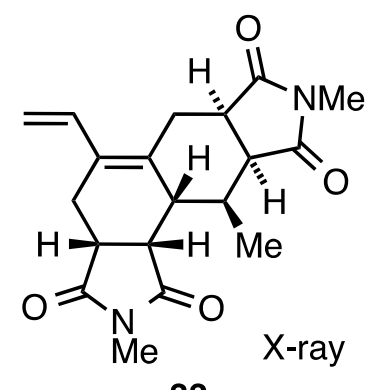

33

${ }^{13} \mathrm{C}$ NMR spectrum

$75 \mathrm{MHz}$, in $\mathrm{CDCl}_{3}$

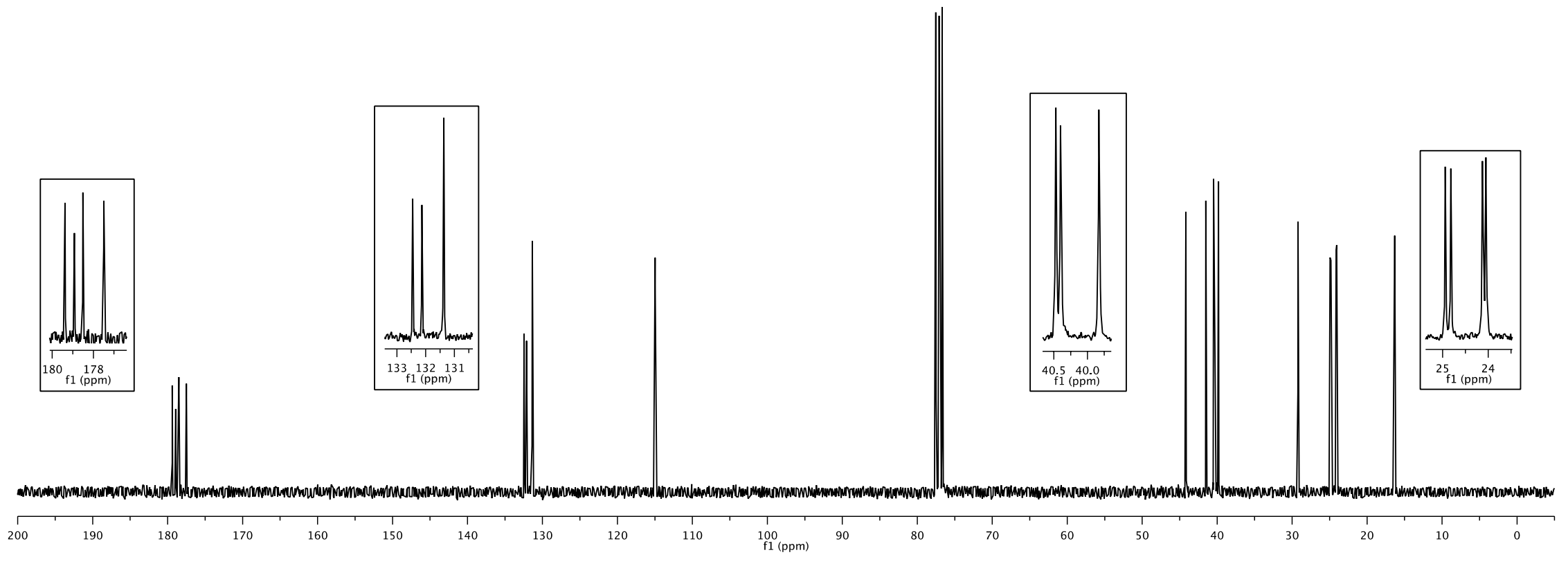




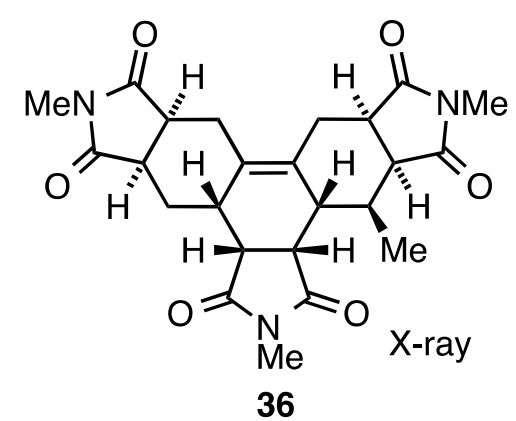

${ }^{1} \mathrm{H}$ NMR spectrum $300 \mathrm{MHz}$, in $\mathrm{CDCl}_{3}$

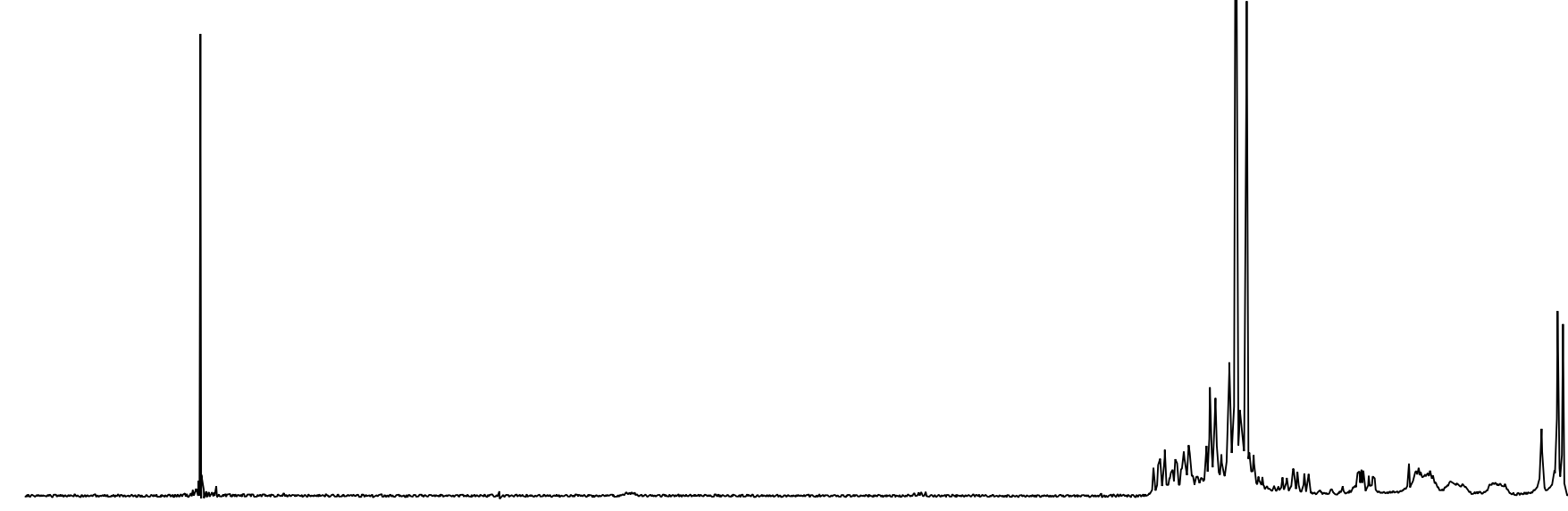

1T

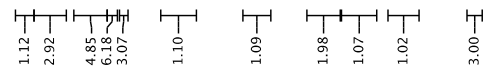

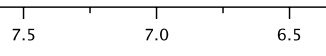

6.0

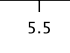

5.0

4.5

$\int_{4.0}{ }_{\mathrm{f} 1(\mathrm{ppm})} 3.5$

3.0

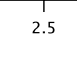

2.0

0.5

0.0 


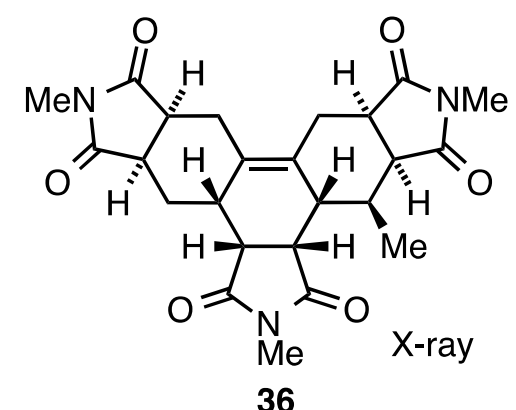

${ }^{13} \mathrm{C}$ NMR spectrum

$75 \mathrm{MHz}$, in $\mathrm{CDCl}_{3}$
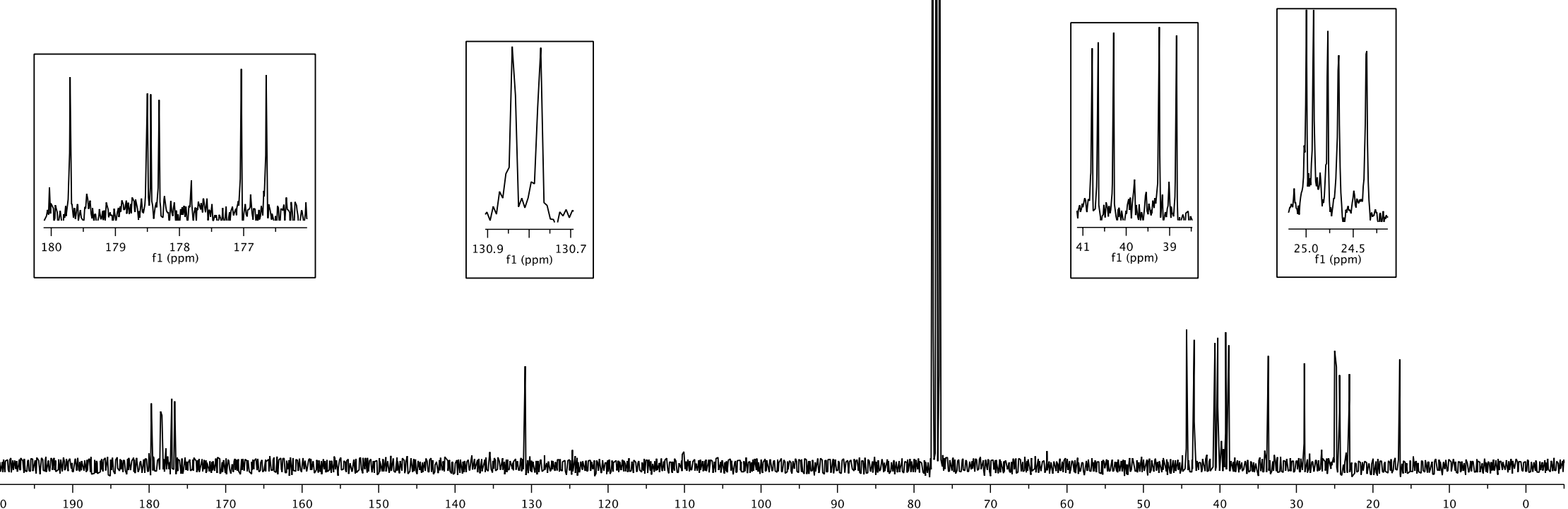


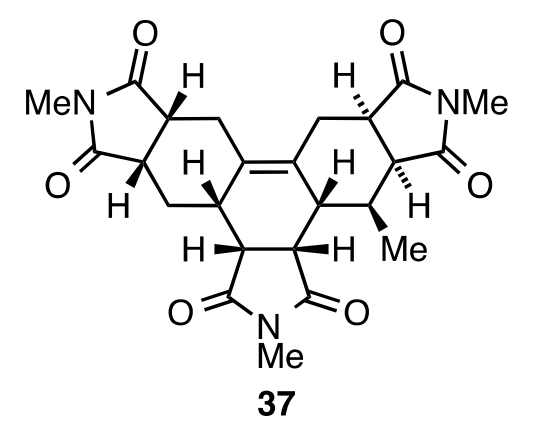

${ }^{1} \mathrm{H}$ NMR spectrum

$800 \mathrm{MHz}$, in $\mathrm{CDCl}_{3}$

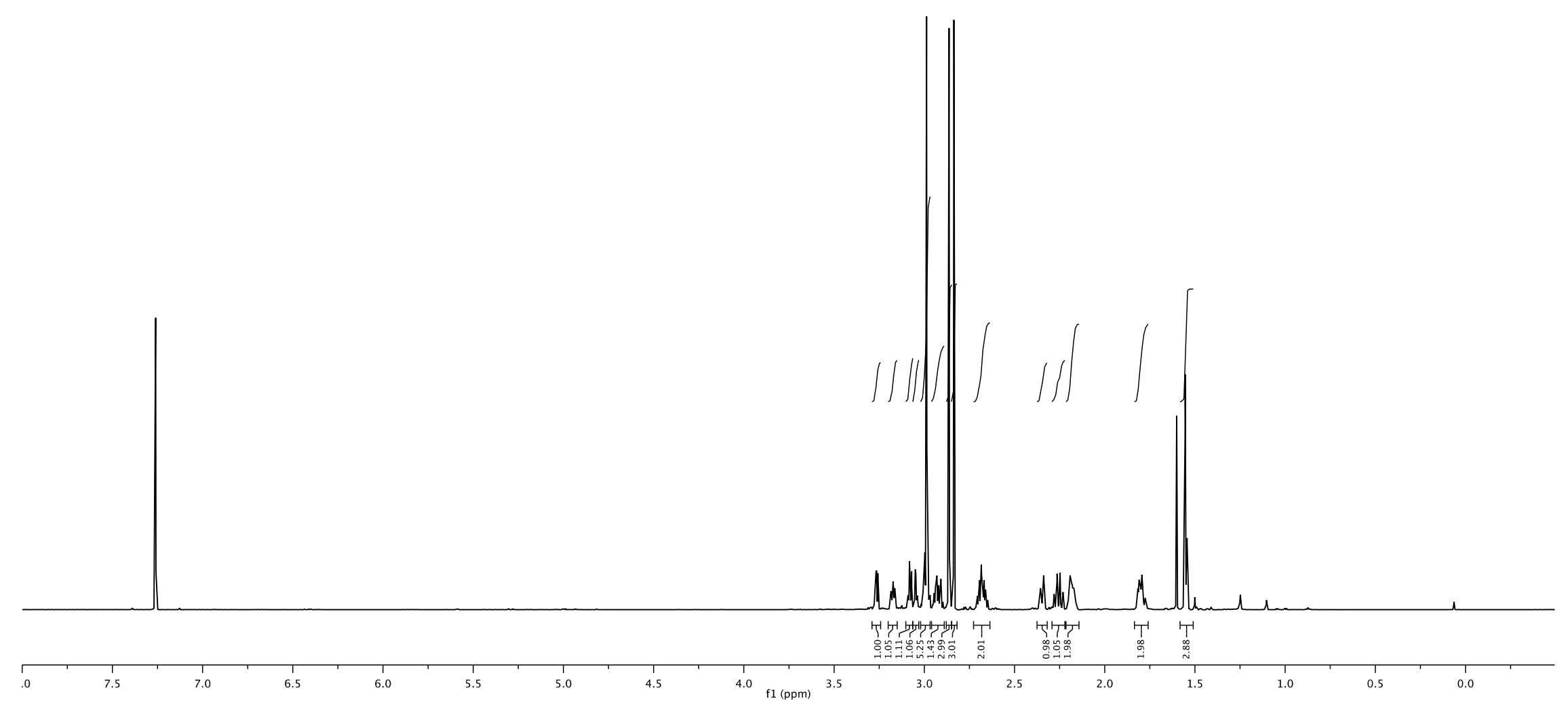




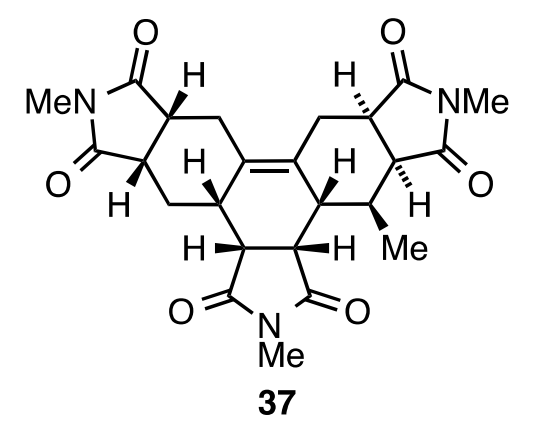

${ }^{13} \mathrm{C}$ NMR spectrum $200 \mathrm{MHz}$, in $\mathrm{CDCl}_{3}$
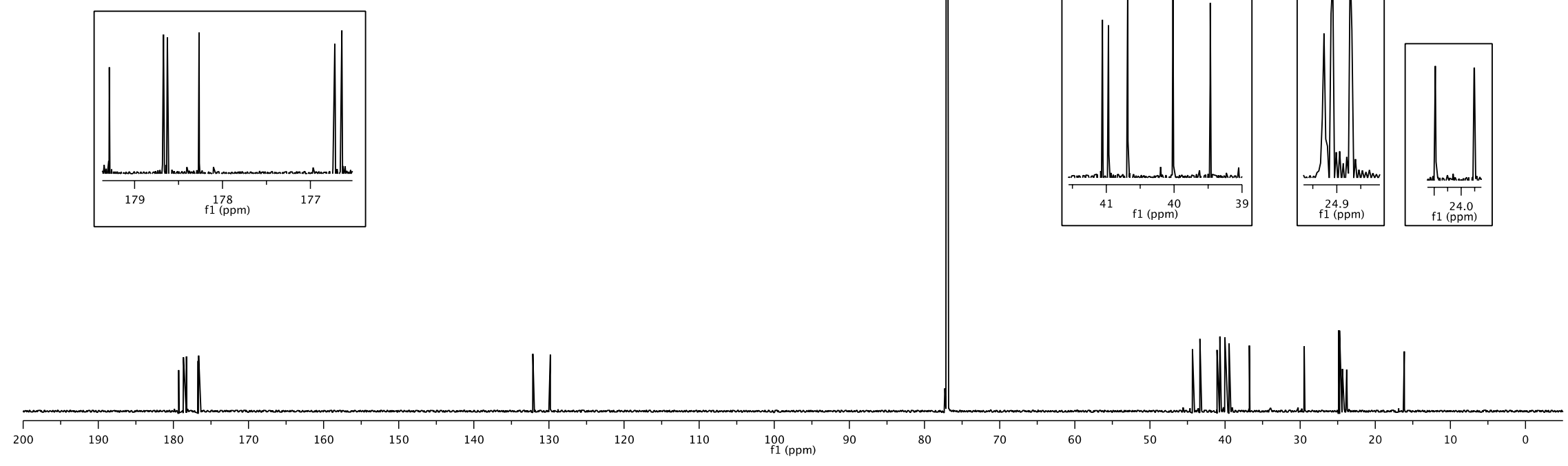

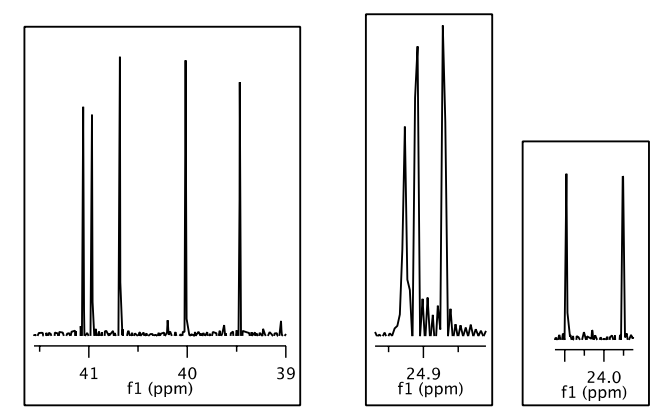




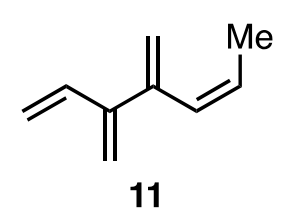

${ }^{1} \mathrm{H}$ NMR spectrum $300 \mathrm{MHz}$, in $\mathrm{CDCl}_{3}$

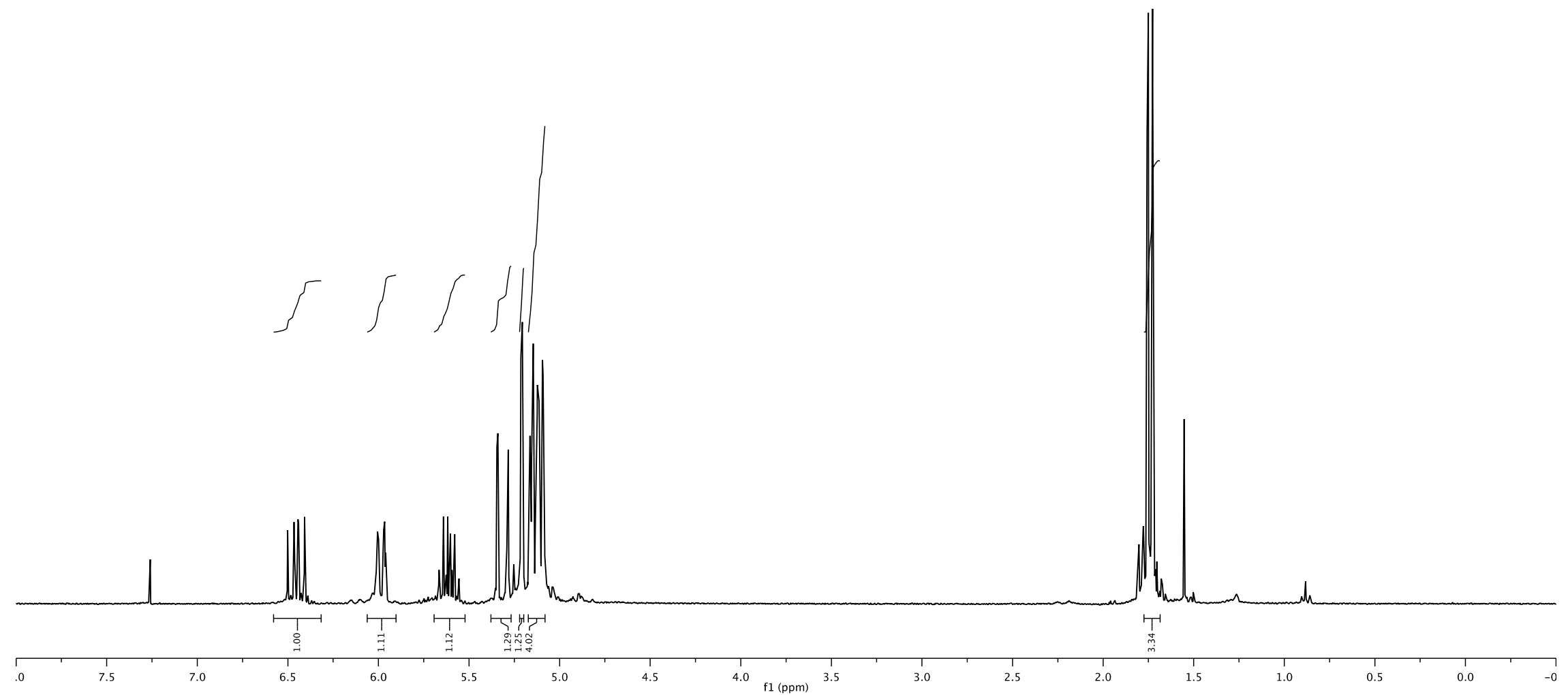




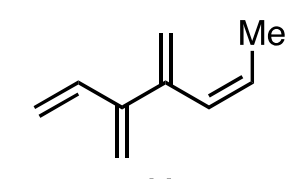

11

${ }^{13} \mathrm{C}$ NMR spectrum

$75 \mathrm{MHz}$, in $\mathrm{CDCl}_{3}$

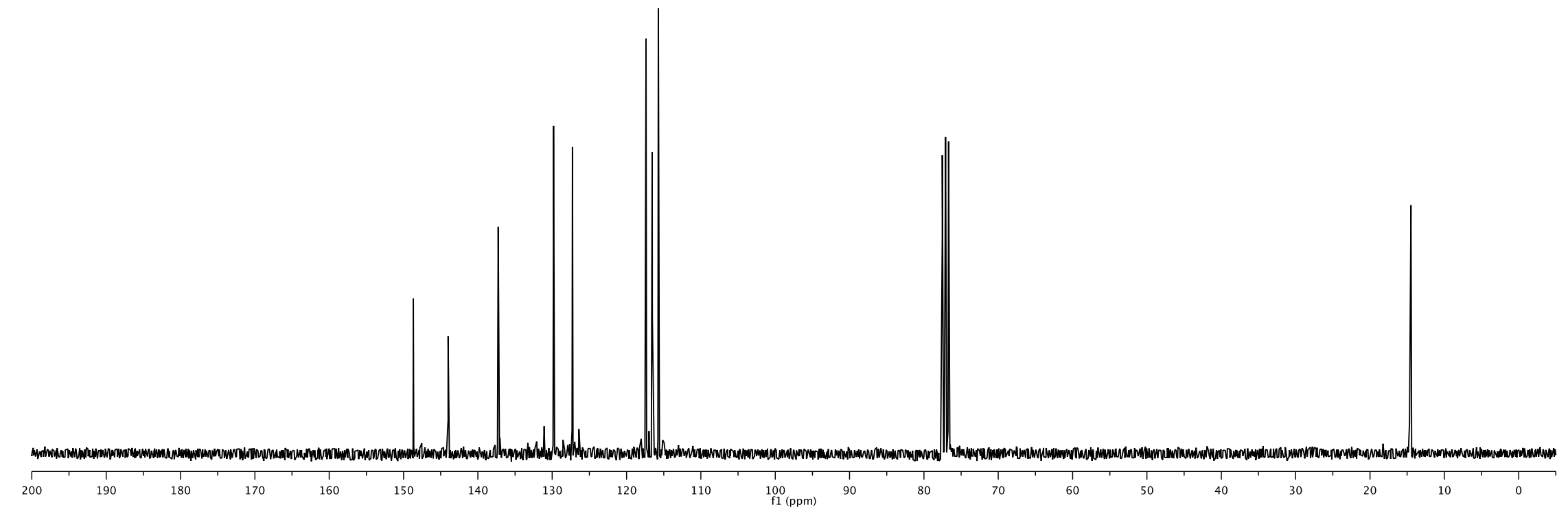




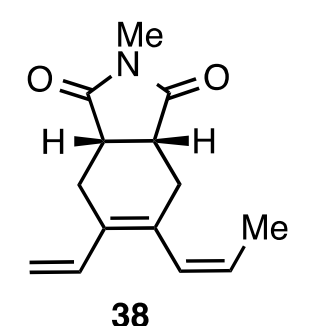

${ }^{1} \mathrm{H}$ NMR spectrum

$300 \mathrm{MHz}$, in $\mathrm{CDCl}_{3}$

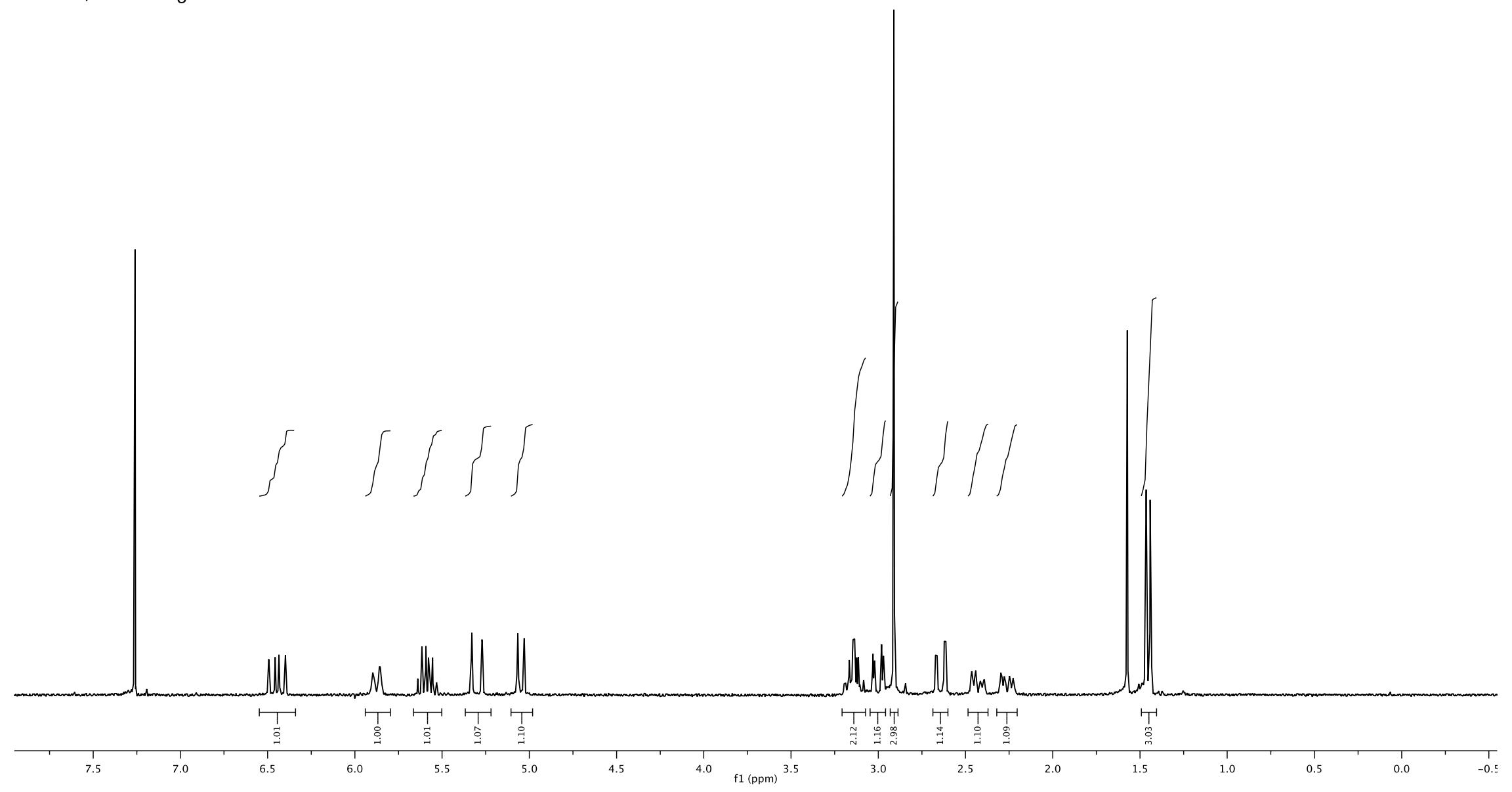




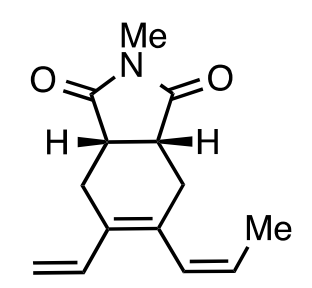

38

${ }^{13} \mathrm{C}$ NMR spectrum

$75 \mathrm{MHz}$, in $\mathrm{CDCl}_{3}$

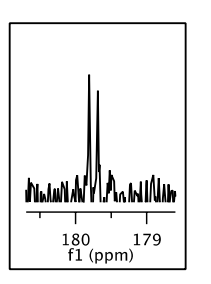

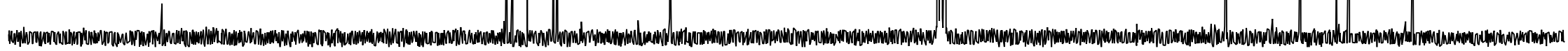

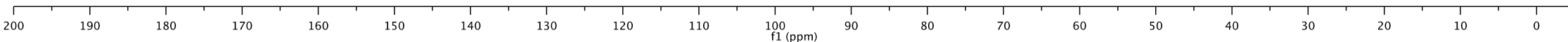




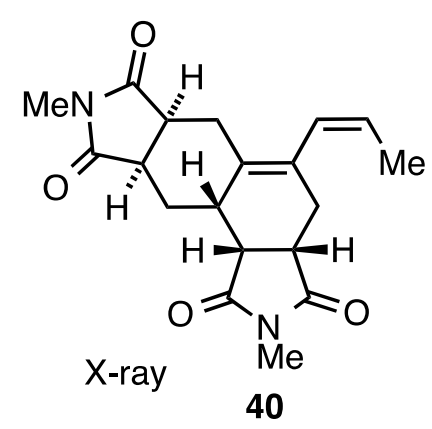

${ }^{1} \mathrm{H}$ NMR spectrum $300 \mathrm{MHz}$, in $\mathrm{CDCl}_{3}$

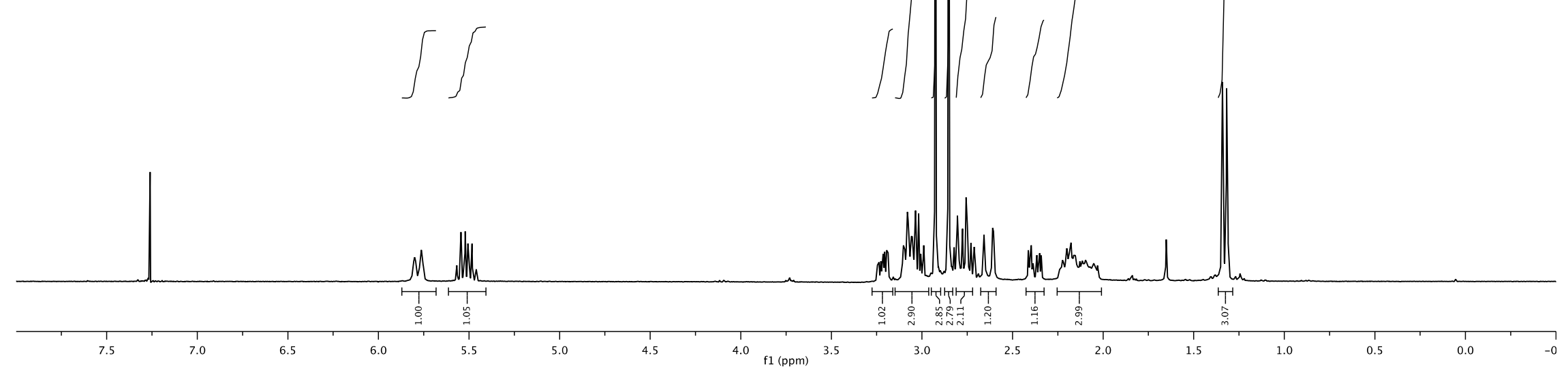




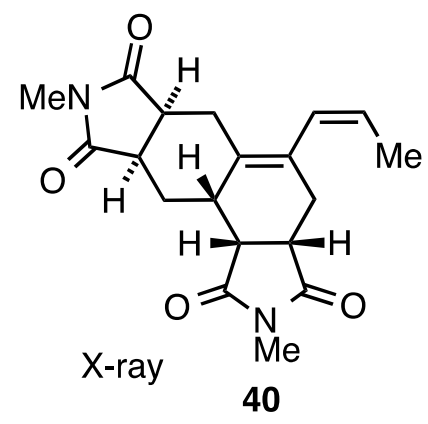

${ }^{13} \mathrm{C}$ NMR spectrum

$75 \mathrm{MHz}$, in $\mathrm{CDCl}_{3}$

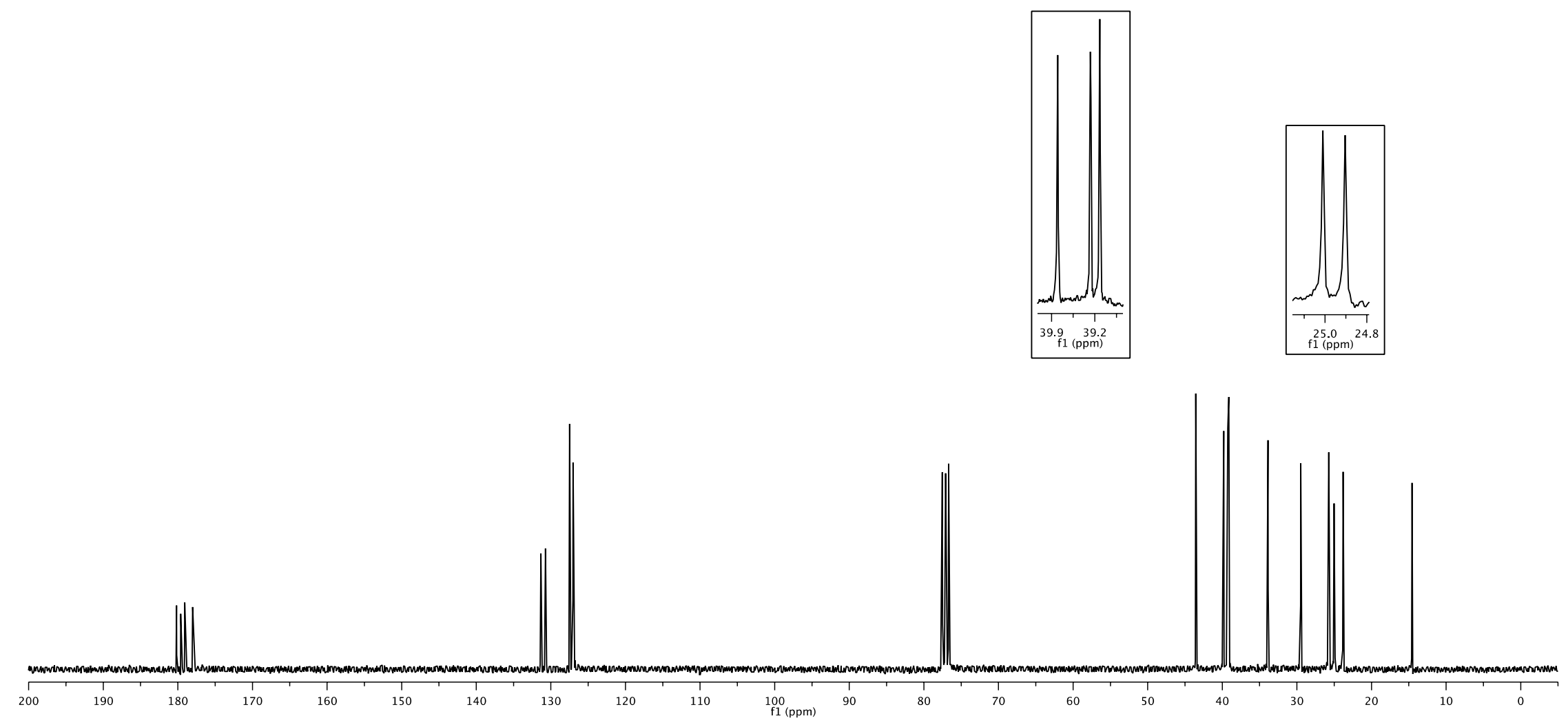




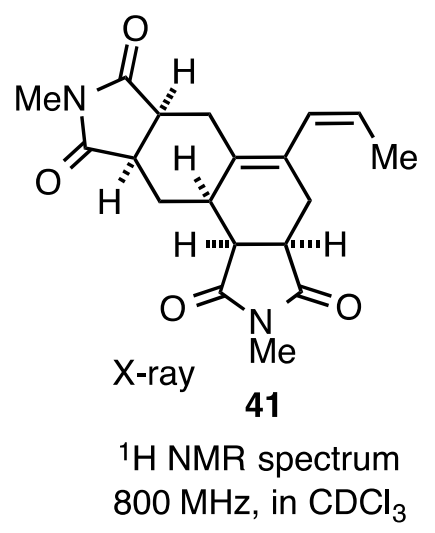

$800 \mathrm{MHz}$, in $\mathrm{CDCl}_{3}$

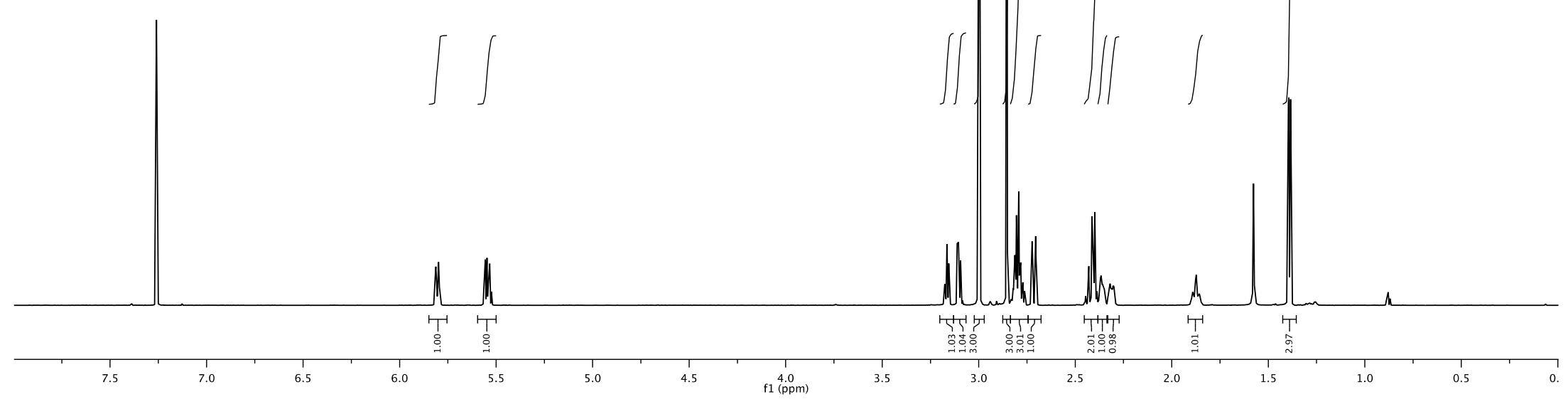




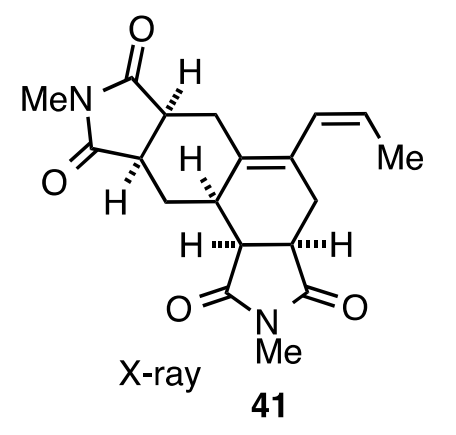

${ }^{13} \mathrm{C}$ NMR spectrum $200 \mathrm{MHz}$, in $\mathrm{CDCl}_{3}$
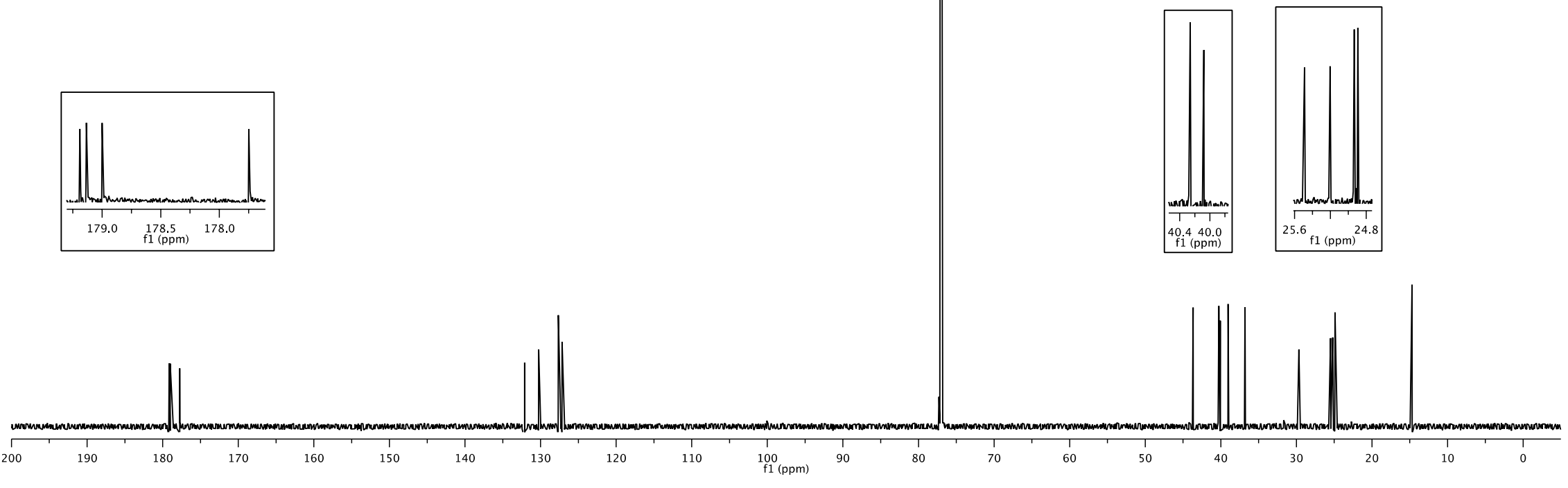


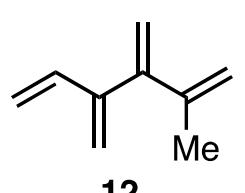

${ }^{1} \mathrm{H}$ NMR spectrum $300 \mathrm{MHz}$, in $\mathrm{CDCl}_{3}$

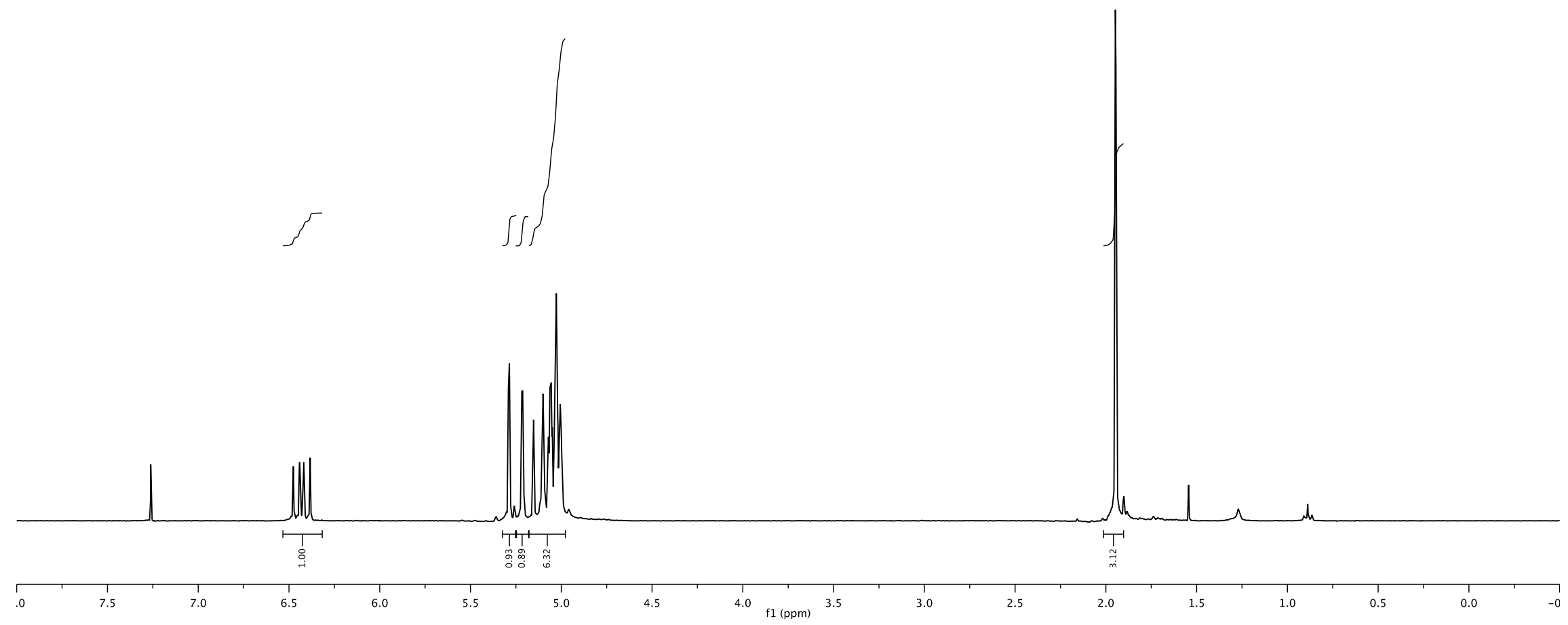




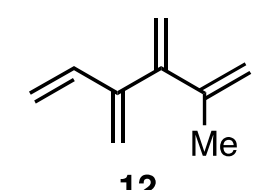

${ }^{13} \mathrm{C}$ NMR spectrum

$75 \mathrm{MHz}$, in $\mathrm{CDCl}_{3}$

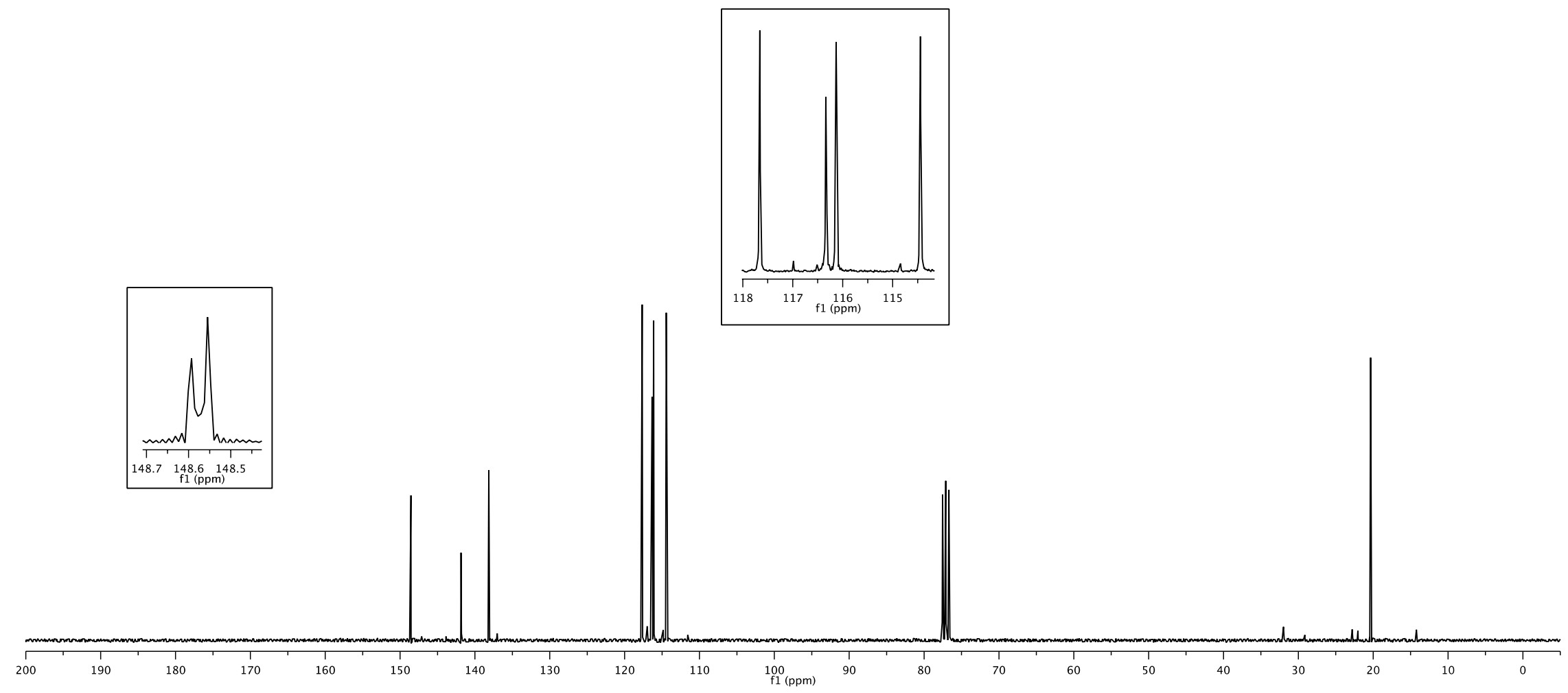




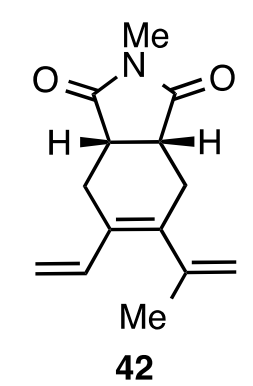

${ }^{1} \mathrm{H}$ NMR spectrum

$300 \mathrm{MHz}$, in $\mathrm{CDCl}_{3}$

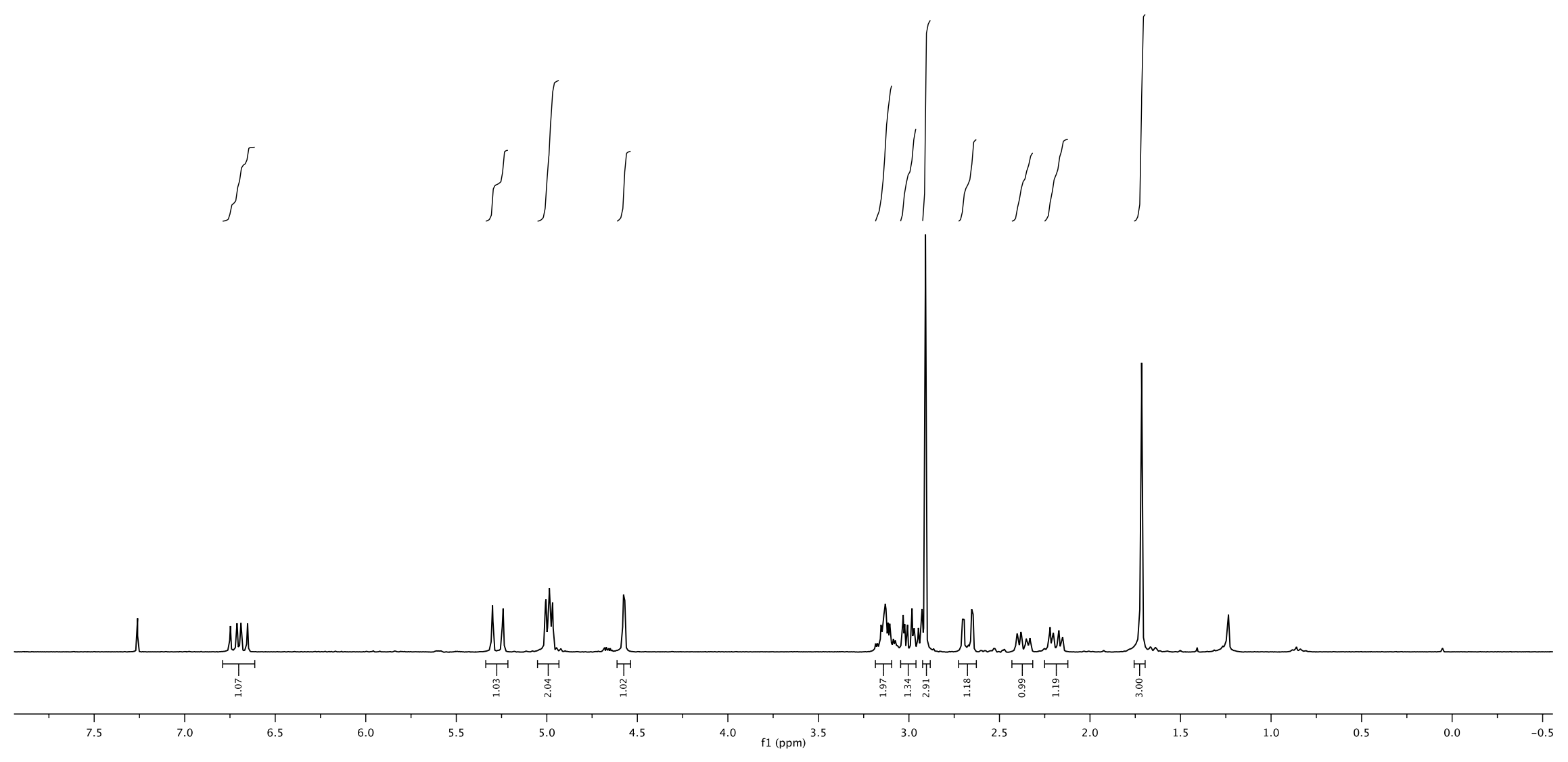




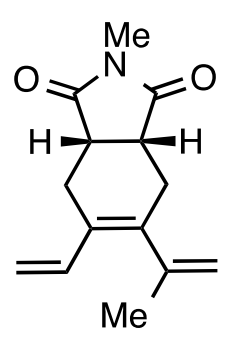

42

${ }^{13} \mathrm{C}$ NMR spectrum

$75 \mathrm{MHz}$, in $\mathrm{CDCl}_{3}$
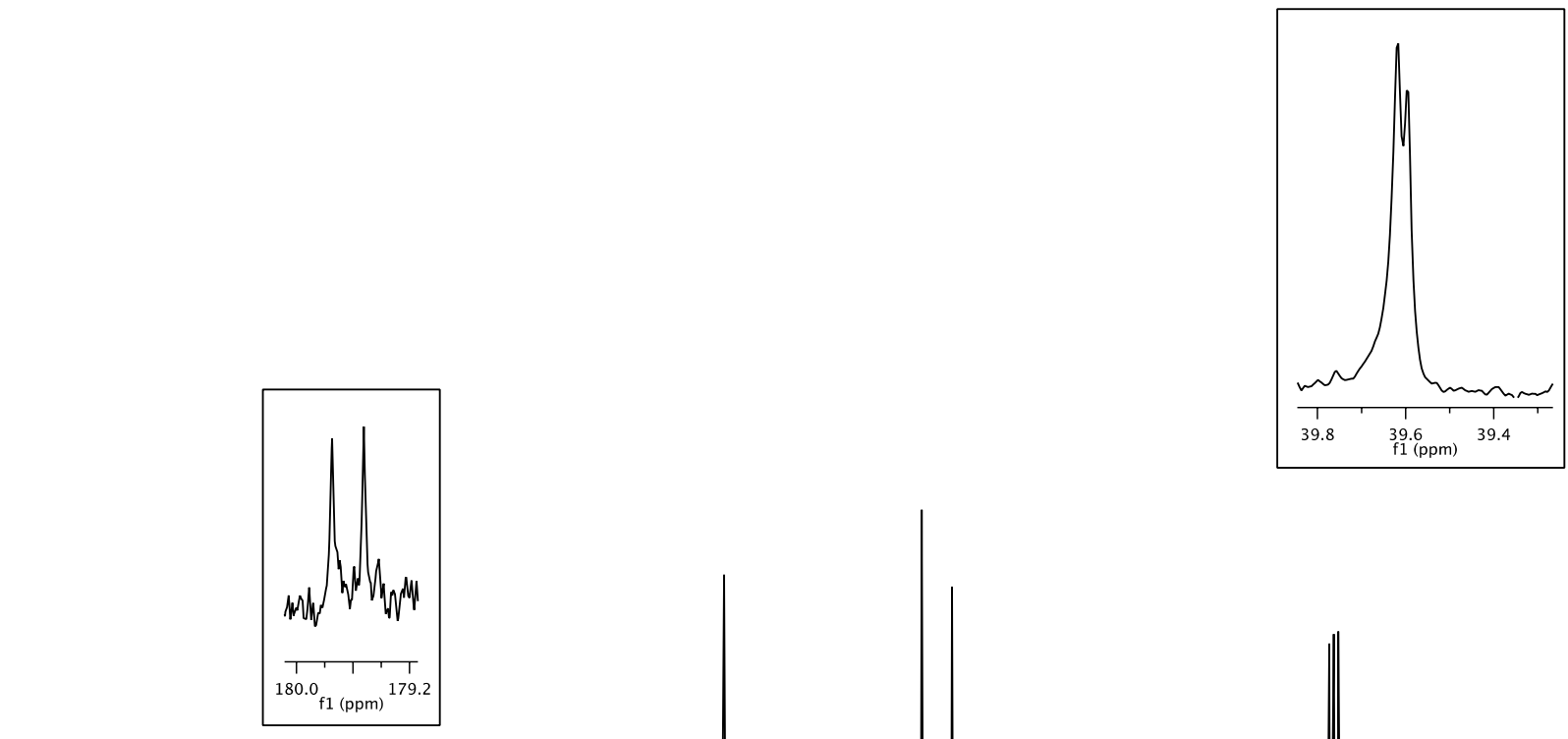

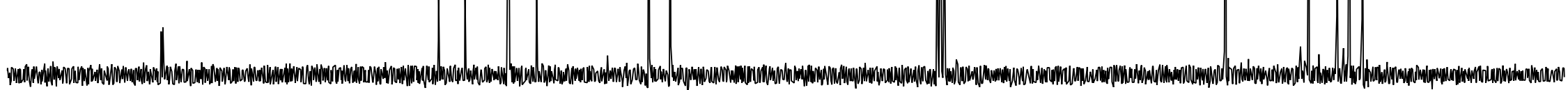
190
180 $160 \quad \frac{1}{150} \quad 1$ $\begin{array}{rrr}1 & 1 \\ 140 & 130 & 120\end{array}$ $\begin{array}{ccc}1 & 1 \\ 120 & 110 & 100 \\ & & 1 \\ \mathrm{f} 1(\mathrm{ppm}) & 90\end{array}$ 


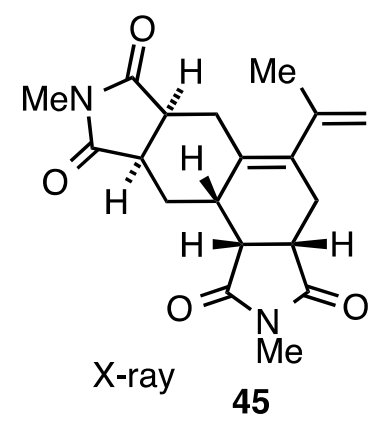

${ }^{1} \mathrm{H}$ NMR spectrum

$300 \mathrm{MHz}$, in $\mathrm{CDCl}_{3}$

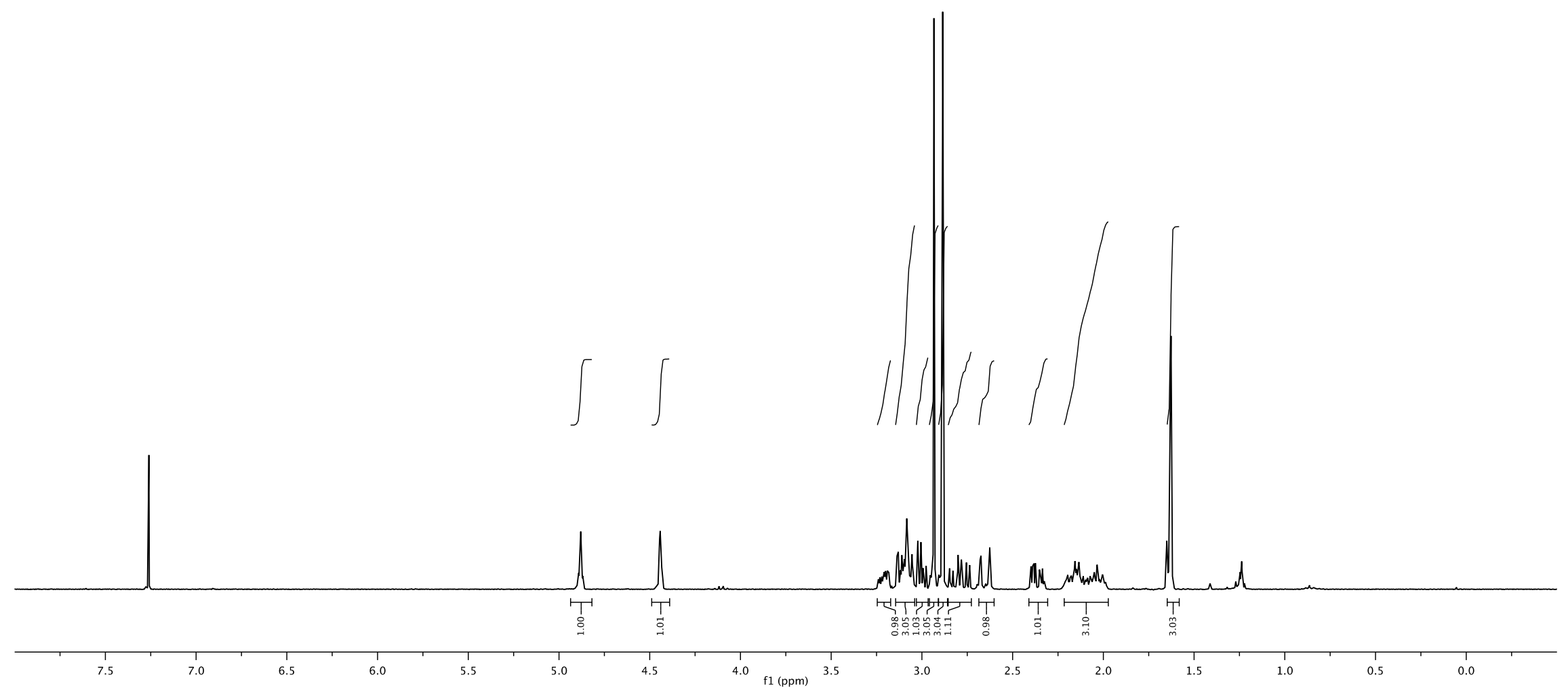




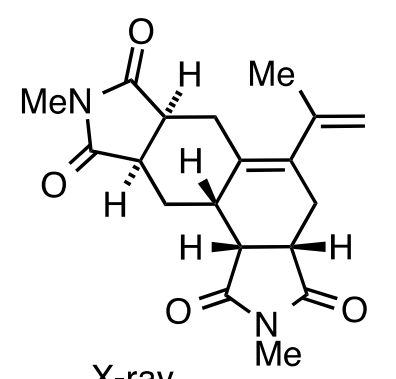

X-ray 45

${ }^{13} \mathrm{C}$ NMR spectrum

$75 \mathrm{MHz}$, in $\mathrm{CDCl}_{3}$

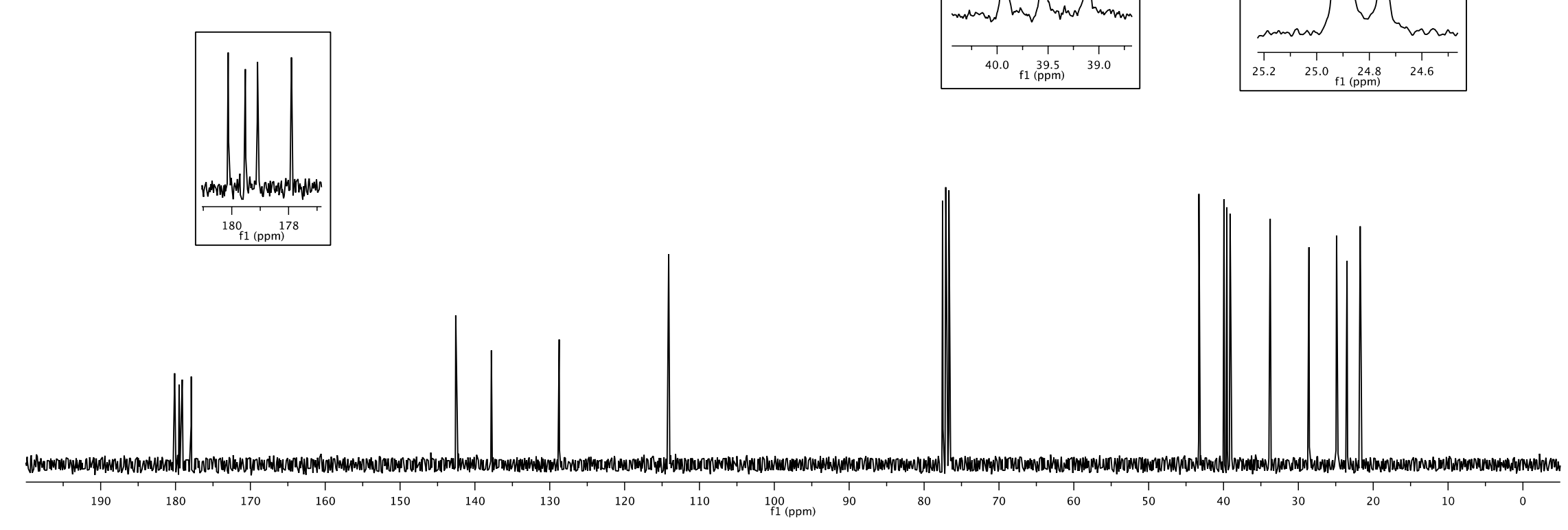




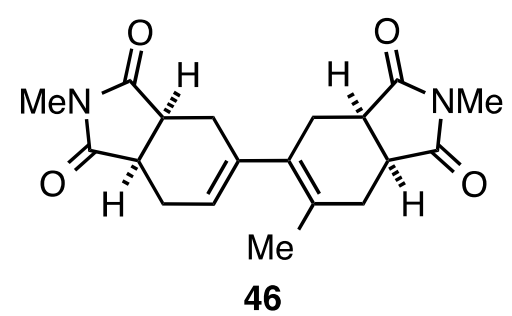

${ }^{1} \mathrm{H}$ NMR spectrum $300 \mathrm{MHz}$, in $\mathrm{CDCl}_{3}$

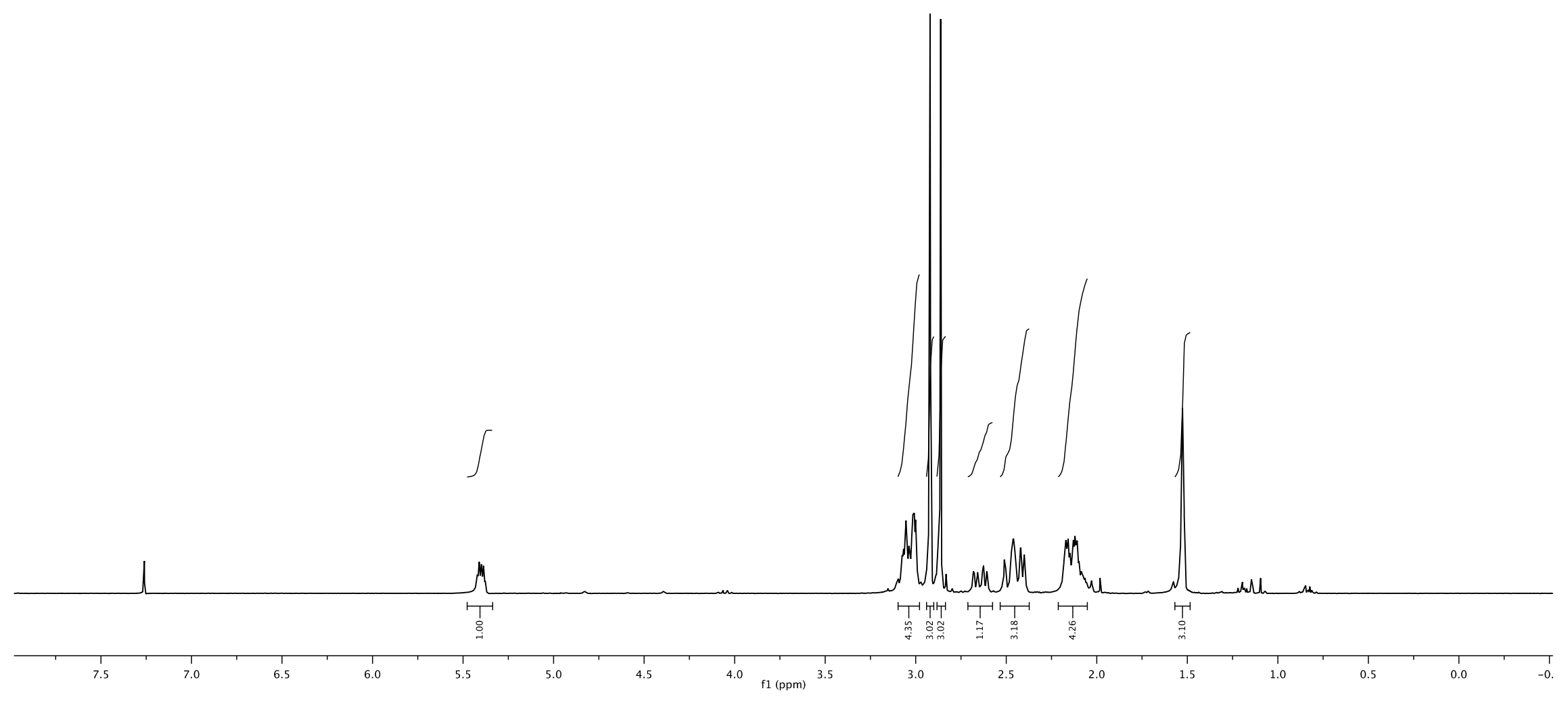




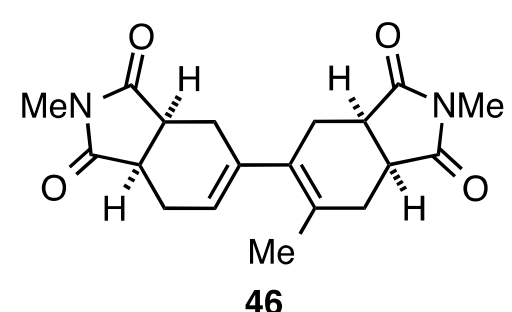

${ }^{13} \mathrm{C}$ NMR spectrum $75 \mathrm{MHz}$, in $\mathrm{CDCl}_{3}$
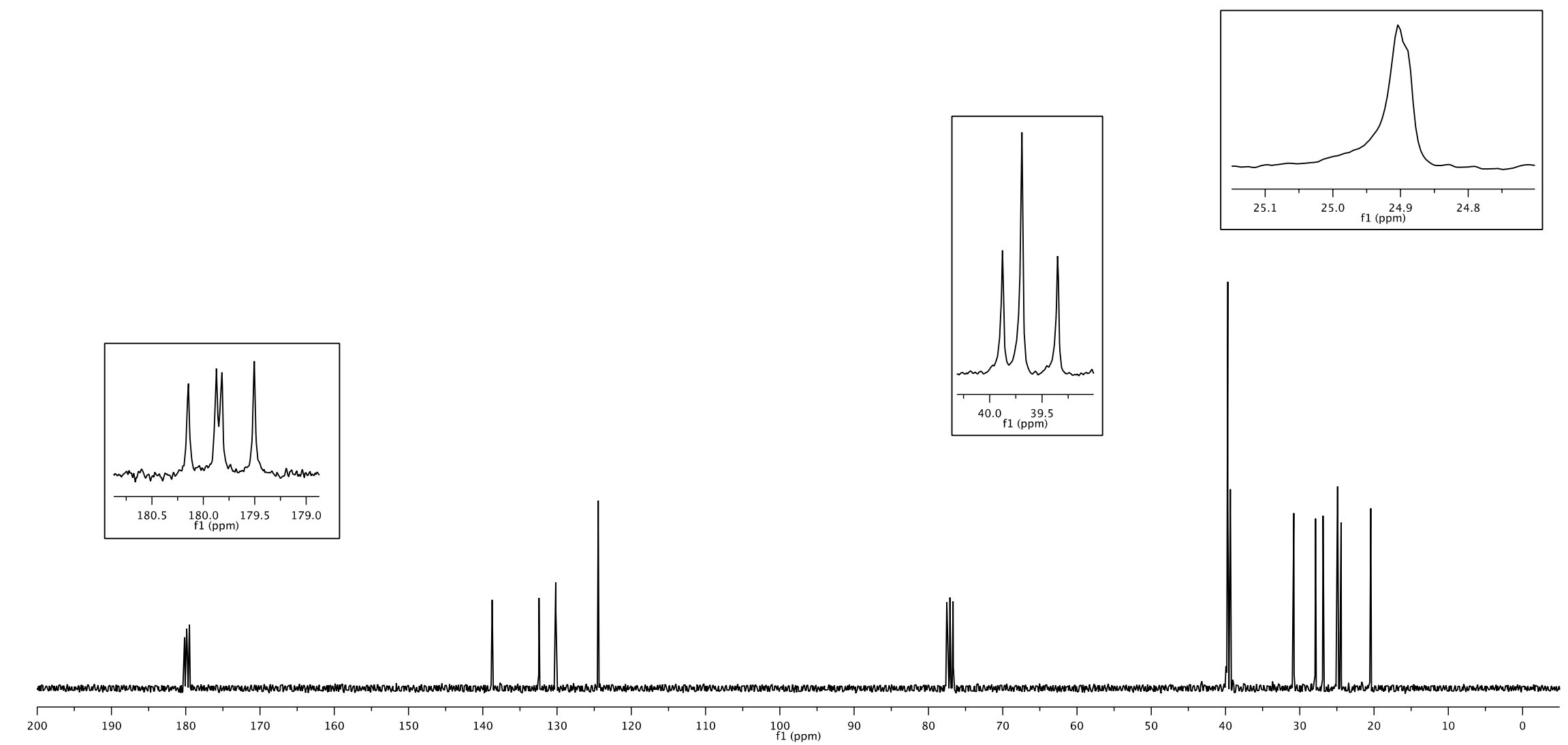


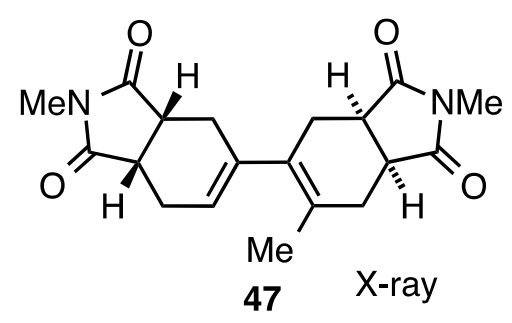

${ }^{1} \mathrm{H}$ NMR spectrum $300 \mathrm{MHz}$, in $\mathrm{CDCl}_{3}$

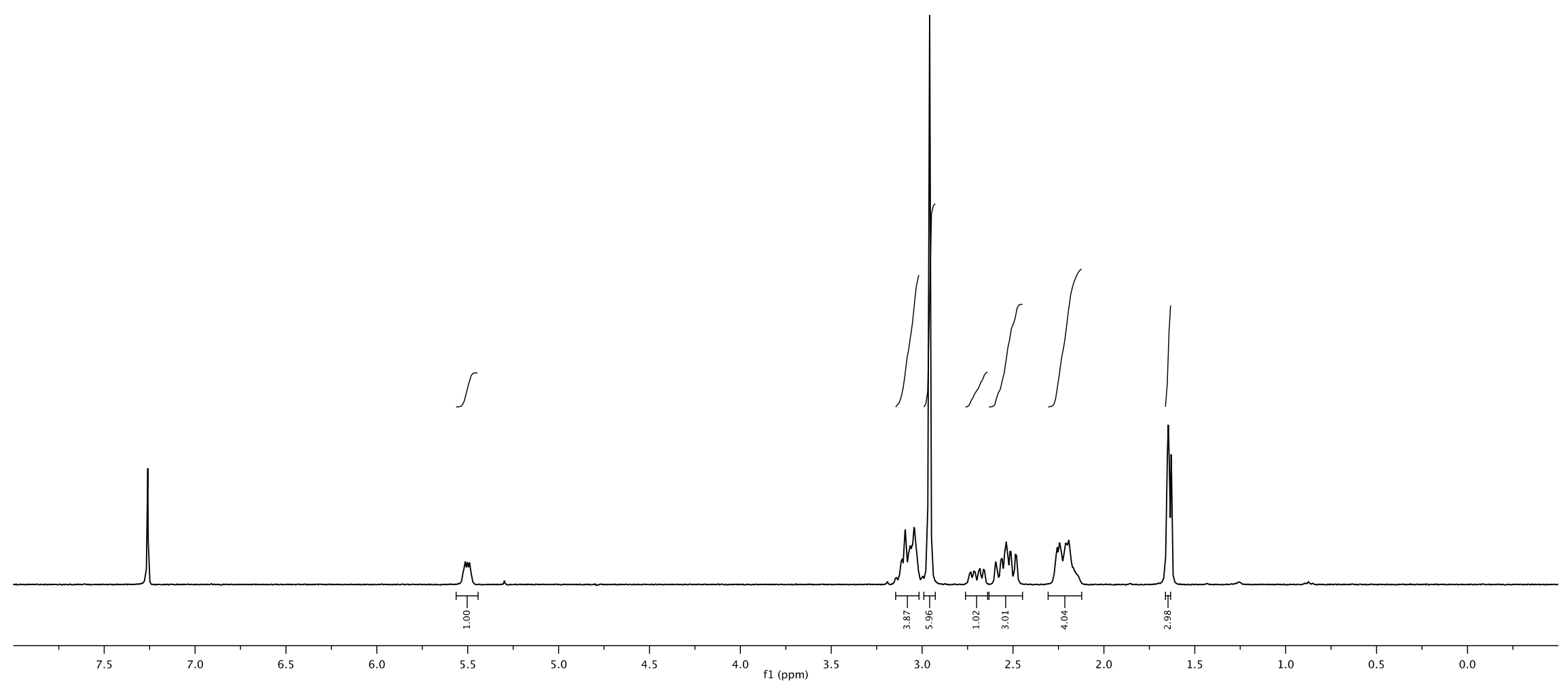




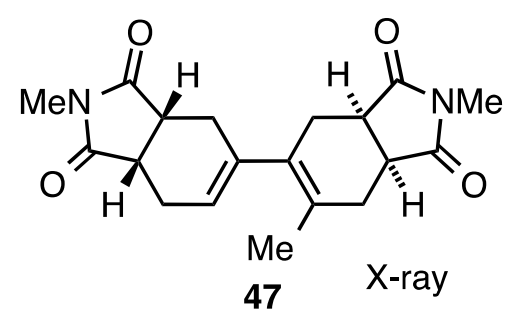

${ }^{13} \mathrm{C}$ NMR spectrum $75 \mathrm{MHz}$, in $\mathrm{CDCl}_{3}$

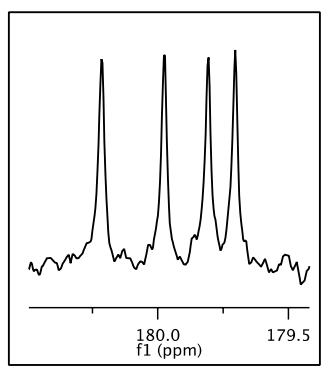

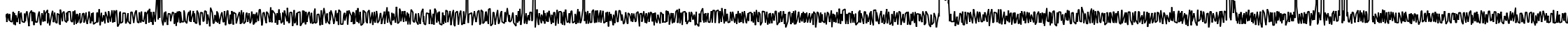

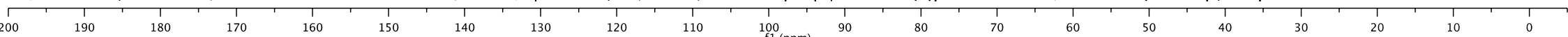

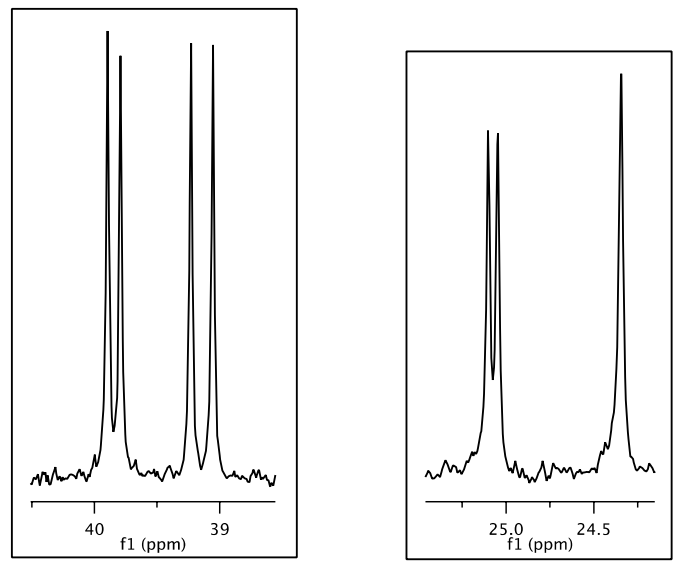

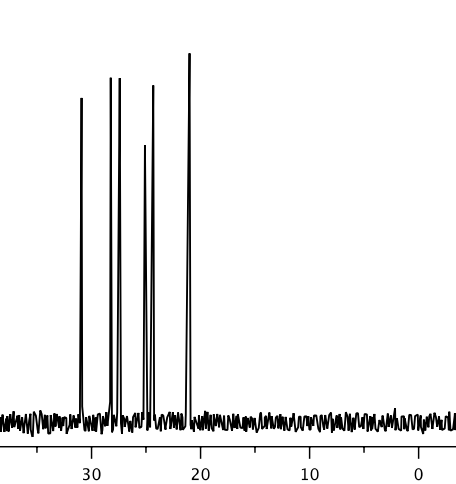




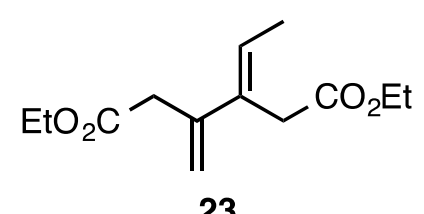

${ }^{1} \mathrm{H}$ NMR spectrum $300 \mathrm{MHz}$, in $\mathrm{CDCl}_{3}$

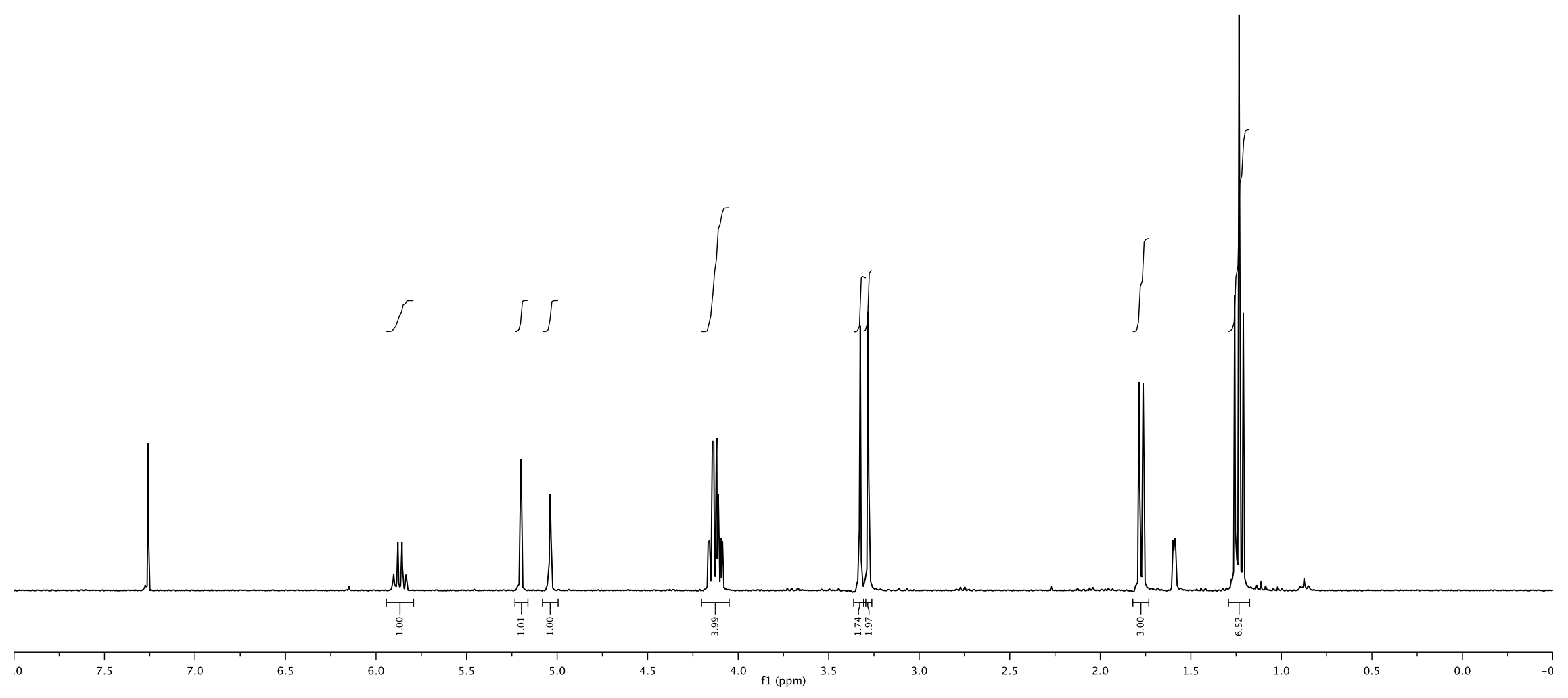




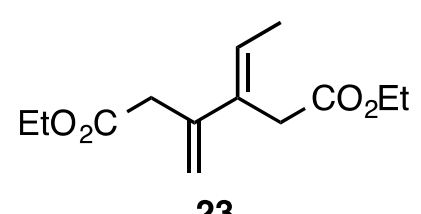

${ }^{13} \mathrm{C}$ NMR spectrum

$75 \mathrm{MHz}$, in $\mathrm{CDCl}_{3}$

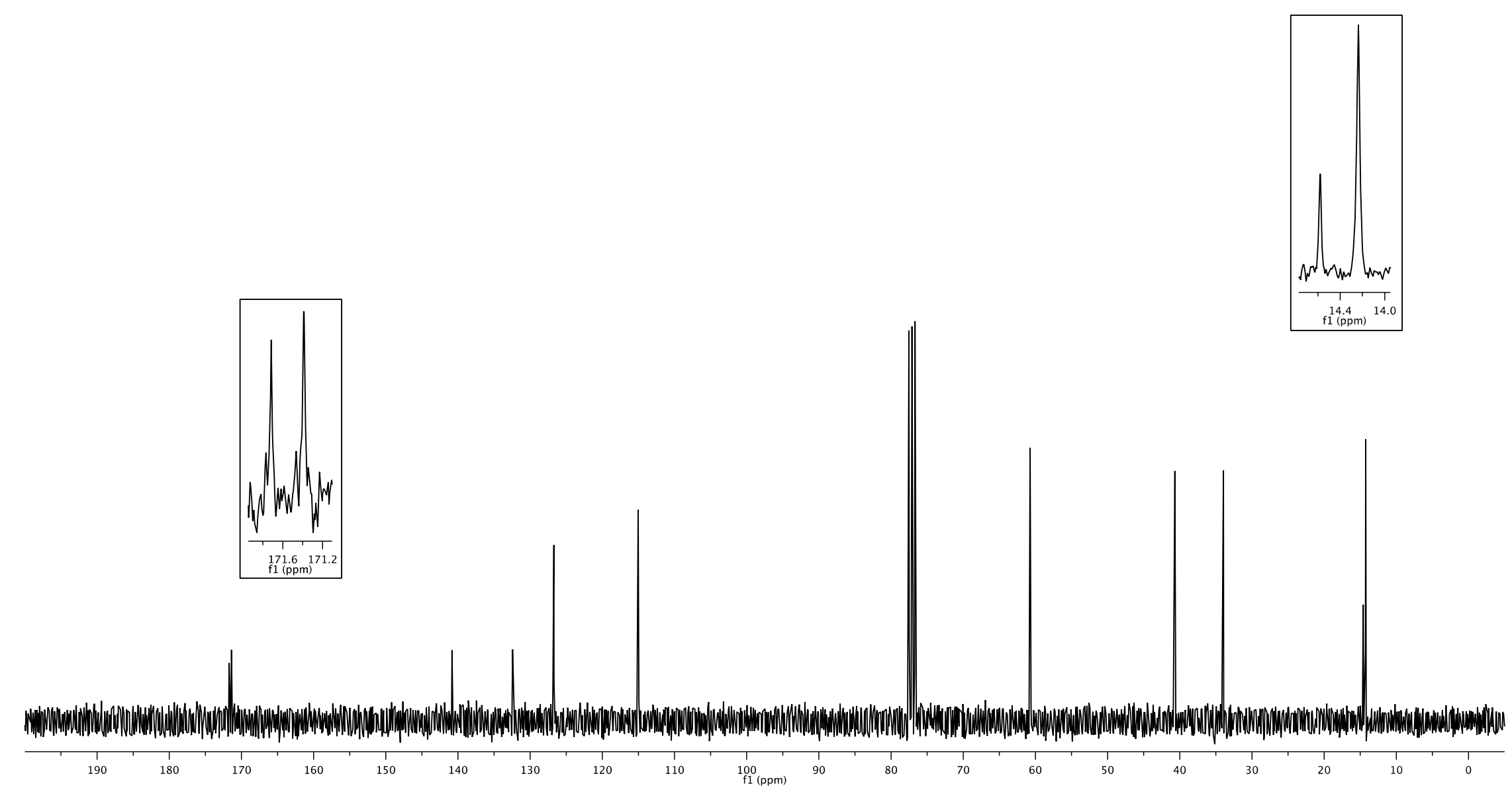




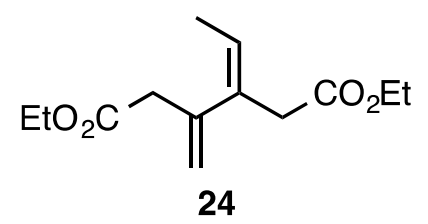

${ }^{1} \mathrm{H}$ NMR spectrum $300 \mathrm{MHz}$, in $\mathrm{CDCl}_{3}$

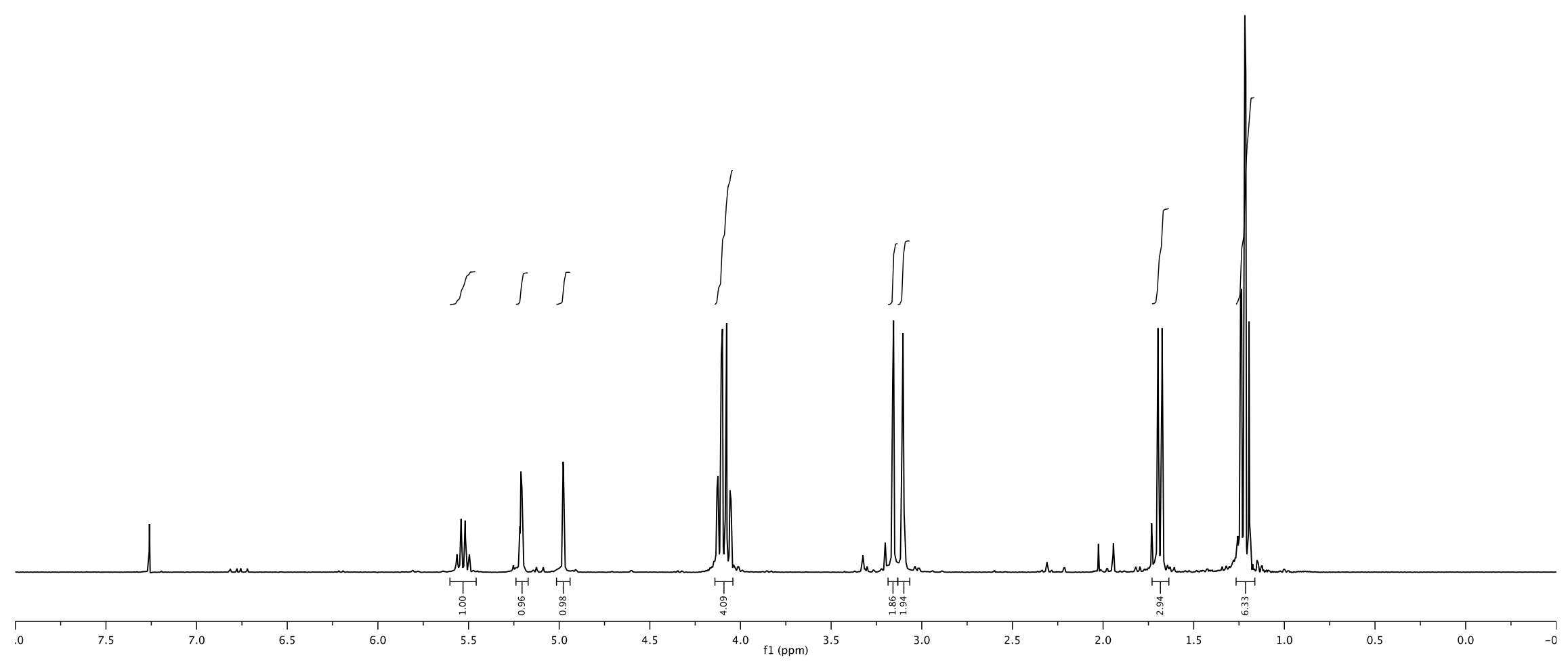




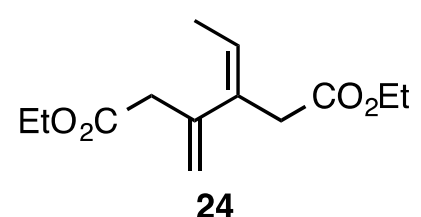

${ }^{13} \mathrm{C}$ NMR spectrum

$75 \mathrm{MHz}$, in $\mathrm{CDCl}_{3}$

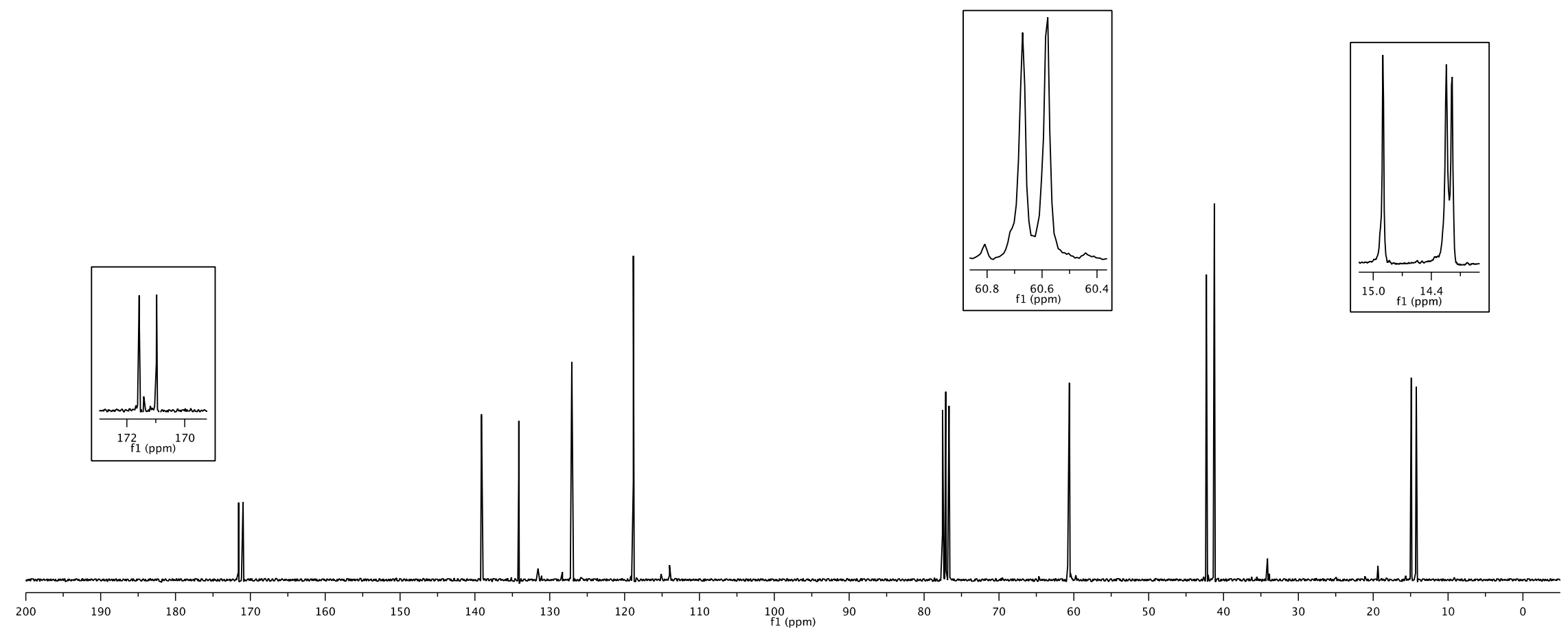




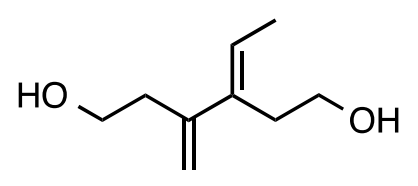

25

${ }^{1} \mathrm{H}$ NMR spectrum

$300 \mathrm{MHz}$, in $\mathrm{CDCl}_{3}$

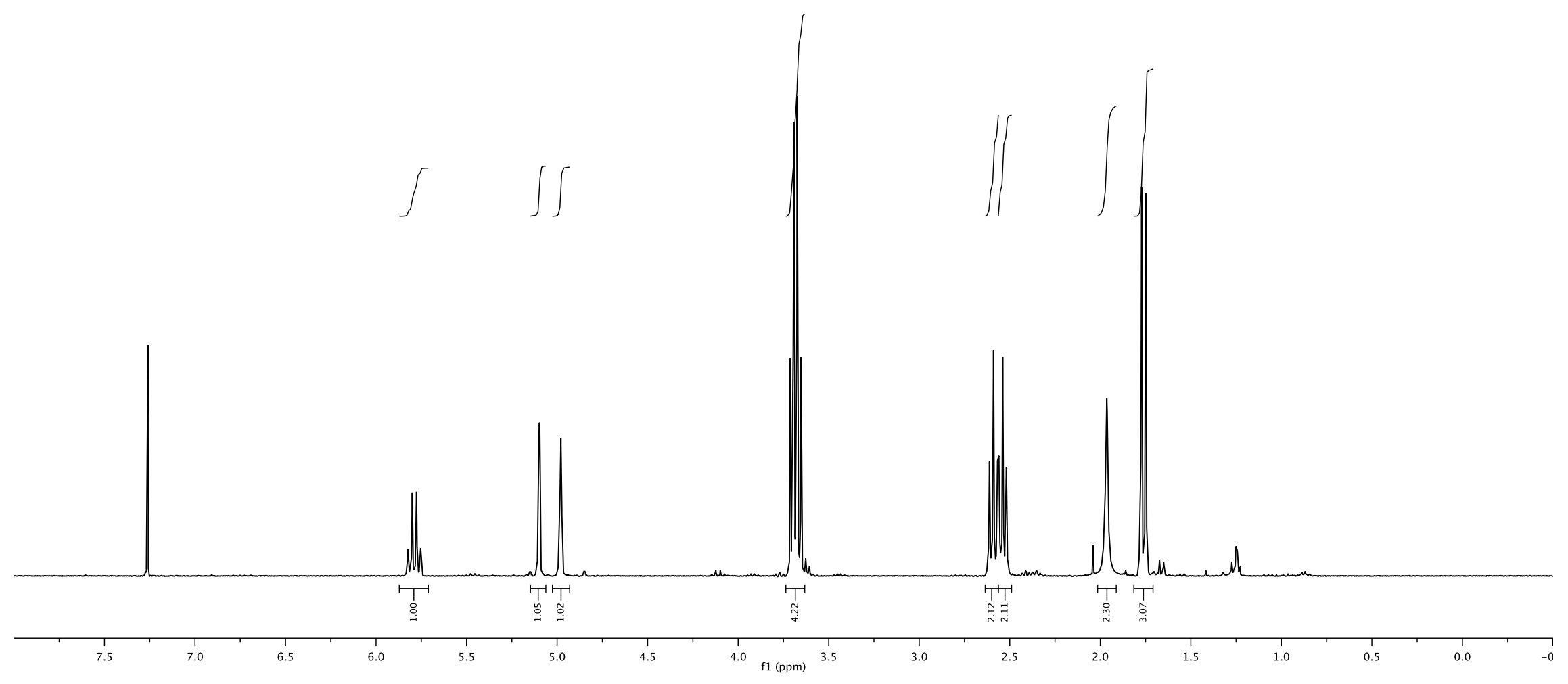




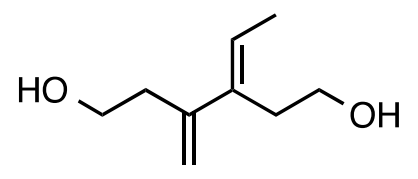

25

${ }^{13} \mathrm{C}$ NMR spectrum

$75 \mathrm{MHz}$, in $\mathrm{CDCl}_{3}$

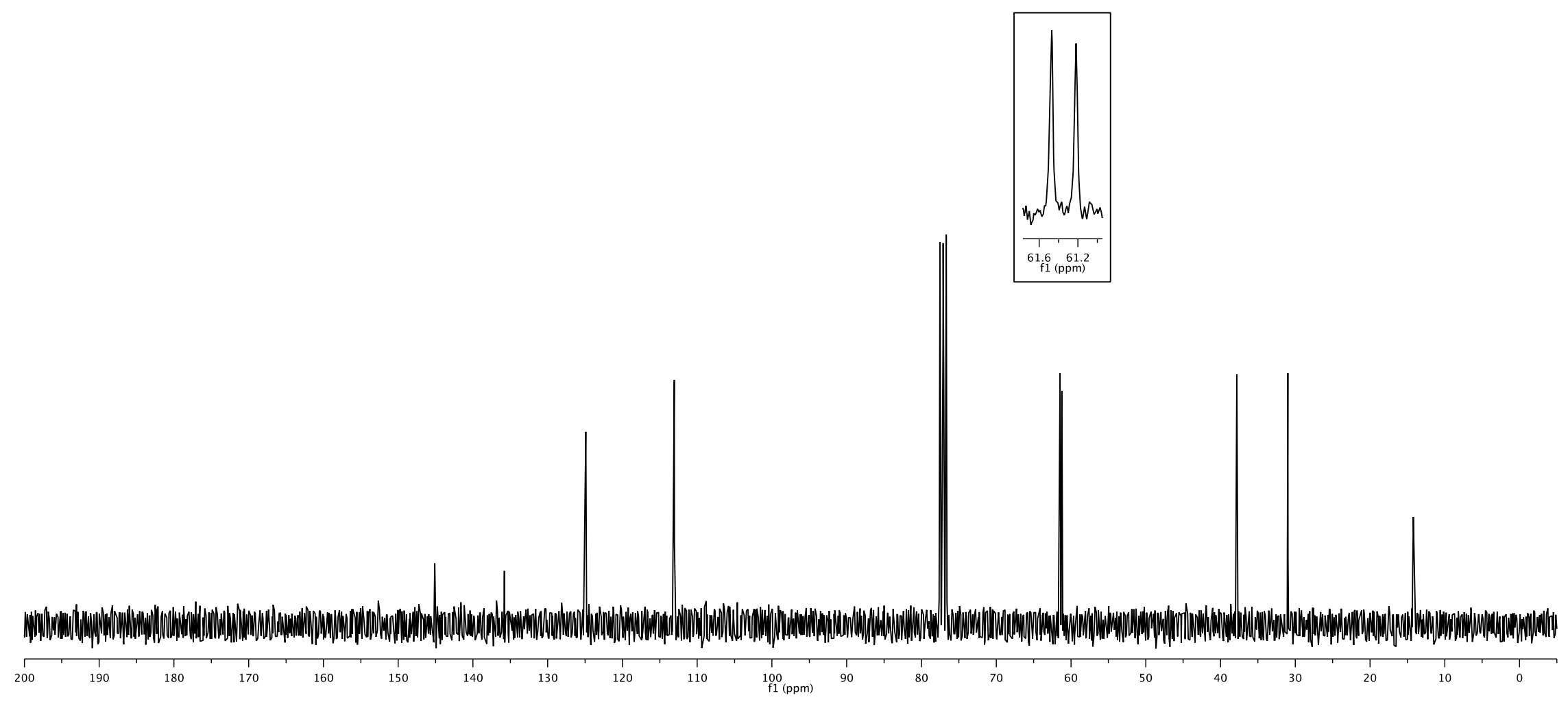




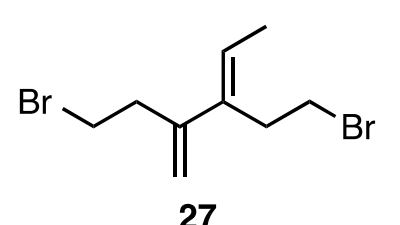

${ }^{1} \mathrm{H}$ NMR spectrum

$300 \mathrm{MHz}$, in $\mathrm{CDCl}_{3}$

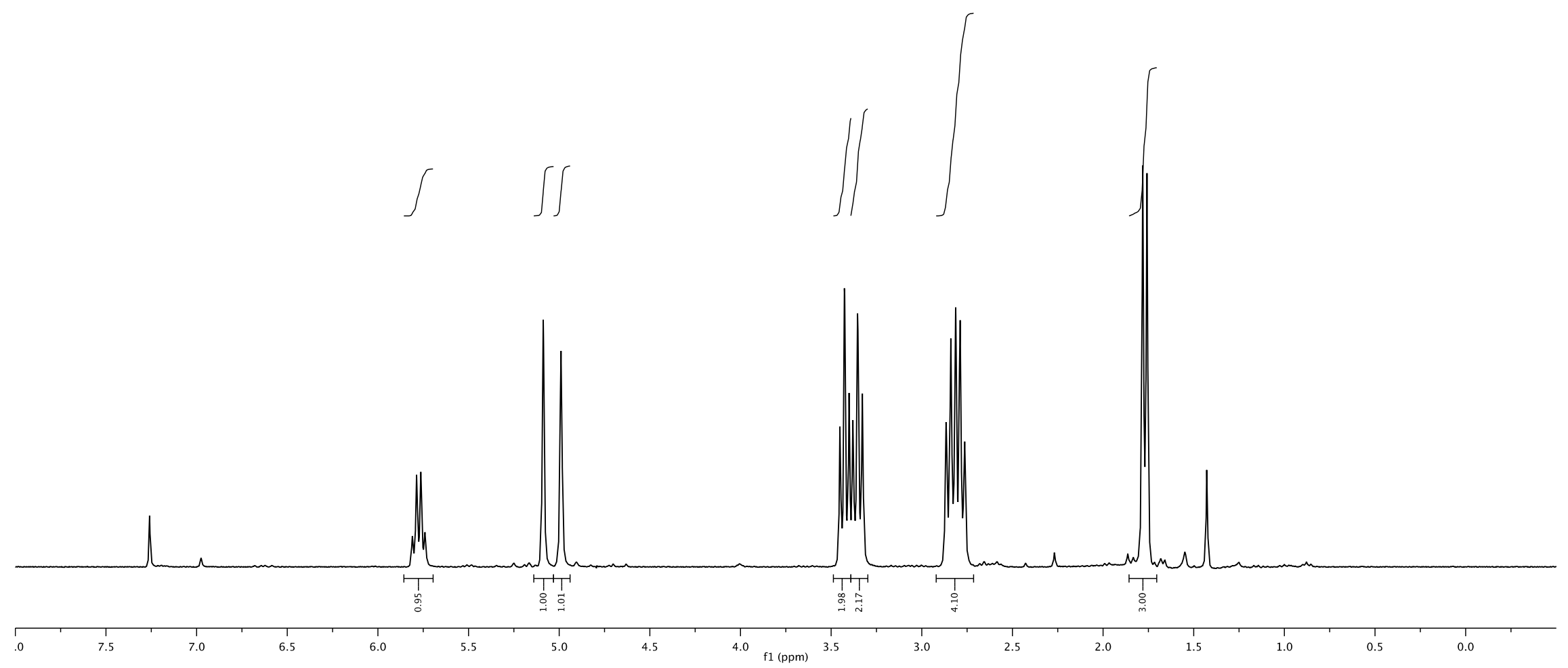




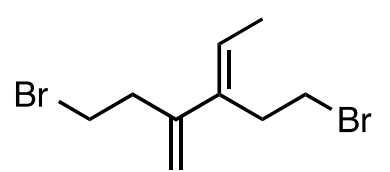

27

${ }^{13} \mathrm{C}$ NMR spectrum

$75 \mathrm{MHz}$, in $\mathrm{CDCl}_{3}$

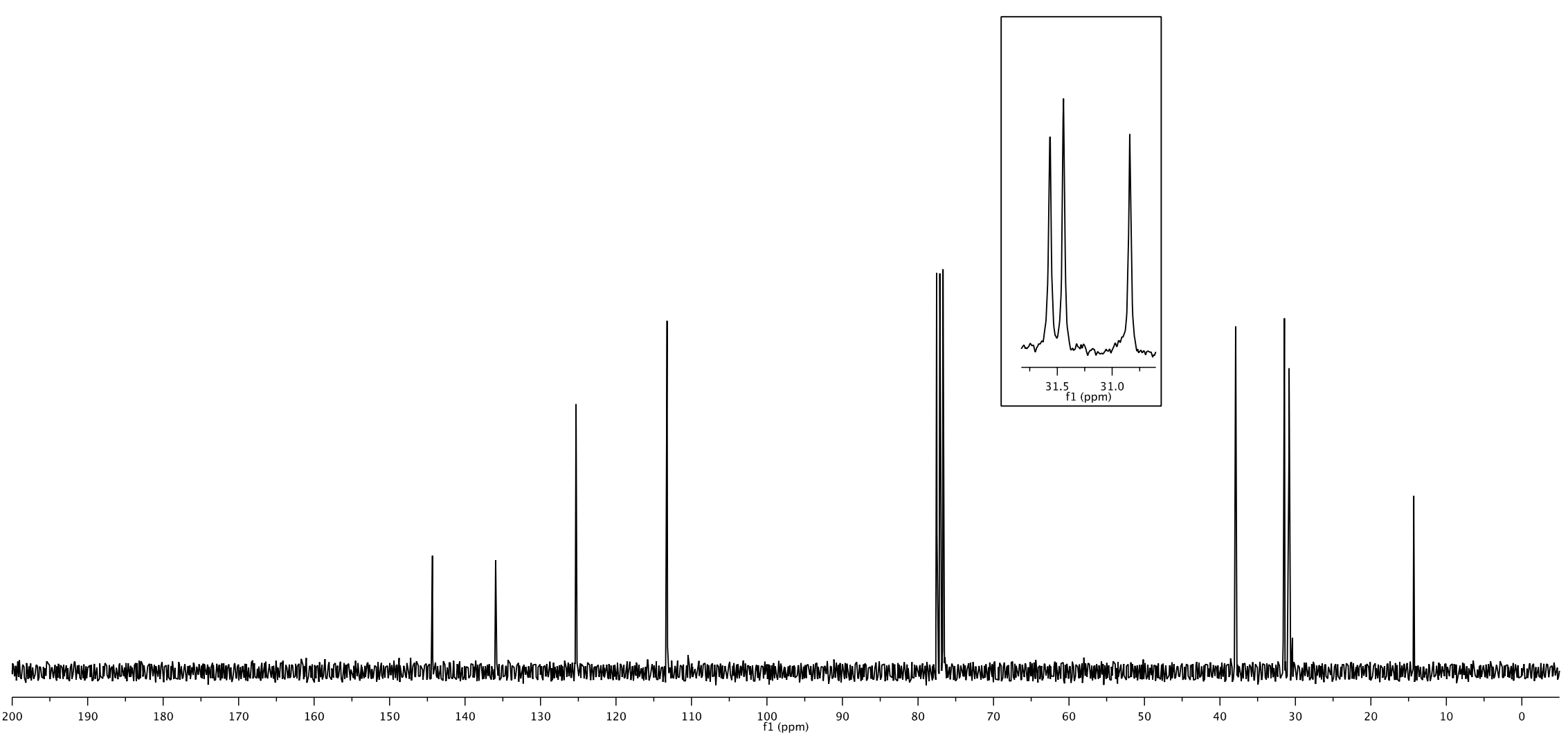


<smiles>C=CC(=C)C(C=C)=CC</smiles>

${ }^{1} \mathrm{H}$ NMR spectrum $300 \mathrm{MHz}$, in $\mathrm{CDCl}_{3}$

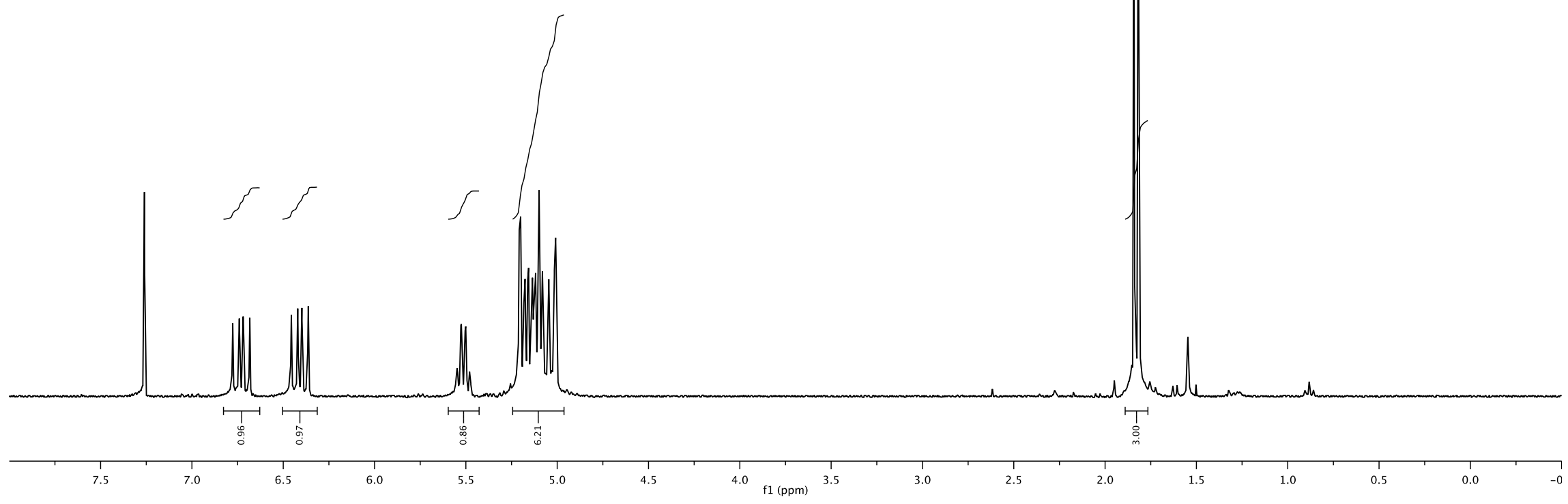

S61 


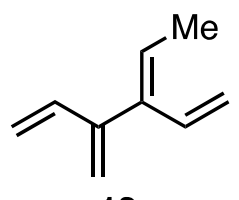

13

${ }^{13} \mathrm{C}$ NMR spectrum

$75 \mathrm{MHz}$, in $\mathrm{CDCl}_{3}$
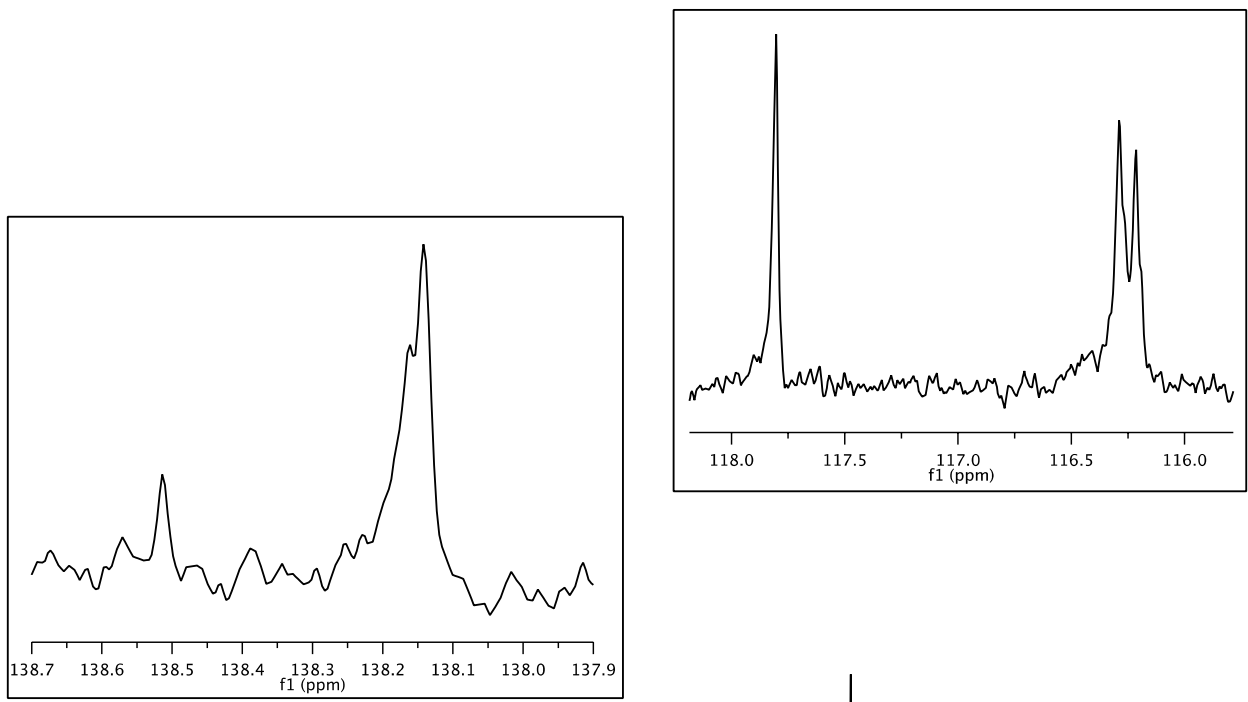

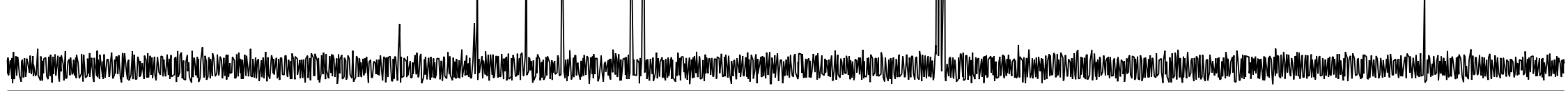

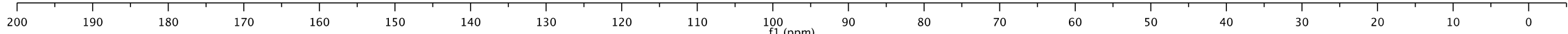




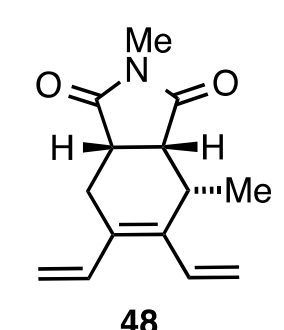

${ }^{1} \mathrm{H}$ NMR spectrum $300 \mathrm{MHz}$, in $\mathrm{CDCl}_{3}$

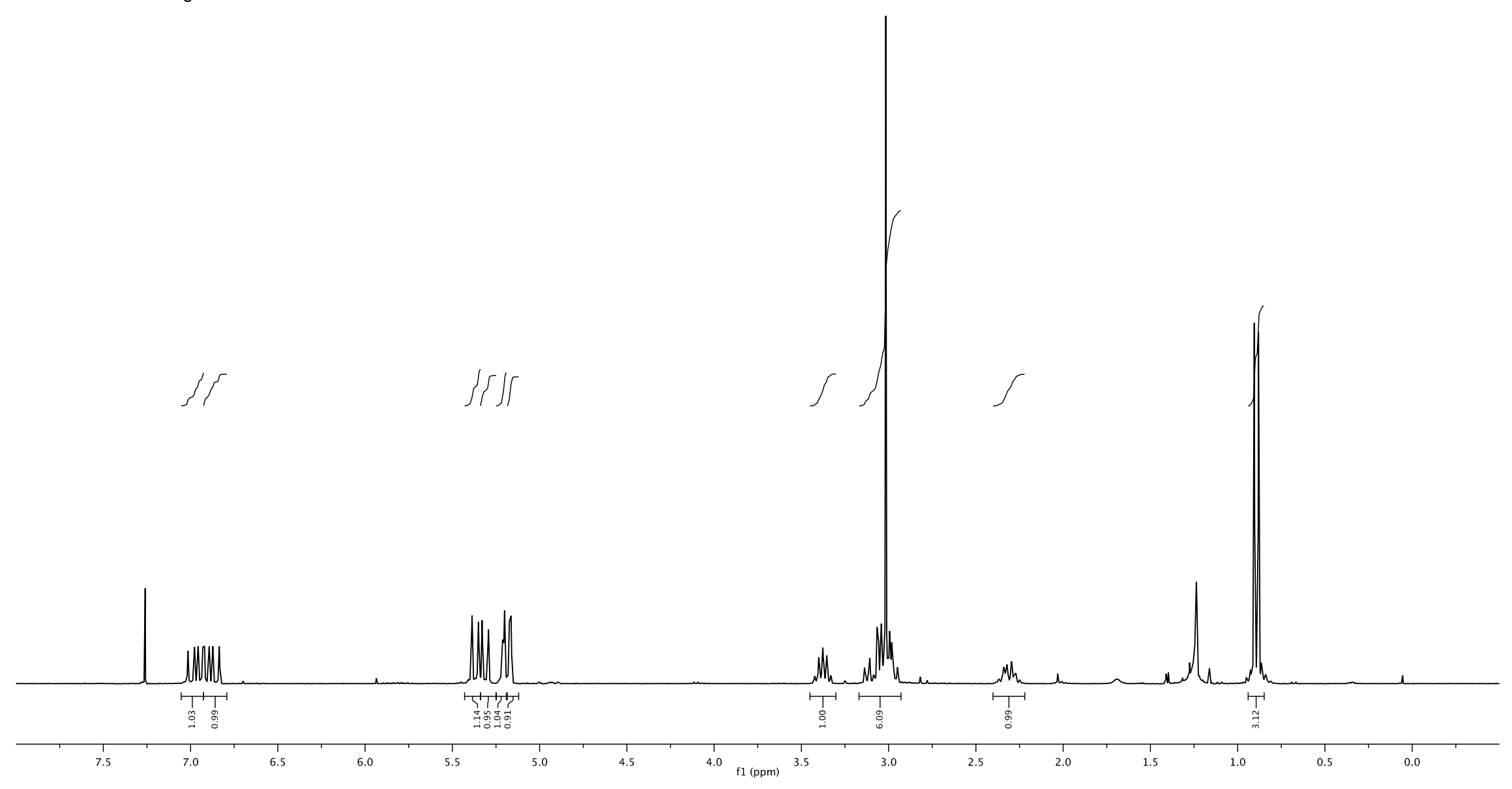




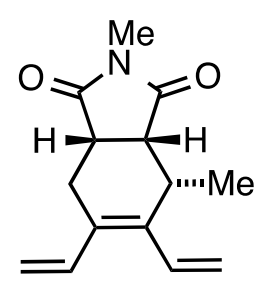

48

${ }^{13} \mathrm{C}$ NMR spectrum

$75 \mathrm{MHz}$, in $\mathrm{CDCl}_{3}$

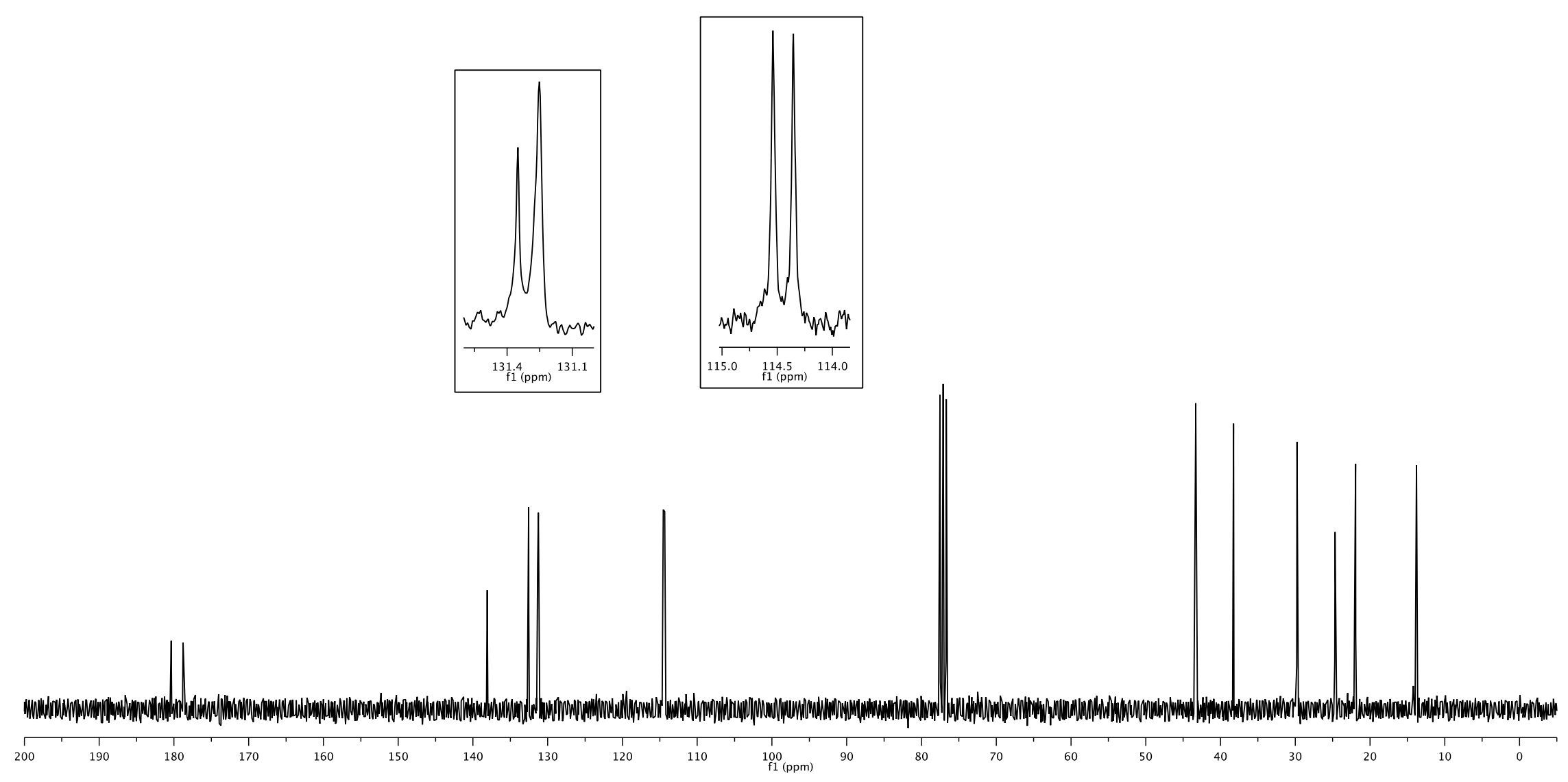




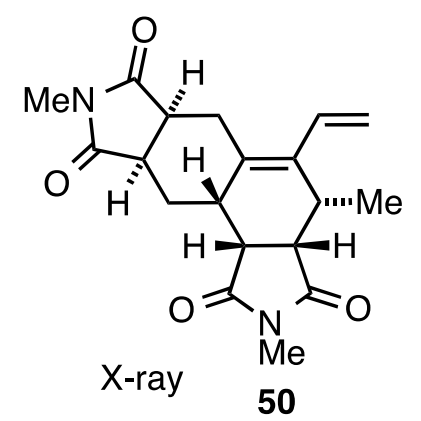

${ }^{1} \mathrm{H}$ NMR spectrum $300 \mathrm{MHz}$, in $\mathrm{CDCl}_{3}$

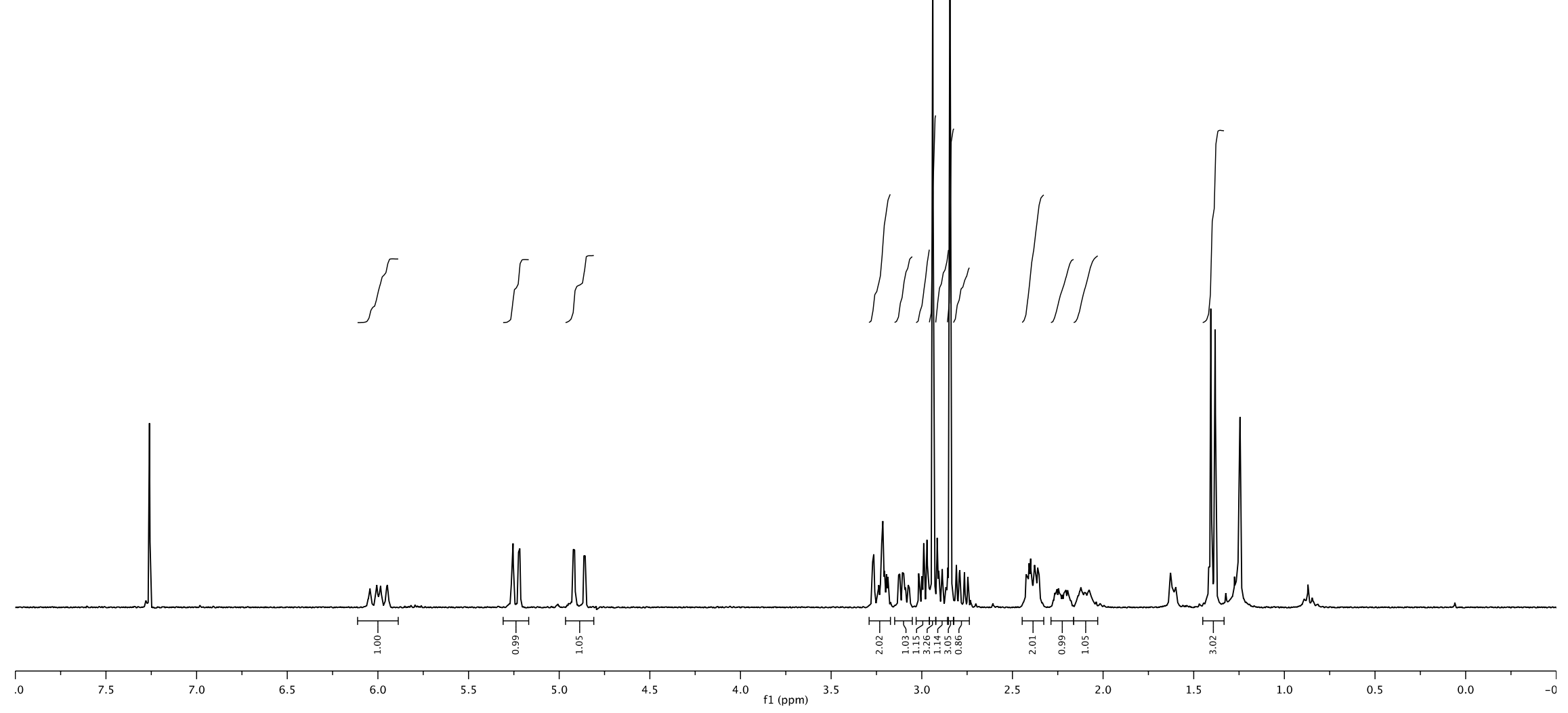




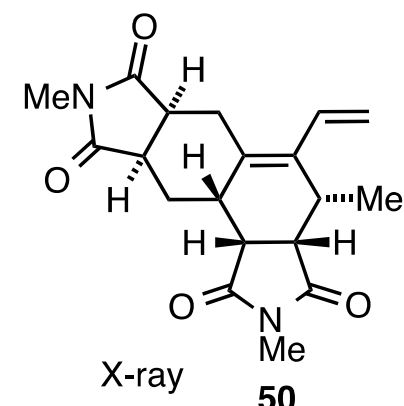

${ }^{13} \mathrm{C}$ NMR spectrum $75 \mathrm{MHz}$, in $\mathrm{CDCl}_{3}$
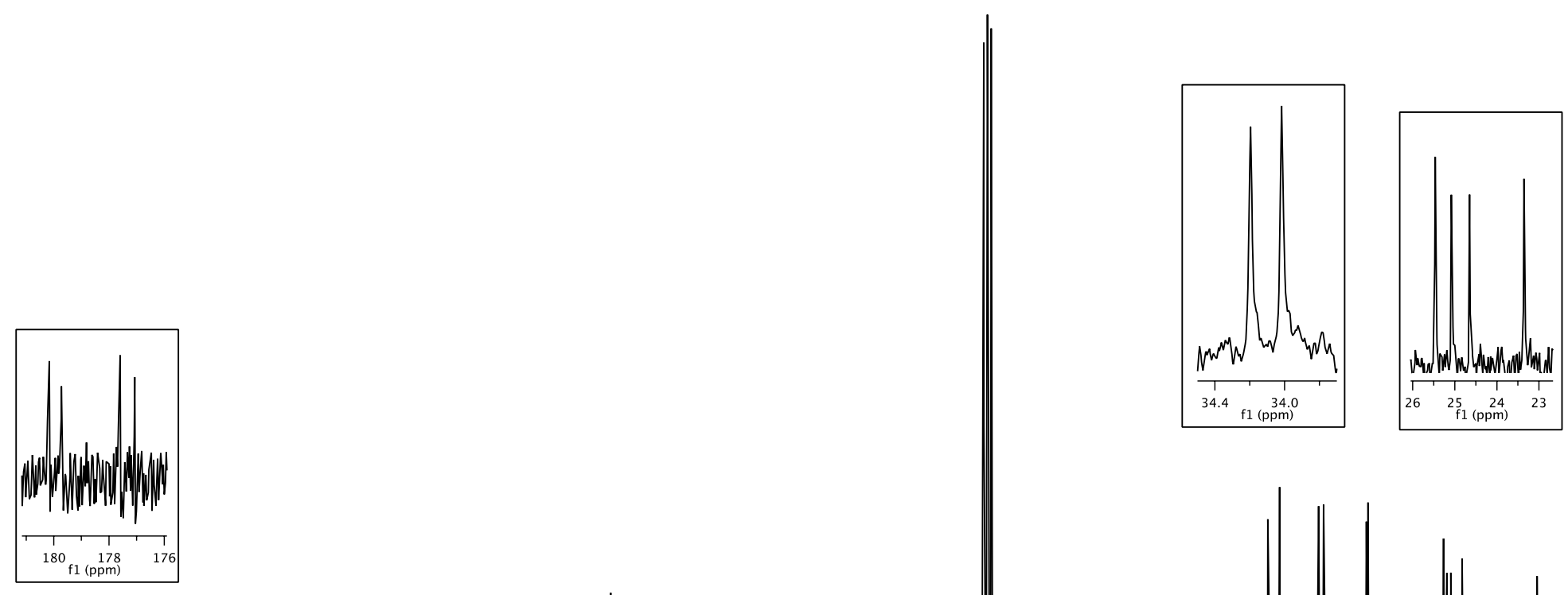

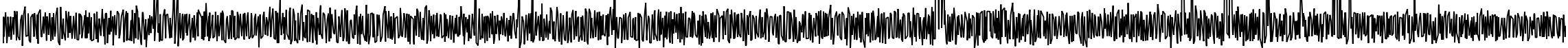

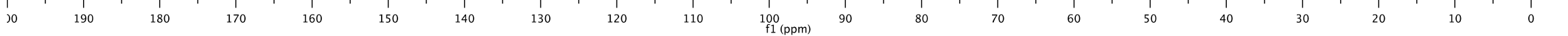




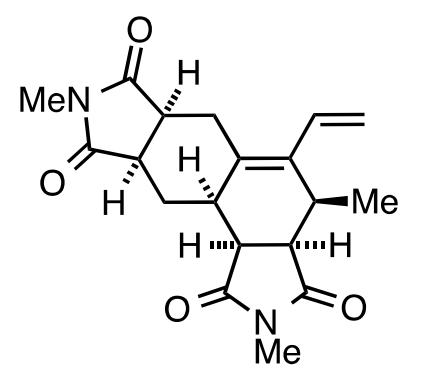

${ }^{1} \mathrm{H}$ NMR spectrum

$300 \mathrm{MHz}$, in $\mathrm{CDCl}_{3}$

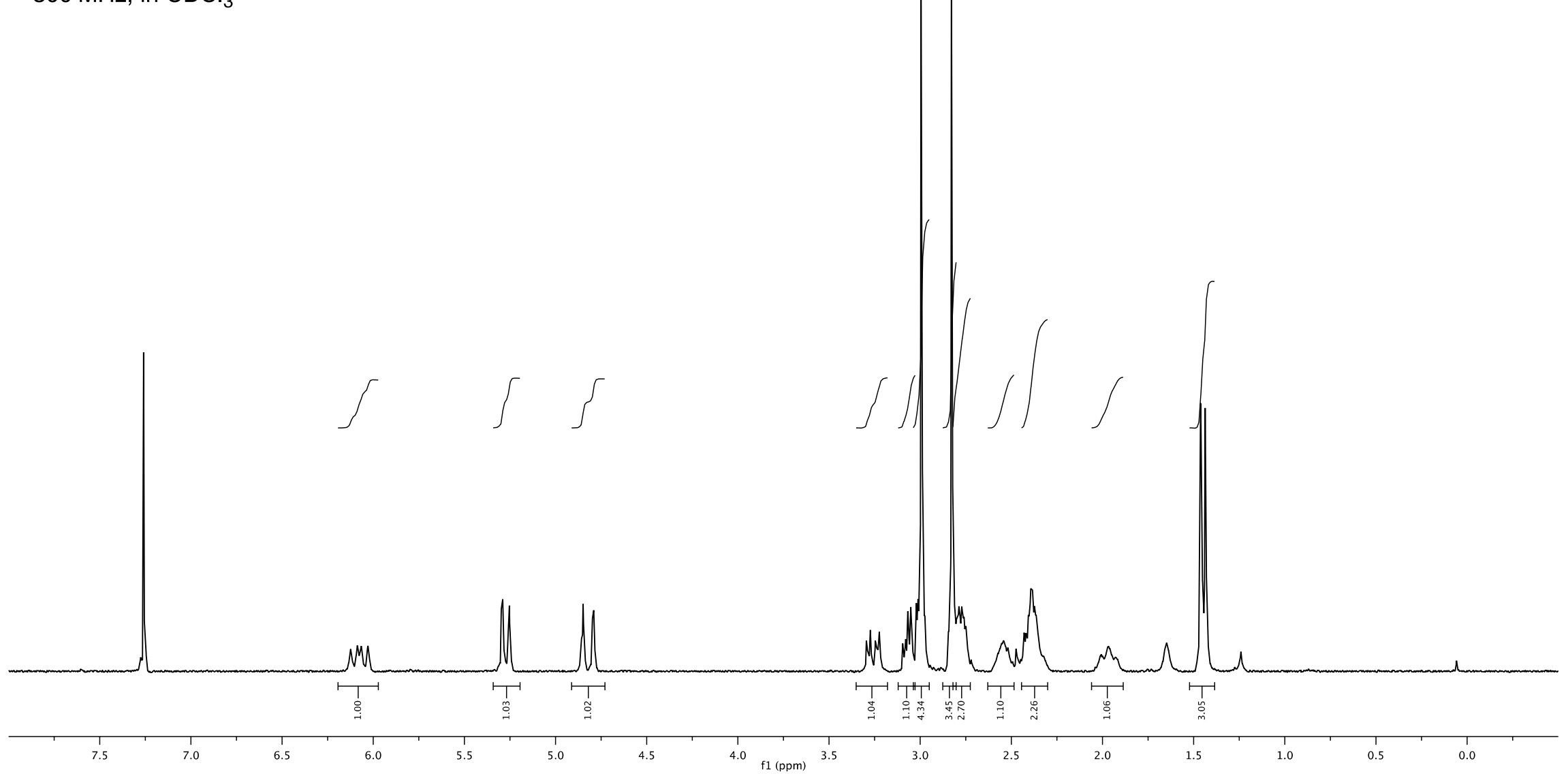




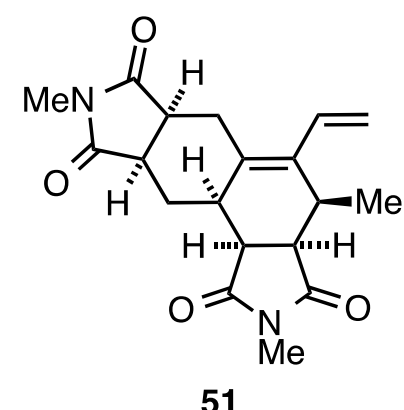

${ }^{13} \mathrm{C}$ NMR spectrum

$75 \mathrm{MHz}$, in $\mathrm{CDCl}_{3}$

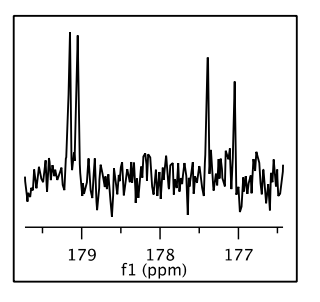

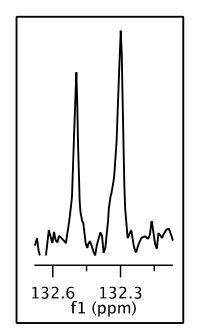
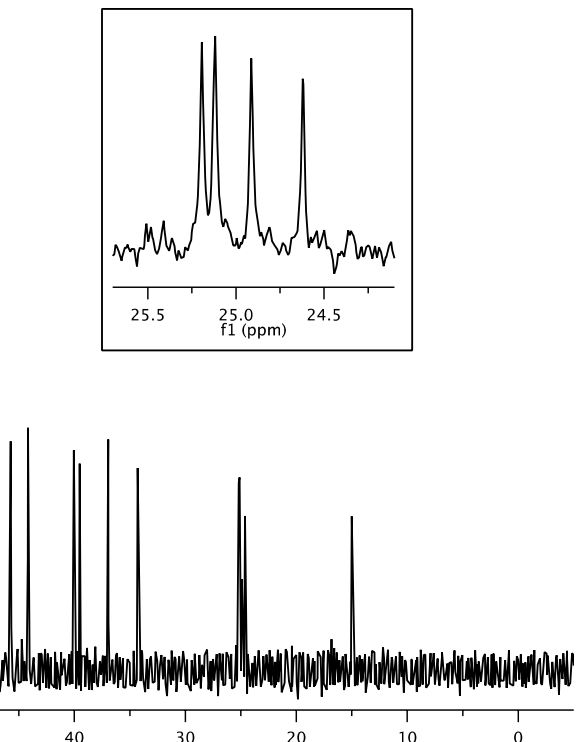


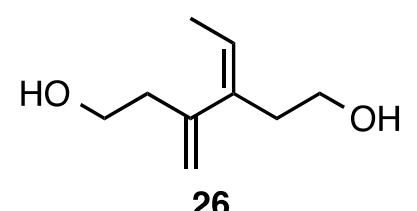

${ }^{1} \mathrm{H}$ NMR spectrum

$300 \mathrm{MHz}$, in $\mathrm{CDCl}_{3}$

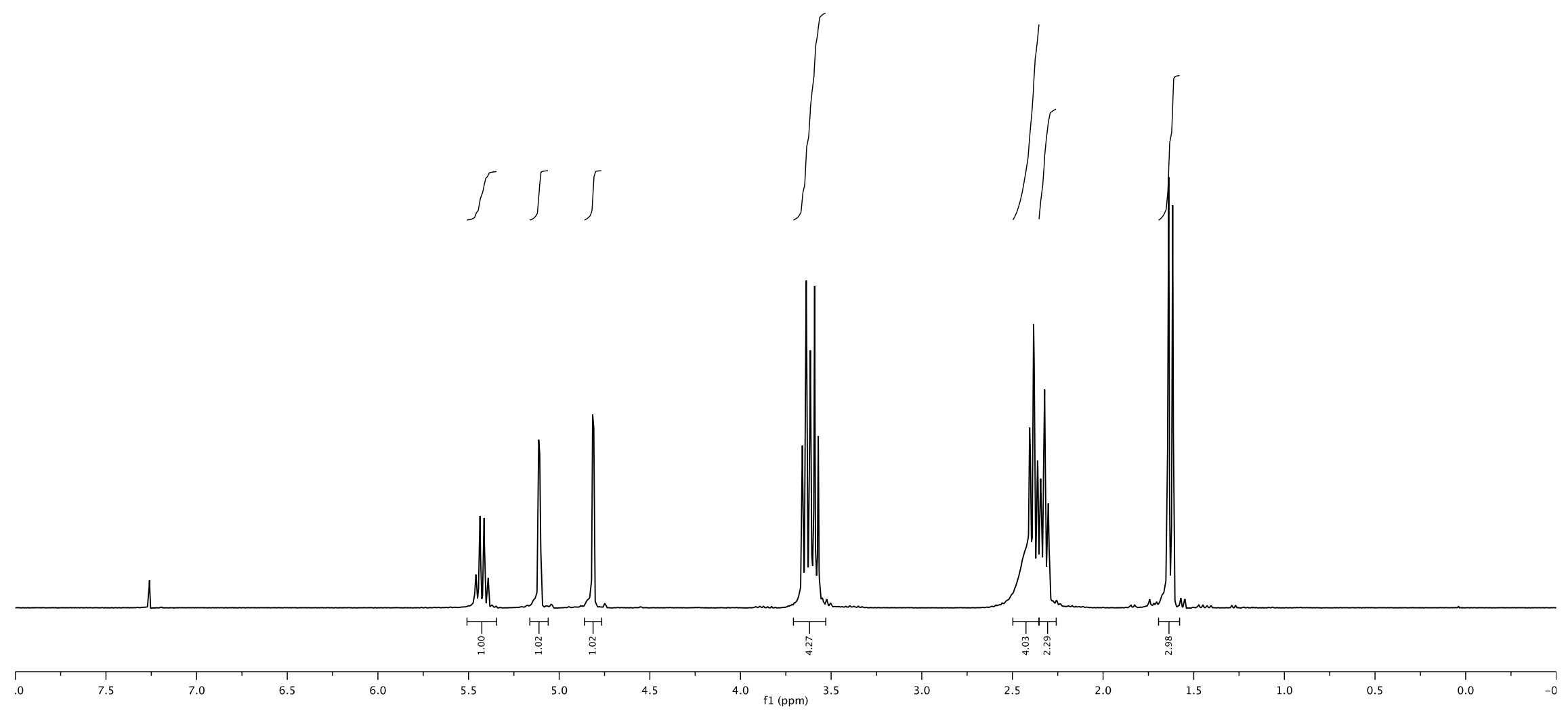




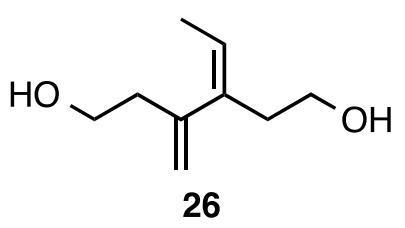

${ }^{13} \mathrm{C}$ NMR spectrum

$75 \mathrm{MHz}$, in $\mathrm{CDCl}_{3}$

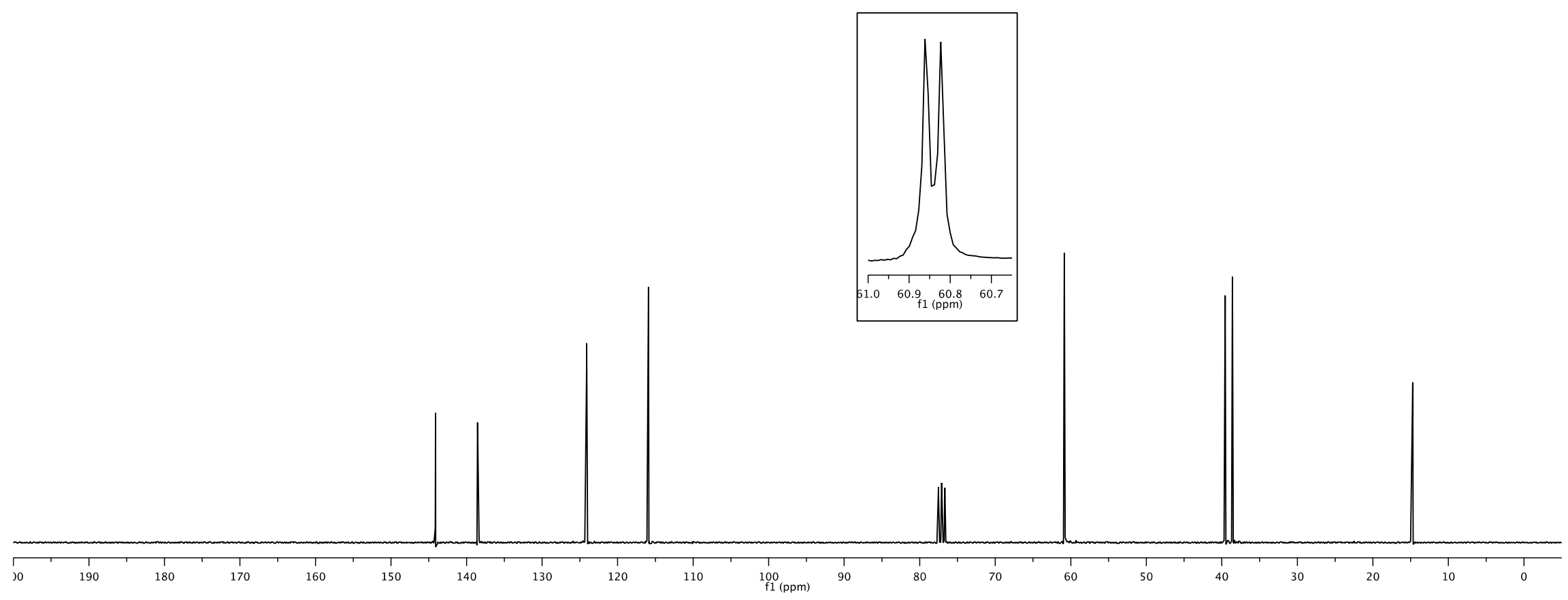

S70 


$$
\text { . }
$$

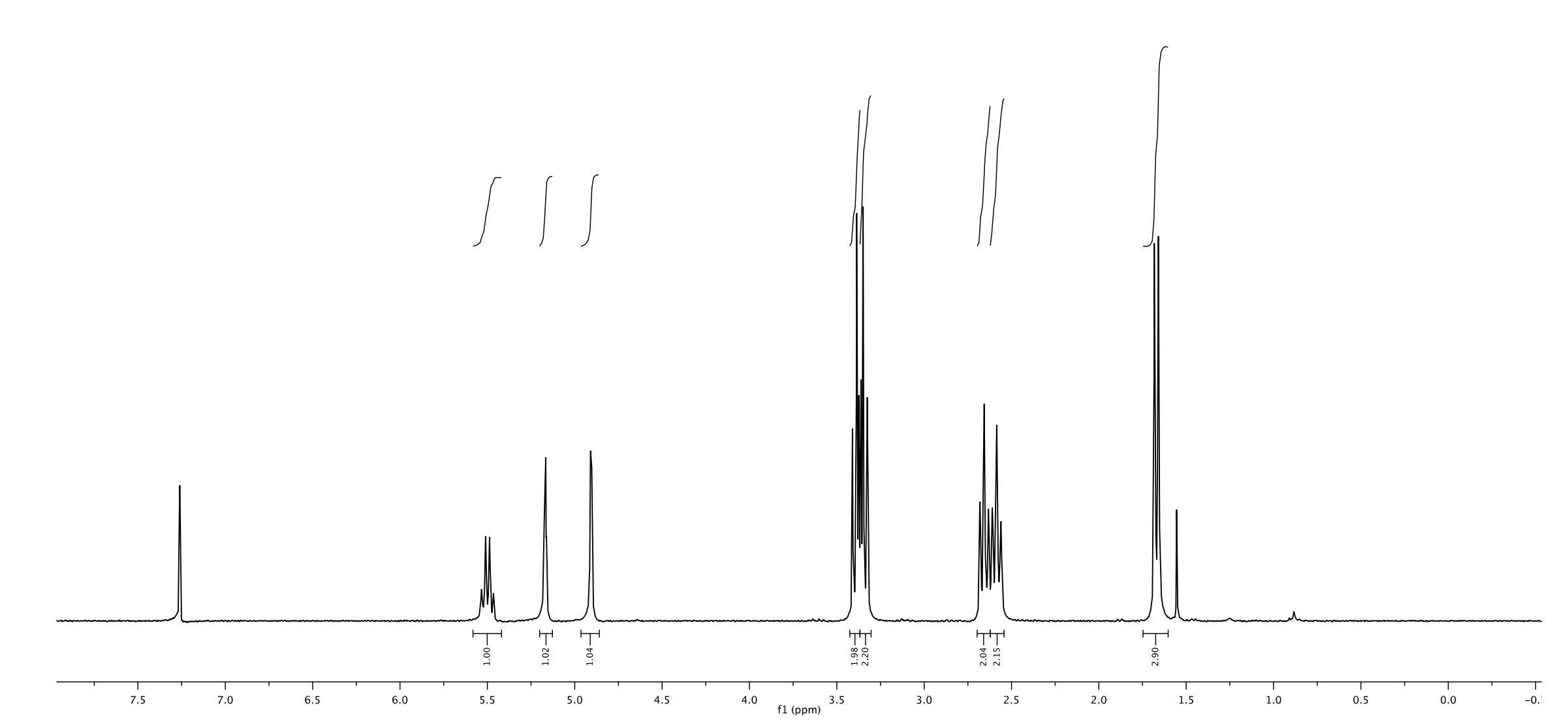




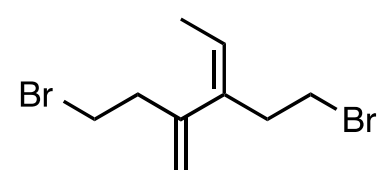

28

${ }^{13} \mathrm{C}$ NMR spectrum

$75 \mathrm{MHz}$, in $\mathrm{CDCl}_{3}$

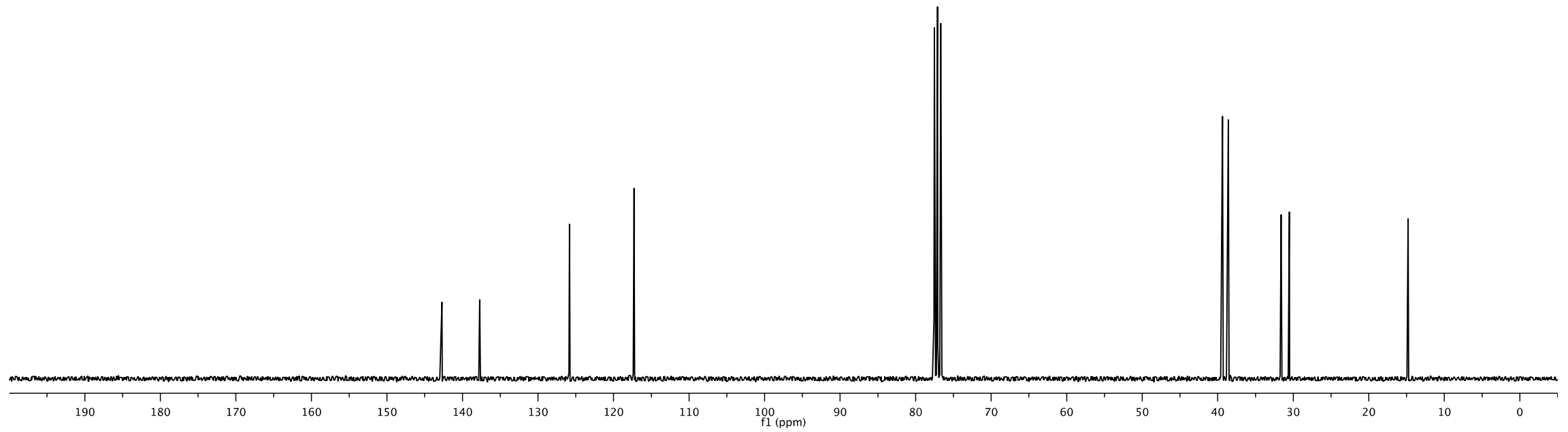


<smiles>C=CC(=C)C(C=C)=CC</smiles>

14

${ }^{1} \mathrm{H}$ NMR spectrum

$300 \mathrm{MHz}$, in $\mathrm{CDCl}_{3}$

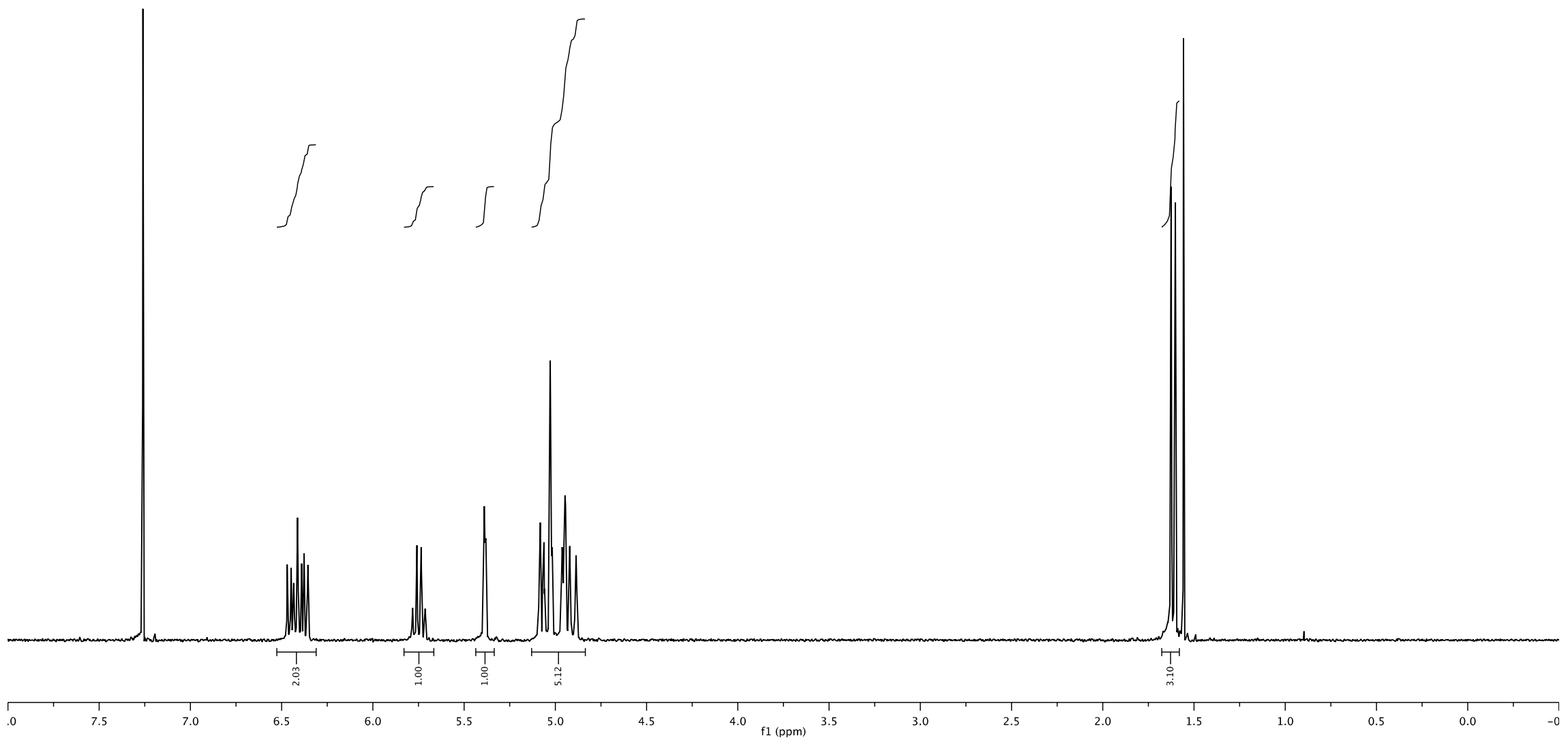

S73 
<smiles>C=CC(=C)C(C=C)=CC</smiles>

14

${ }^{13} \mathrm{C}$ NMR spectrum $75 \mathrm{MHz}$, in $\mathrm{CDCl}_{3}$

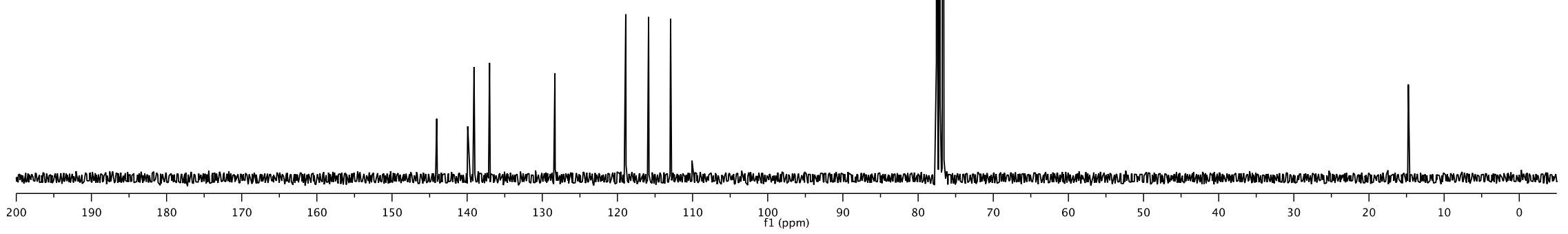

S74 


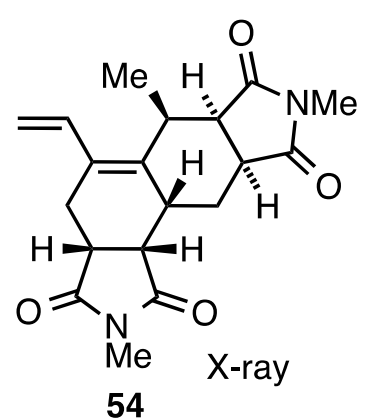

${ }^{1} \mathrm{H}$ NMR spectrum $300 \mathrm{MHz}$, in $\mathrm{CDCl}_{3}$

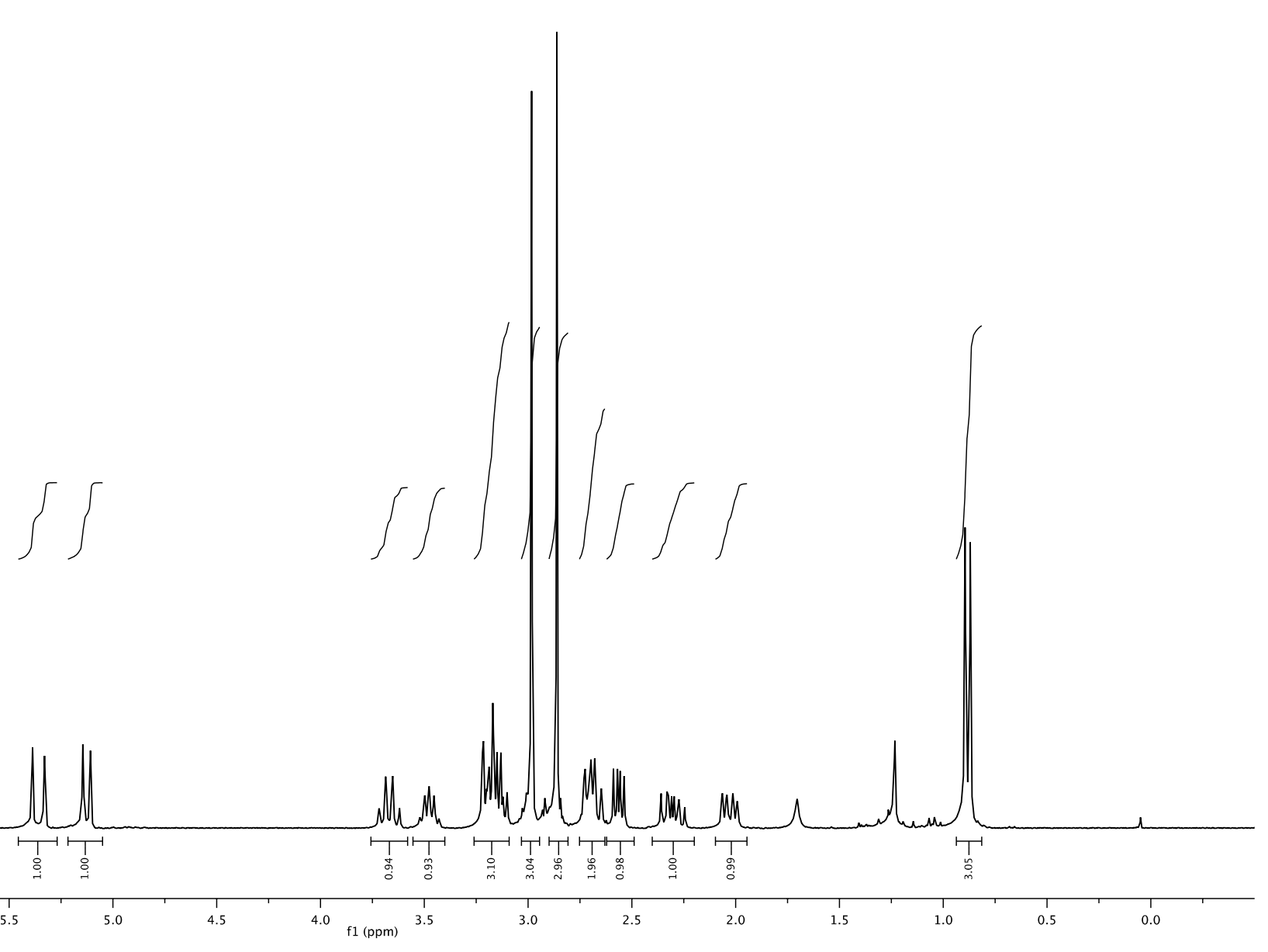




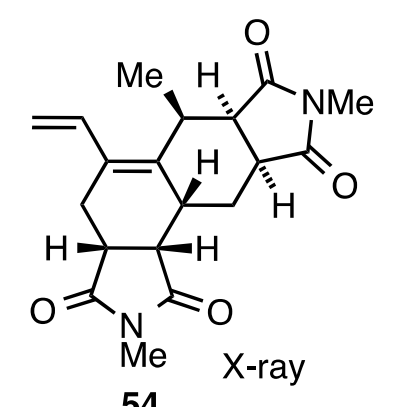

${ }^{13} \mathrm{C}$ NMR spectrum

$75 \mathrm{MHz}$, in $\mathrm{CDCl}_{3}$

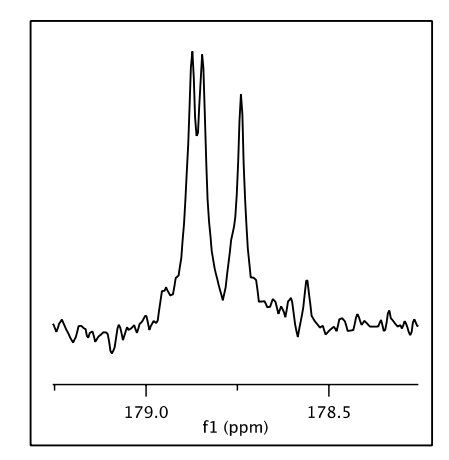

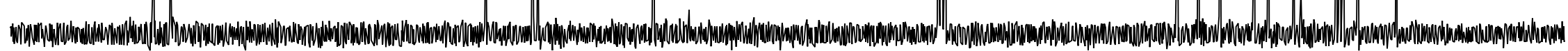

$$
200 \quad 190
$$

$190 \quad 180 \quad 170$

160

150
140

130

120

110

${ }_{\mathrm{f} 1}^{100}(\mathrm{ppm})$ 


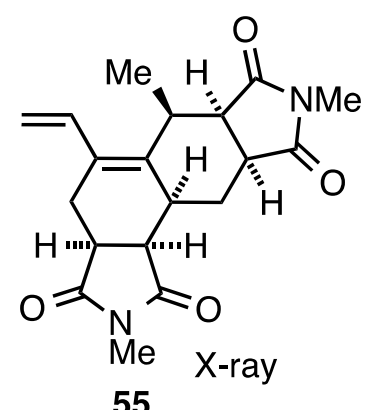

${ }^{1} \mathrm{H}$ NMR spectrum

$300 \mathrm{MHz}$, in $\mathrm{CDCl}_{3}$

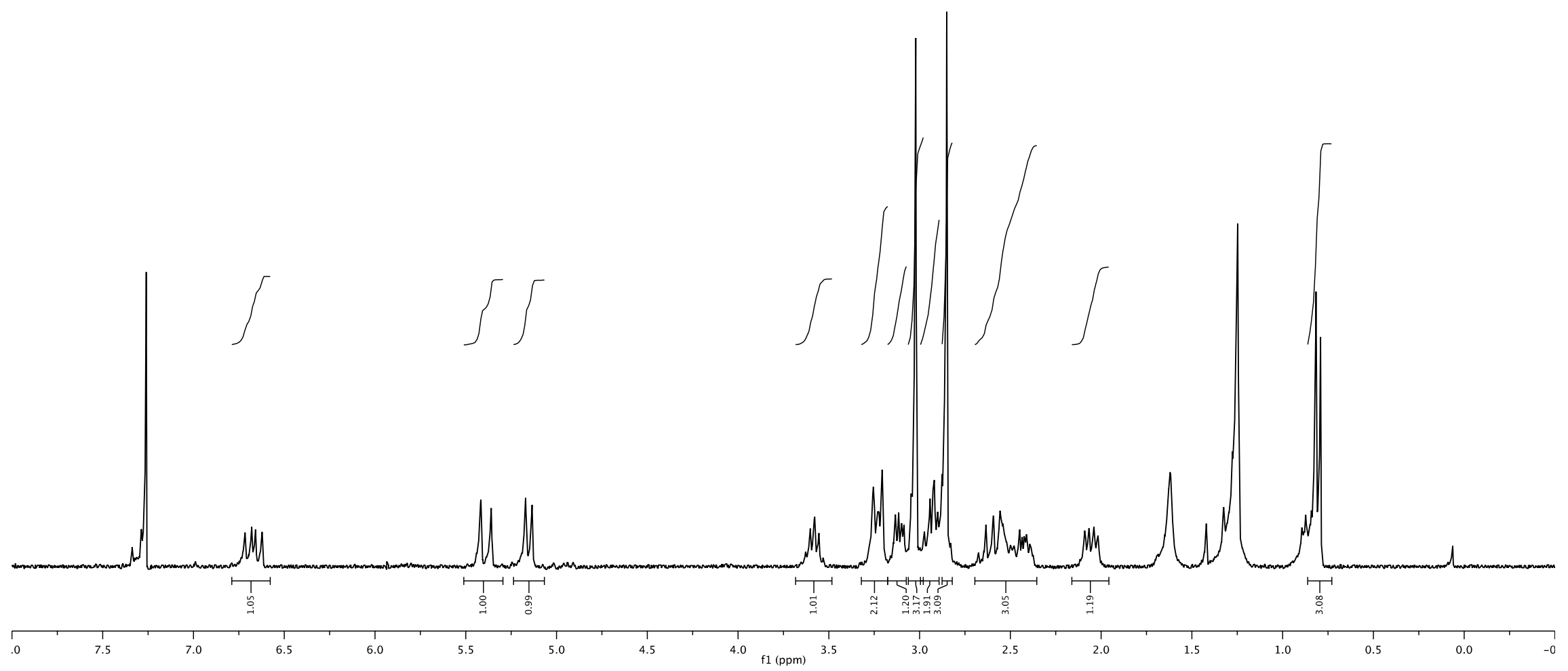




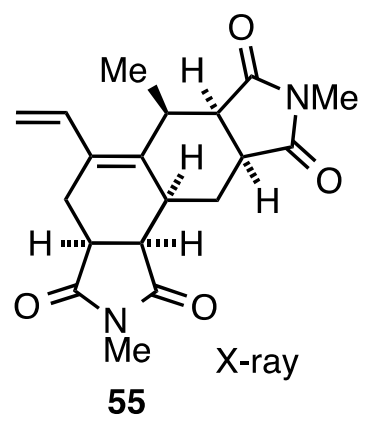

${ }^{13} \mathrm{C}$ NMR spectrum $75 \mathrm{MHz}$, in $\mathrm{CDCl}_{3}$

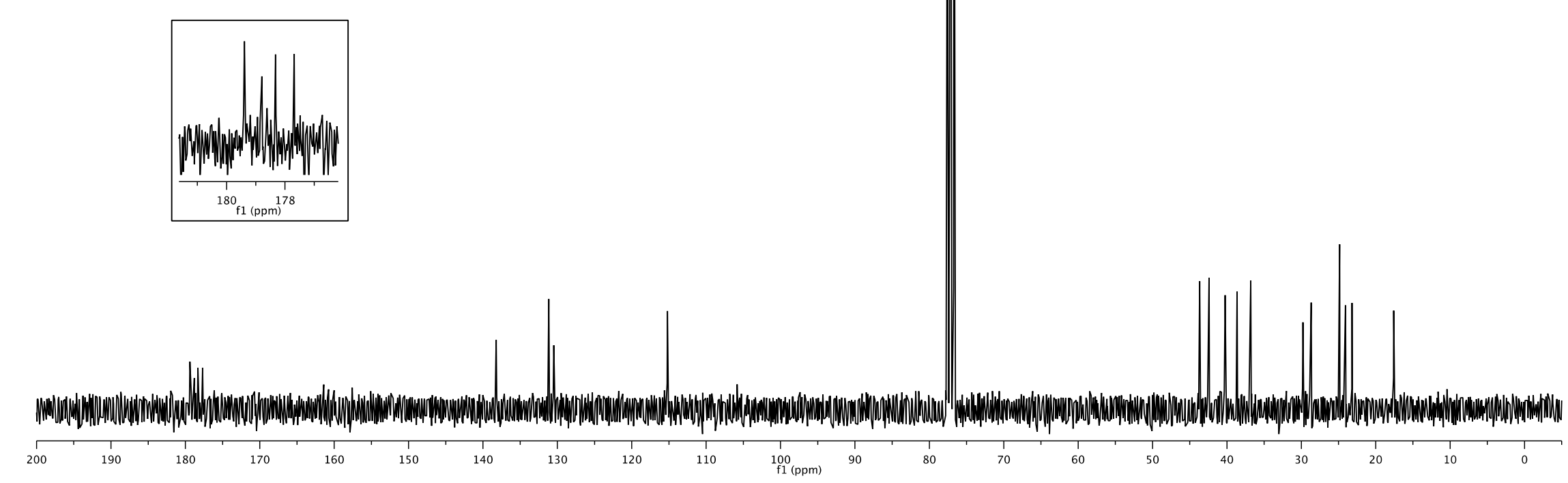

S78 


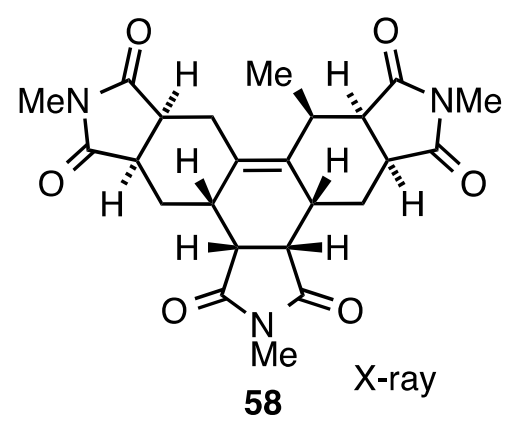

${ }^{1} \mathrm{H}$ NMR spectrum $300 \mathrm{MHz}$, in $\mathrm{CDCl}_{3}$

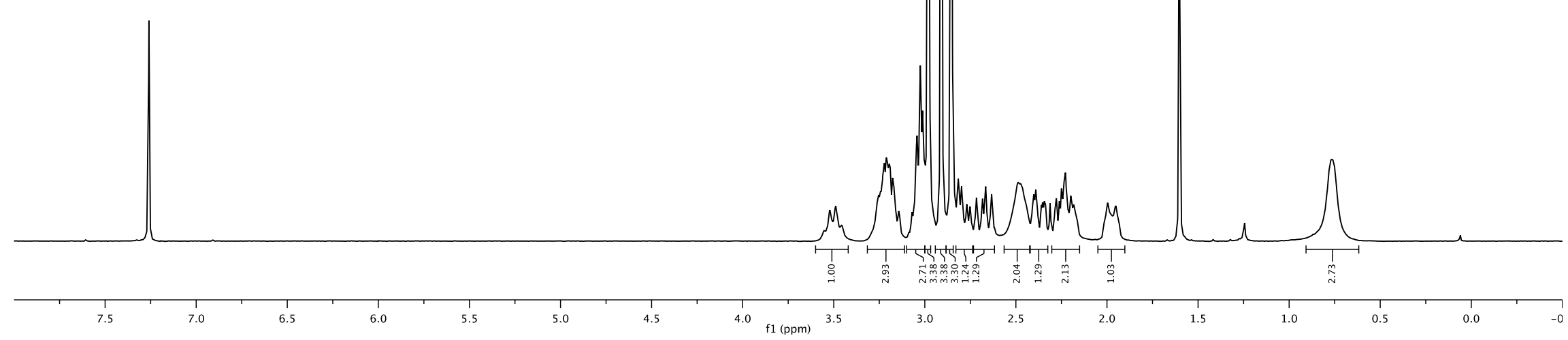




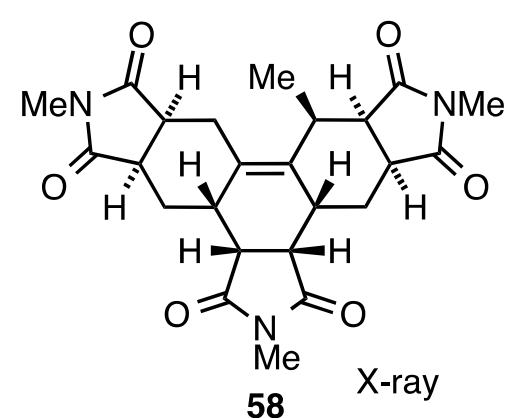

${ }^{13} \mathrm{C}$ NMR spectrum $75 \mathrm{MHz}$, in $\mathrm{CDCl}_{3}$

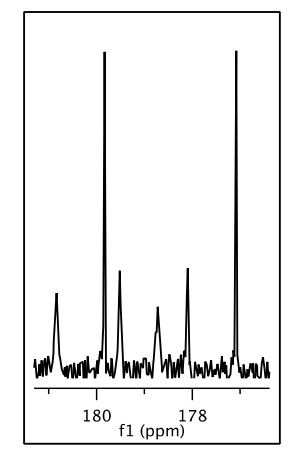

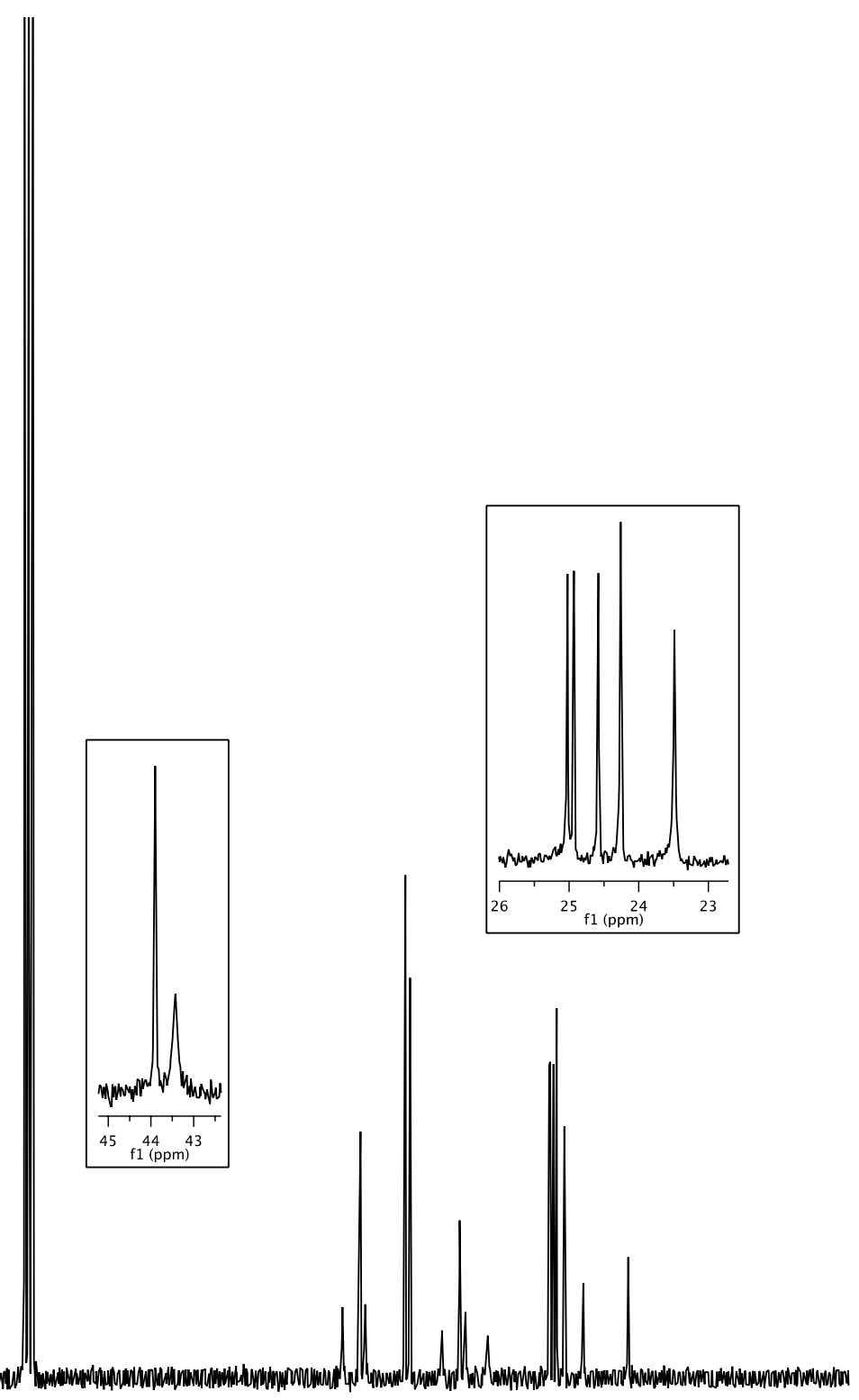

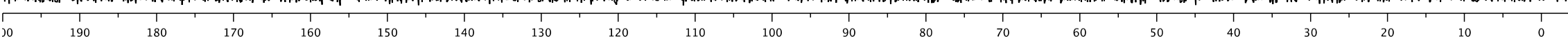




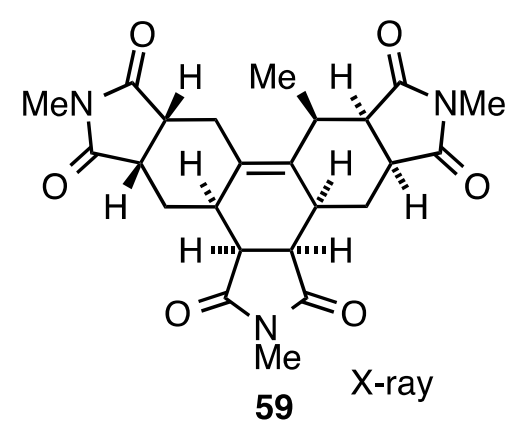

${ }^{1} \mathrm{H}$ NMR spectrum

$300 \mathrm{MHz}$, in $\mathrm{CDCl}_{3}$

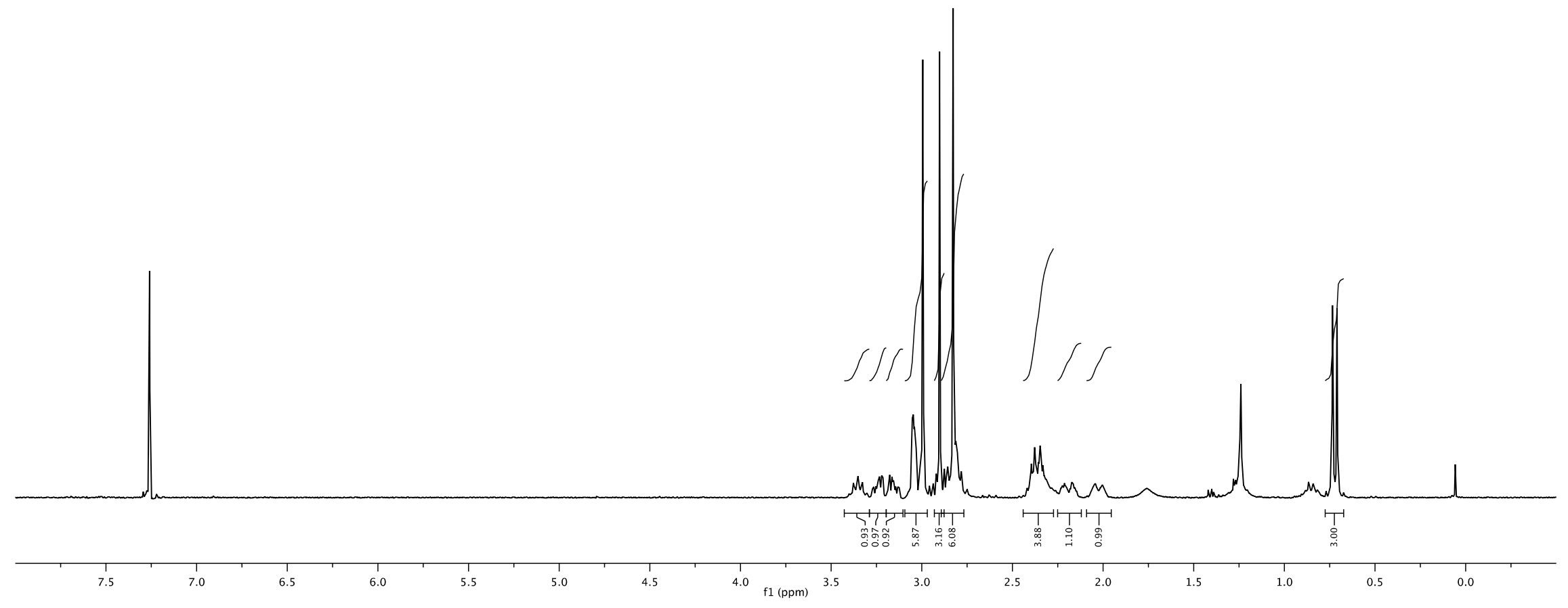




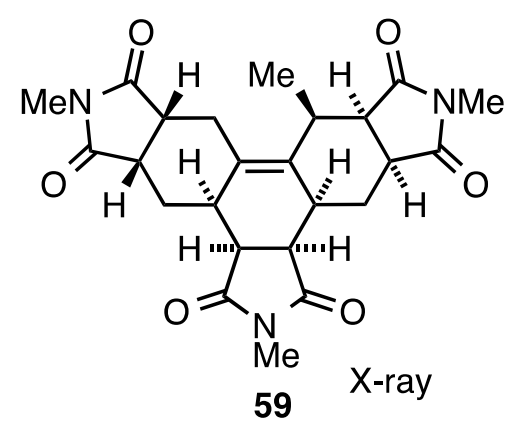

${ }^{13} \mathrm{C}$ NMR spectrum

$75 \mathrm{MHz}$, in $\mathrm{CDCl}_{3}$
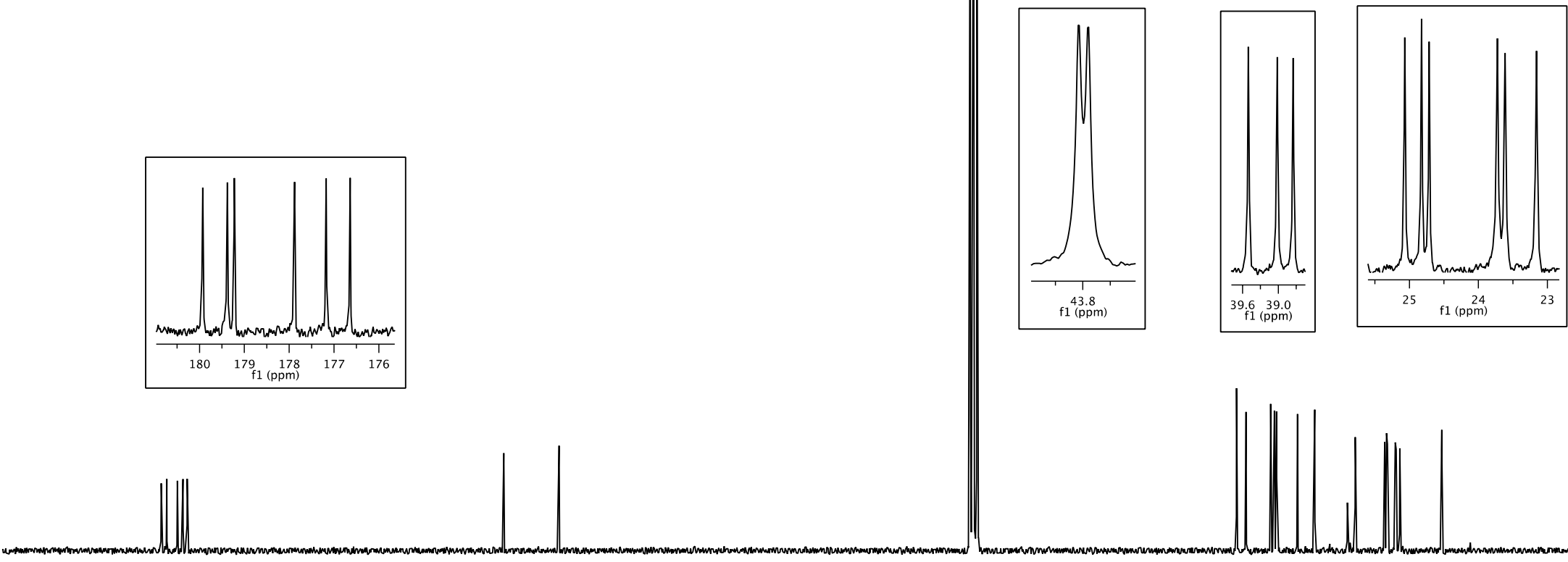

الالبللالم.

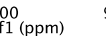




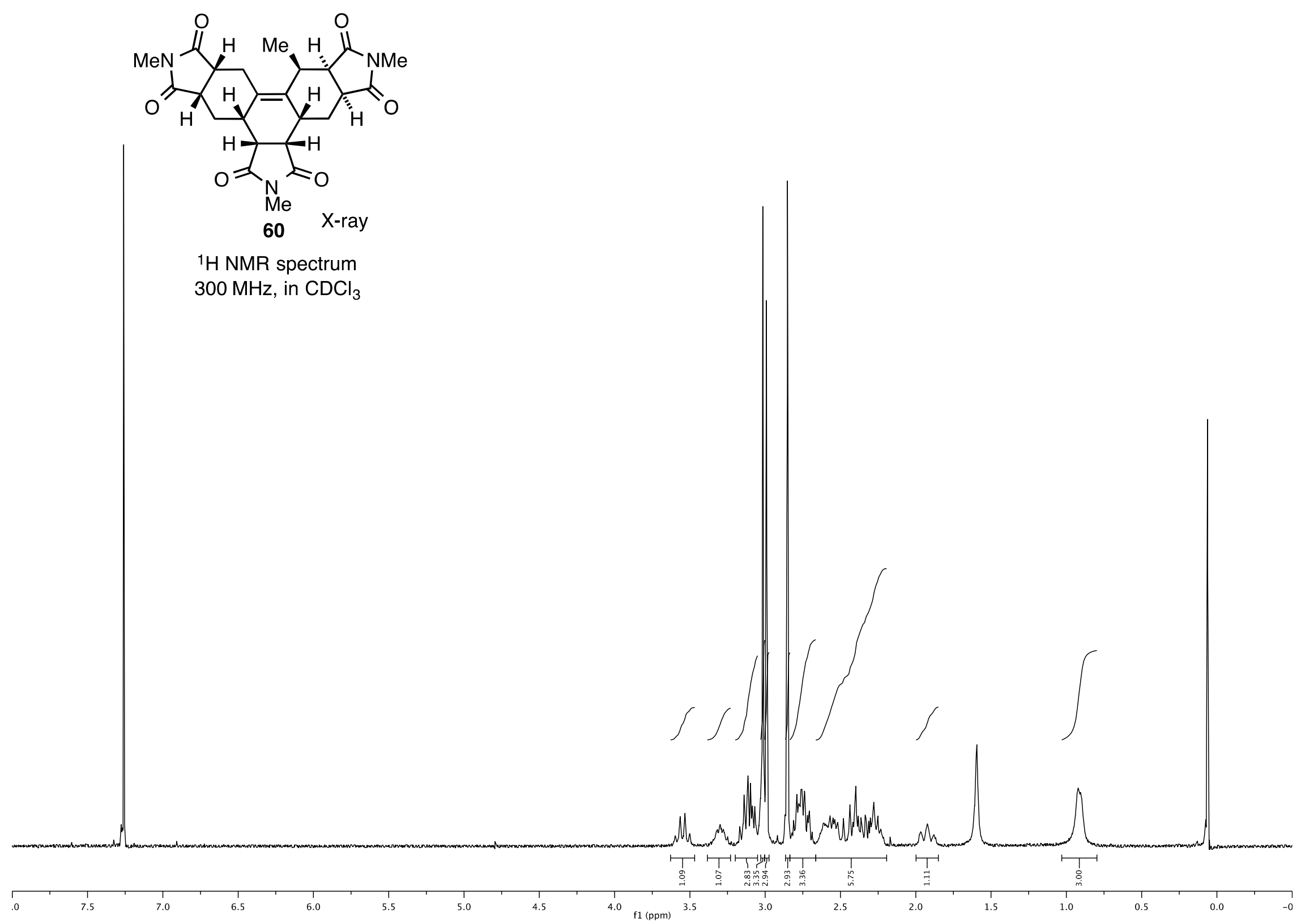




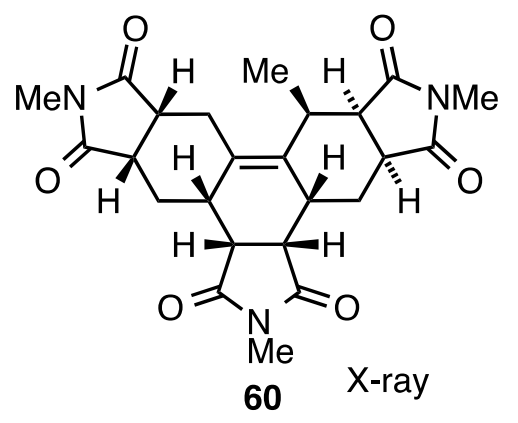

${ }^{13} \mathrm{C}$ NMR spectrum $75 \mathrm{MHz}$, in $\mathrm{CDCl}_{3}$
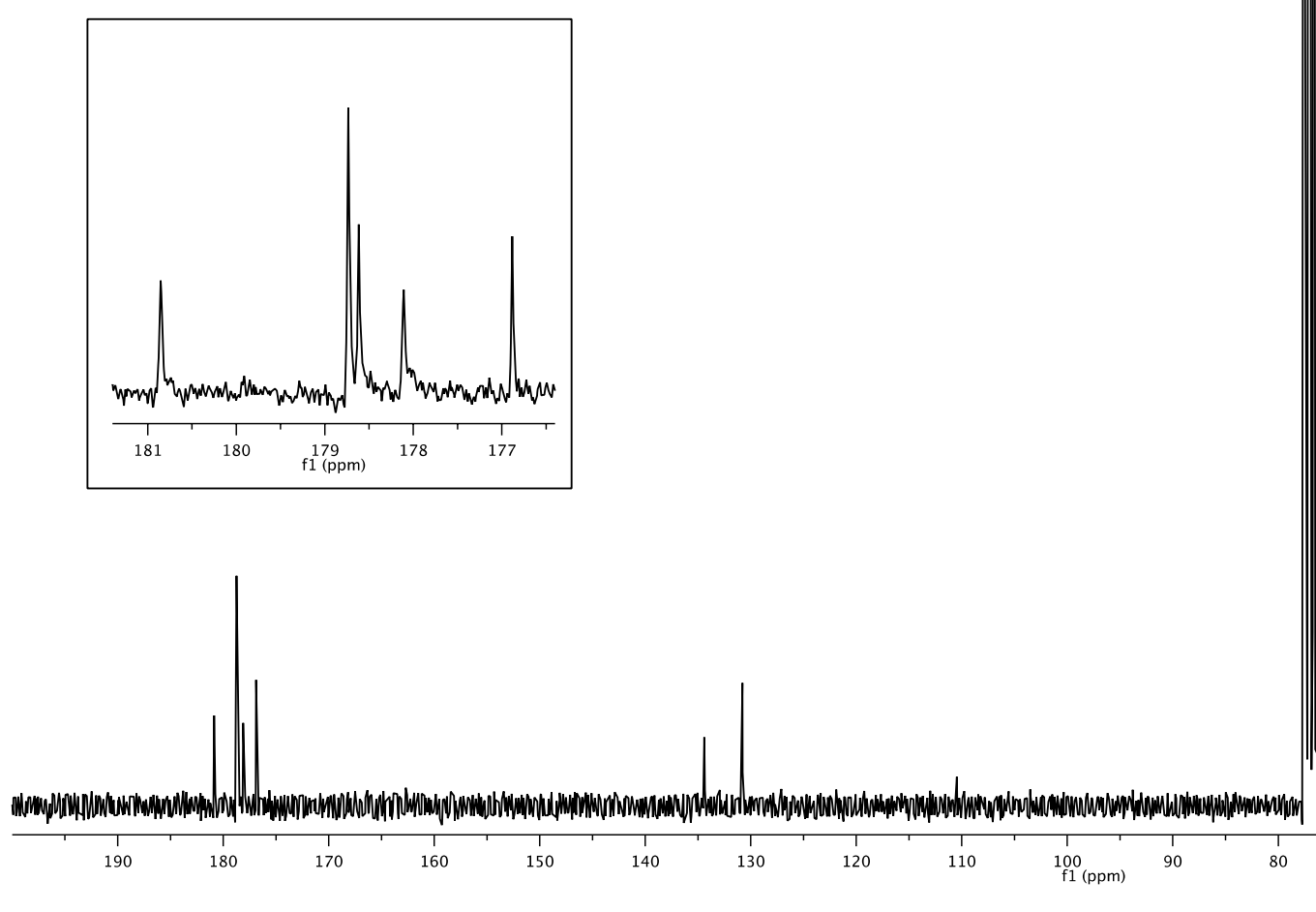
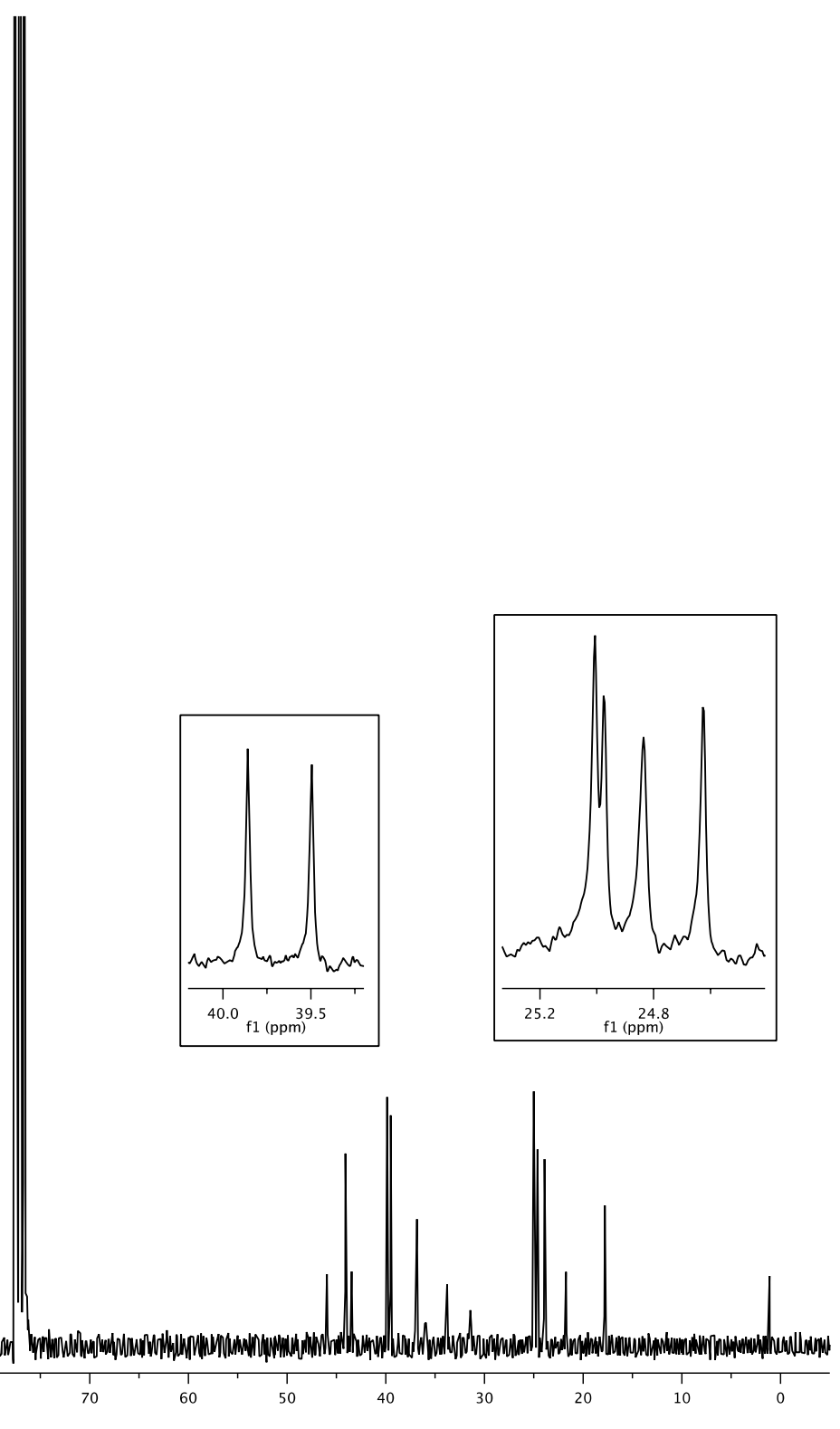

S84 


\section{Stereochemical Assignments for 13, 14, 23, 24, 32, 37, 46, and 51.}

The stereochemistry of 23 was secured through $2 \mathrm{D}$ NMR experiments. The ${ }^{1} \mathrm{H}-{ }^{1} \mathrm{H}$ NOESY spectrum is shown in Figure S13.

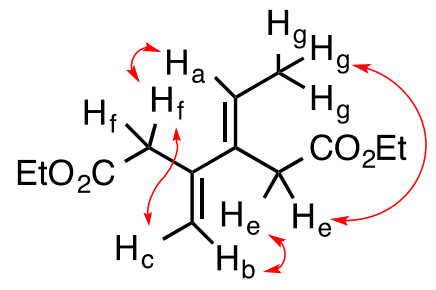

23

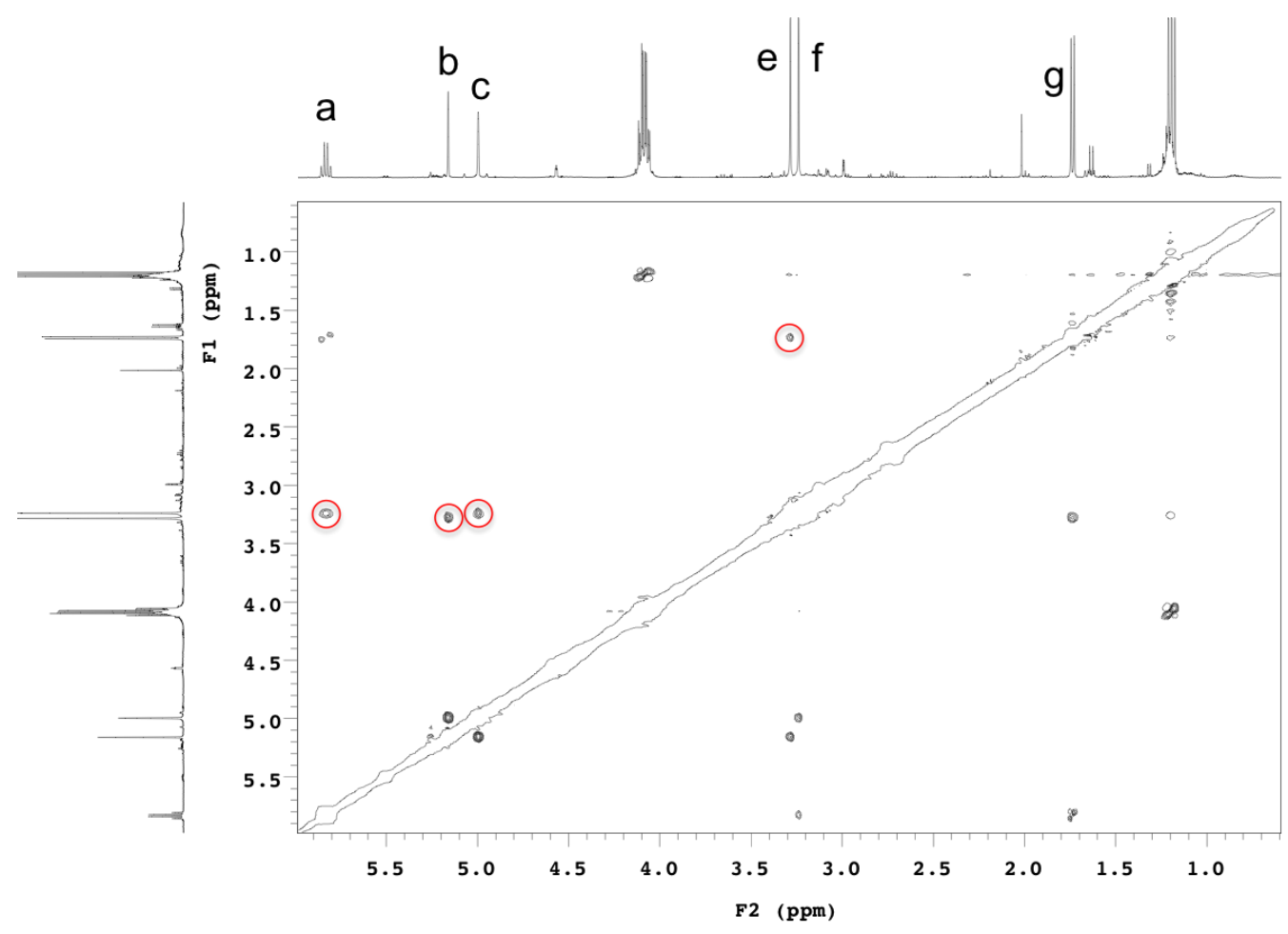

Figure S13: ${ }^{1} \mathrm{H}-{ }^{1} \mathrm{H}$ NOESY NMR (400 MHz, in $\left.\mathrm{CDCl}_{3}\right)$ spectrum of 23. 
The stereochemistry of 13 was secured through 2D NMR experiments. The ${ }^{1} \mathrm{H}-{ }^{1} \mathrm{H}$ NOESY spectrum is shown in Figure S14.

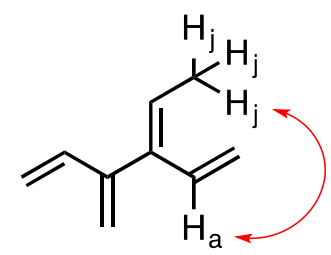

13

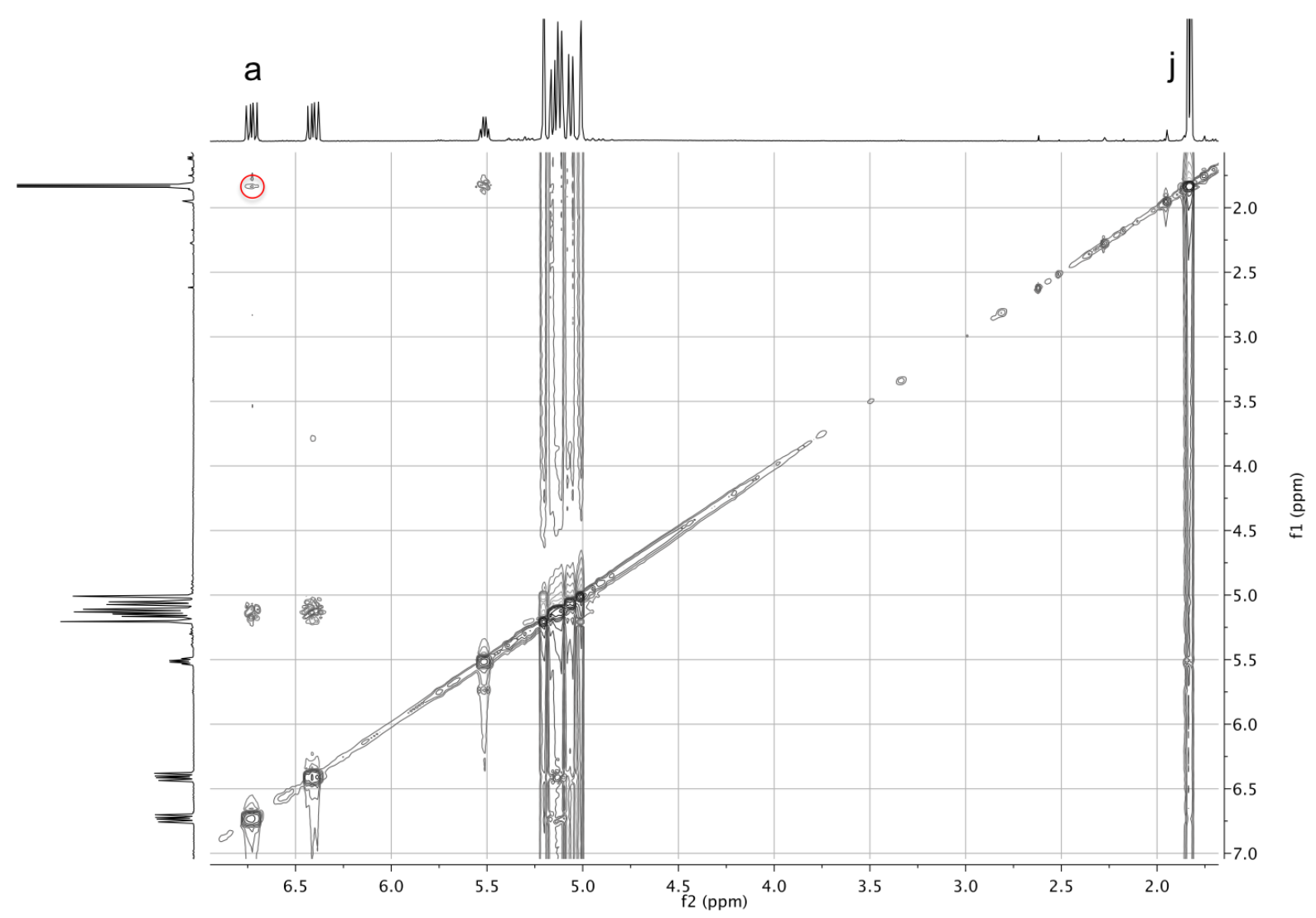

Figure S14: ${ }^{1} \mathrm{H}-{ }^{1} \mathrm{H}$ NOESY NMR $\left(500 \mathrm{MHz}\right.$, in $\left.\mathrm{CDCl}_{3}\right)$ spectrum of 13. 
The stereochemistries of $\mathbf{2 5}$ and 27 were assigned by comparison of ${ }^{1} \mathrm{H}$ NMR spectra with 23 and $\mathbf{1 3}$. Similarities between ${ }^{1} \mathrm{H}$ NMR spectra of 23, 25, 27, and $\mathbf{1 3}$ are highlighted in Figure S15.

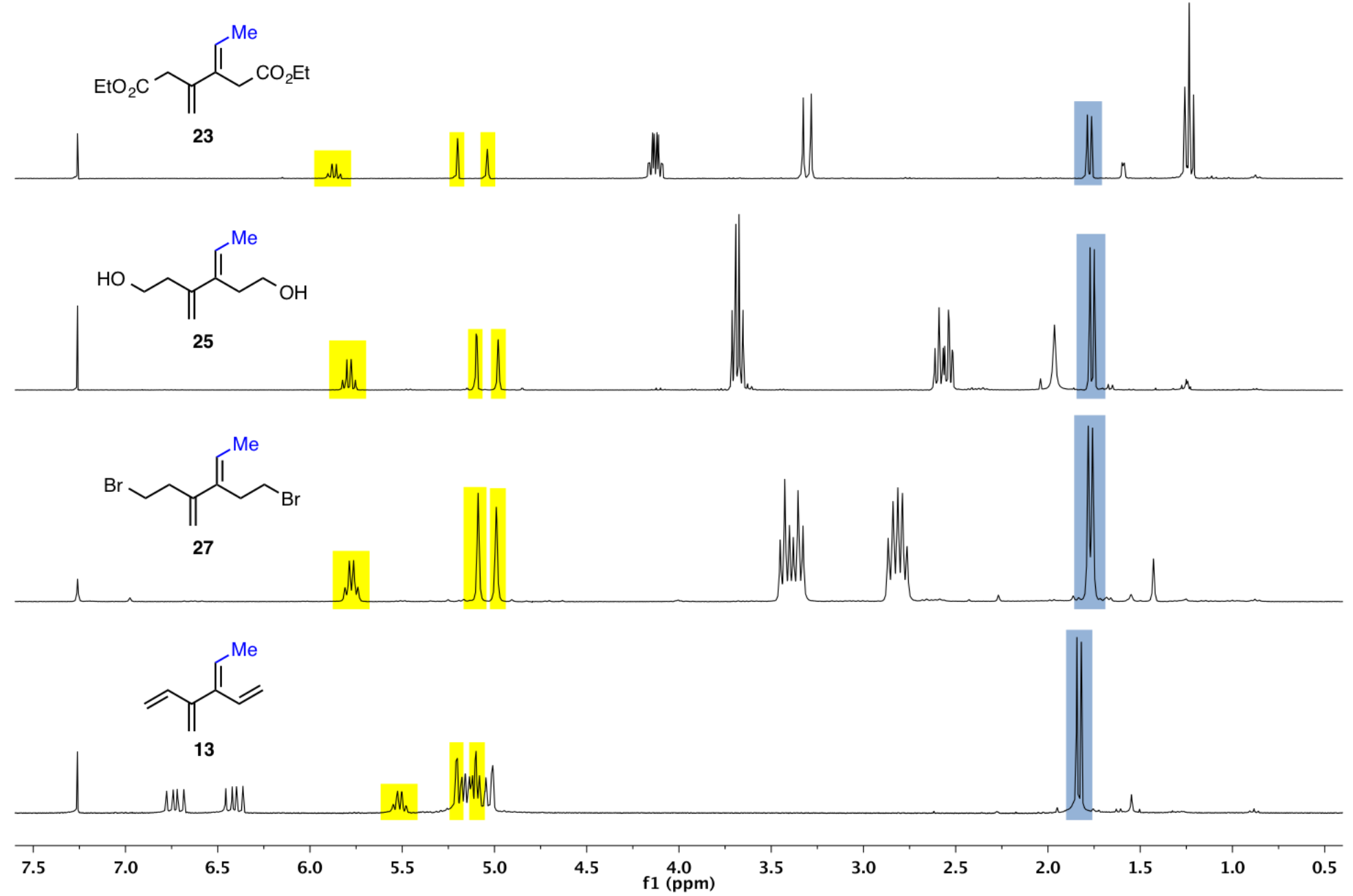

Figure S15: ${ }^{1} \mathrm{H} \mathrm{NMR}$ spectra $\left(300 \mathrm{MHz}\right.$, in $\left.\mathrm{CDCl}_{3}\right)$ of $\mathbf{2 3}, \mathbf{2 5}, \mathbf{2 7}$, and 13. 
The stereochemistry of 24 was secured through $2 \mathrm{D}$ NMR experiments. The ${ }^{1} \mathrm{H}-{ }^{1} \mathrm{H}$ NOESY spectrum is shown in Figure S16.

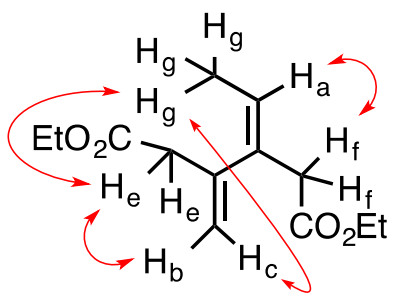

24

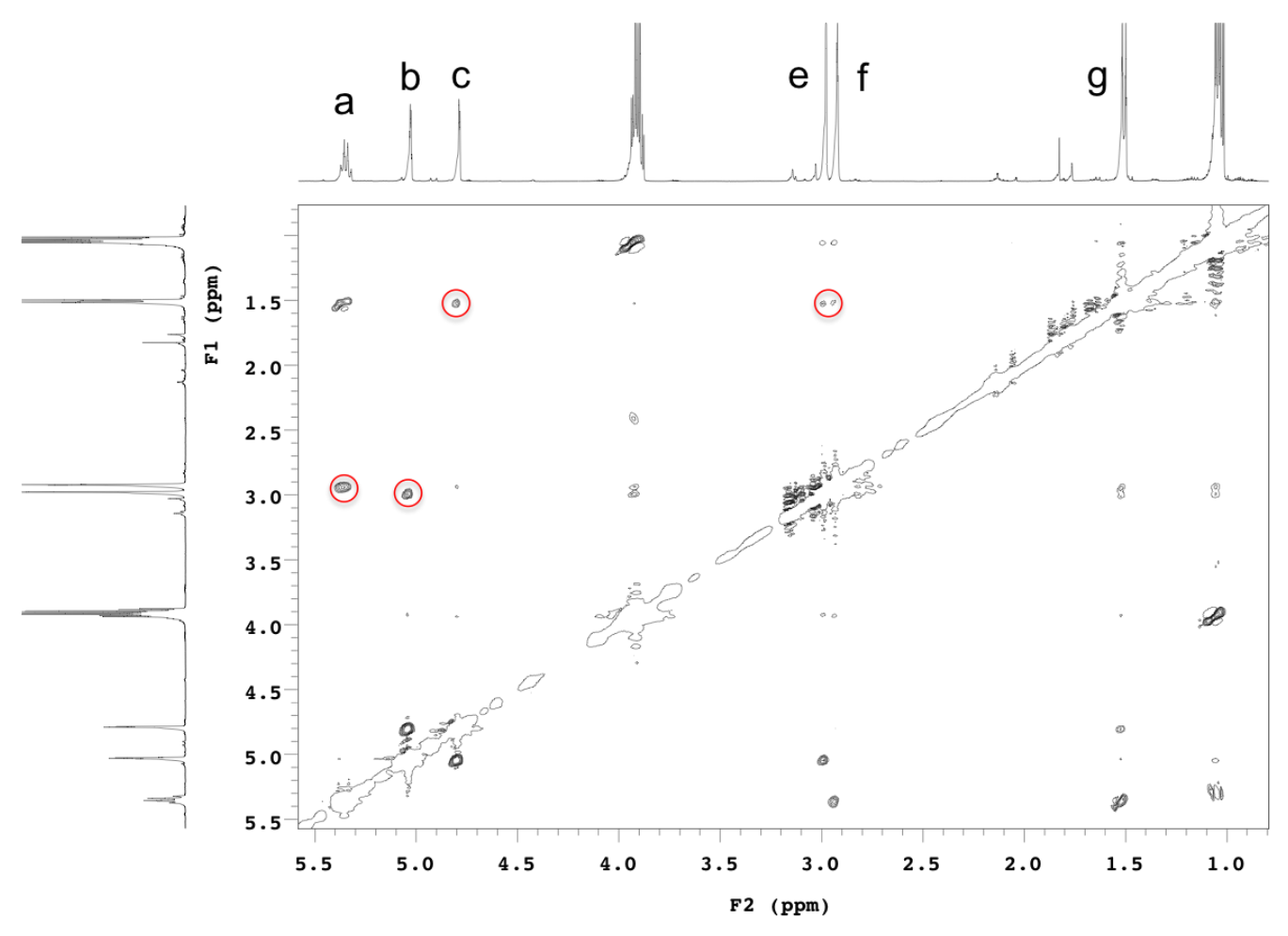

Figure S16: ${ }^{1} \mathrm{H}-{ }^{1} \mathrm{H}$ NOESY NMR $\left(400 \mathrm{MHz}\right.$, in $\left.\mathrm{CDCl}_{3}\right)$ spectrum of 24. 
The stereochemistry of 14 was secured through $2 \mathrm{D}$ NMR experiments. The ${ }^{1} \mathrm{H}-{ }^{1} \mathrm{H}$ NOESY spectrum is shown in Figure S17.

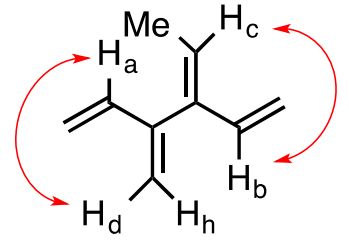

14

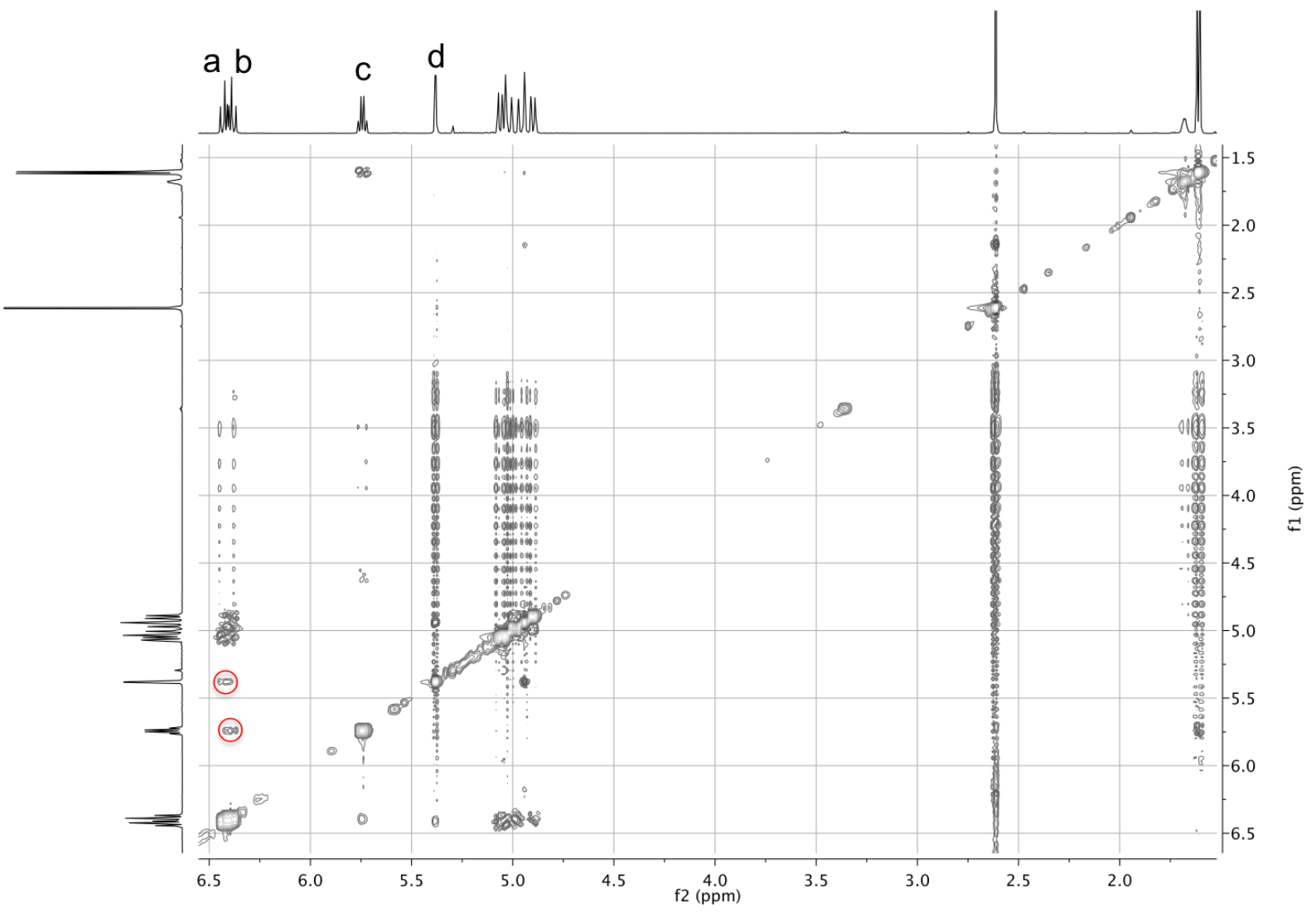

Figure S17: ${ }^{1} \mathrm{H}-{ }^{1} \mathrm{H}$ NOESY NMR $\left(500 \mathrm{MHz}\right.$, in $\left.\mathrm{CDCl}_{3}\right)$ spectrum of 14. 
The stereochemistries of $\mathbf{2 6}$, and 28 were assigned by comparison of ${ }^{1} \mathrm{H}$ NMR spectra with 24 and $\mathbf{1 4}$. Similarities between ${ }^{1} \mathrm{H}$ NMR spectra of 24, 26, 28, and $\mathbf{1 4}$ are highlighted in Figure S18.

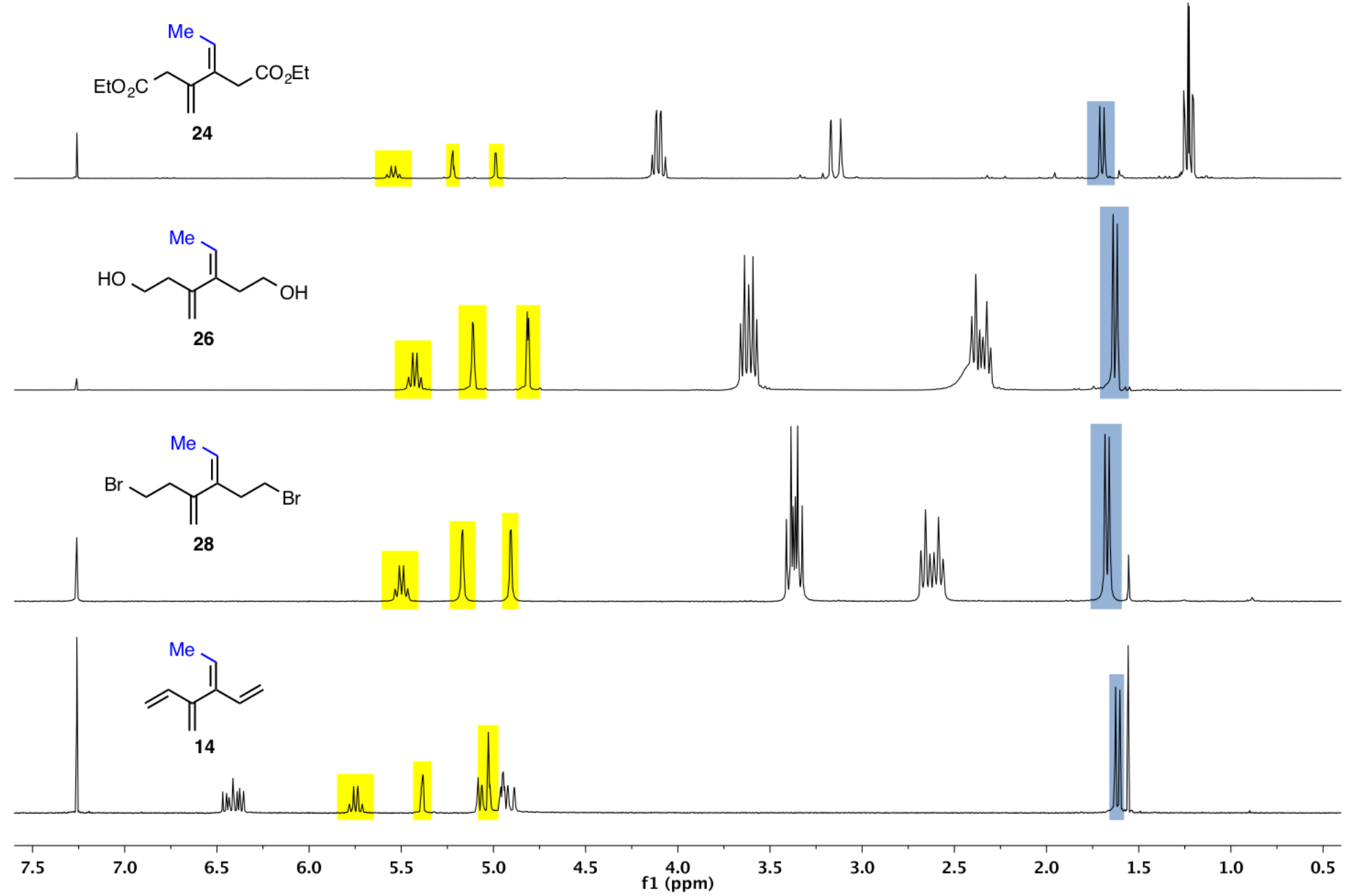

Figure S18: ${ }^{1} \mathrm{H} \mathrm{NMR}$ spectra $\left(300 \mathrm{MHz}\right.$, in $\left.\mathrm{CDCl}_{3}\right)$ of 24, 26, 28, and 14. 
The stereochemistry of 32 was assigned through $2 \mathrm{D}$ NMR experiments. The ${ }^{1} \mathrm{H}-{ }^{1} \mathrm{H}$ NOESY spectrum is shown in Figure S19.

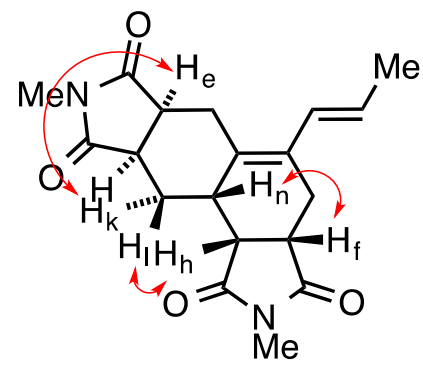

32

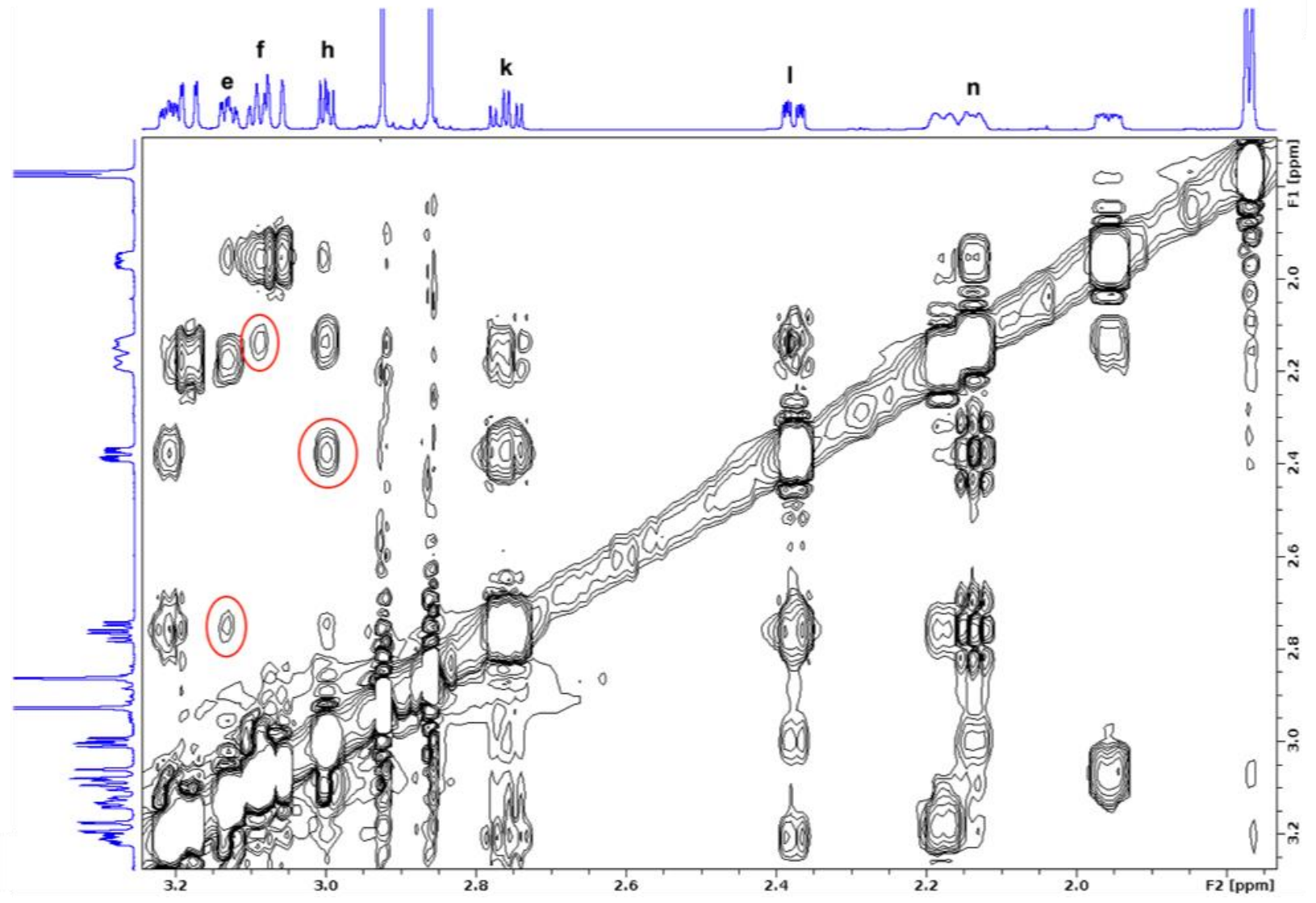

Figure S19: ${ }^{1} \mathrm{H}-{ }^{1} \mathrm{H}$ NOESY NMR spectrum $\left(800 \mathrm{MHz}\right.$, in $\left.\mathrm{CDCl}_{3}\right)$ of 32. 
Similarities between ${ }^{1} \mathrm{H}$ NMR spectra of $\mathbf{5 0}, \mathbf{4 5}, \mathbf{4 0}, \mathbf{3 2}$, and $\mathbf{4}$ are highlighted in Figure S20. Single crystal X-ray analysis of $\mathbf{5 0}$ (Figure S7), $\mathbf{4 5}$ (Figure S5), $\mathbf{4 0}$ (Figure S3) and $\mathbf{4}^{9}$ secured the stereochemical assignments of compound 32.

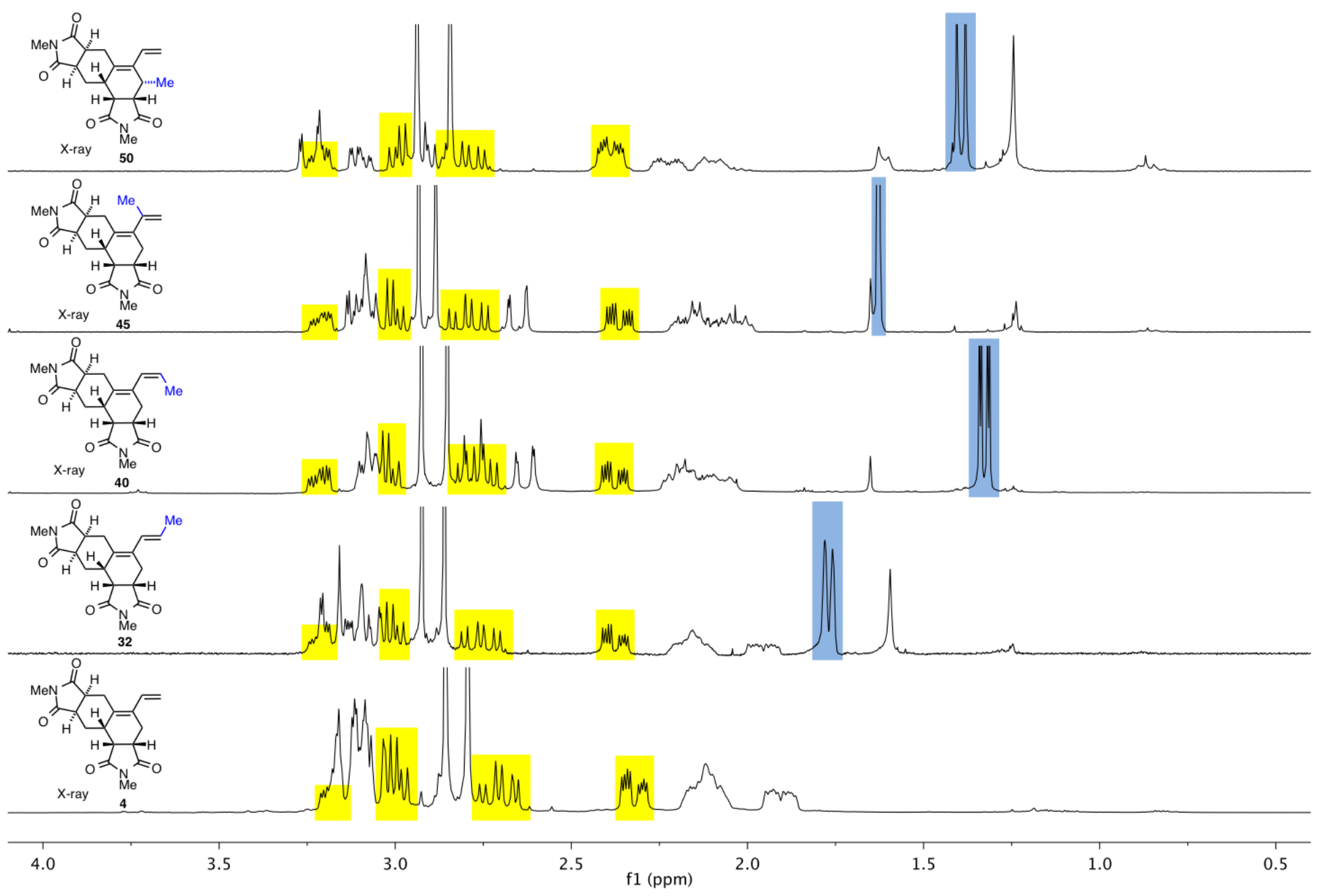

Figure S20: ${ }^{1} \mathrm{H}$ NMR spectra $\left(300 \mathrm{MHz}\right.$, in $\left.\mathrm{CDCl}_{3}\right)$ of $\mathbf{5 0 , 4 5 , 4 0 , 3 2}$ and parent [4]dendralene bis-adduct $4 .{ }^{9}$ 
The stereochemistry of $\mathbf{5 3}$ was assigned through $2 \mathrm{D}$ NMR experiments. The ${ }^{1} \mathrm{H}-{ }^{1} \mathrm{H}$ NOESY spectrum is shown in Figure S21.

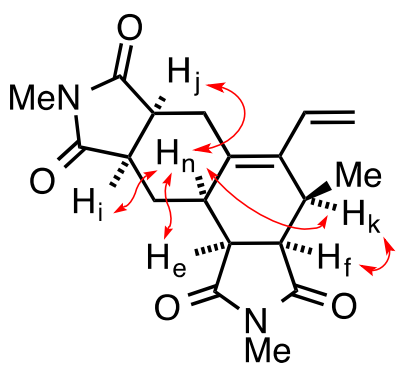

51

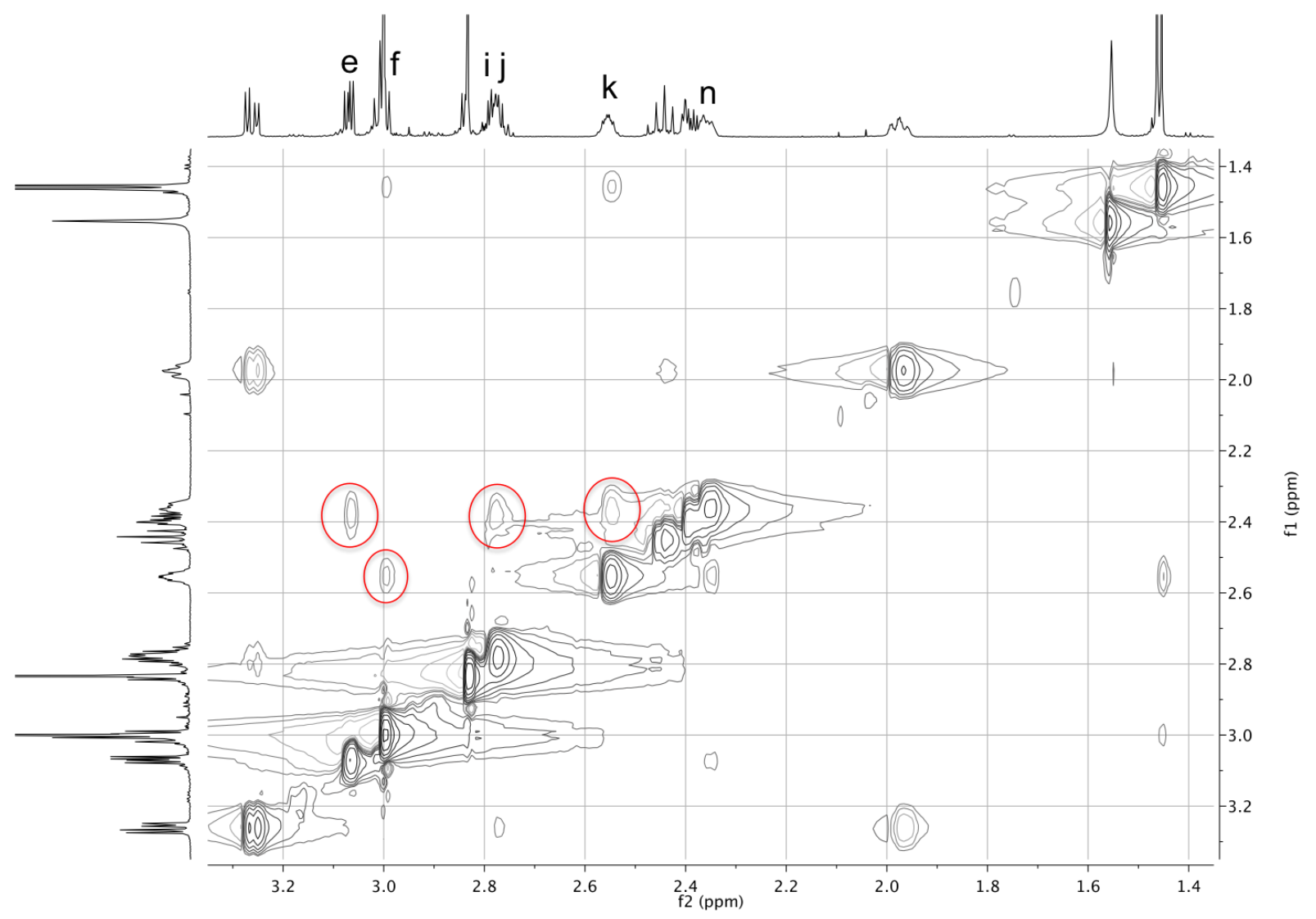

Figure S21: ${ }^{1} \mathrm{H}-{ }^{1} \mathrm{H}$ NOESY NMR spectrum $\left(800 \mathrm{MHz}\right.$, in $\left.\mathrm{CDCl}_{3}\right)$ of 53. 
The stereochemistry of minor bis-adduct $\mathbf{5 1}$ was also assigned by comparison of ${ }^{1} \mathrm{H}$ NMR spectra with minor bis-adduct $\mathbf{4 1}$. Similarities between ${ }^{1} \mathrm{H}$ NMR spectra of $\mathbf{5 1}$ and $\mathbf{4 1}$ are highlighted in Figure S22. Single crystal X-ray analysis of $\mathbf{4 1}$ (see Figure S4) secured the stereochemical assignments of compound $\mathbf{5 1 .}$

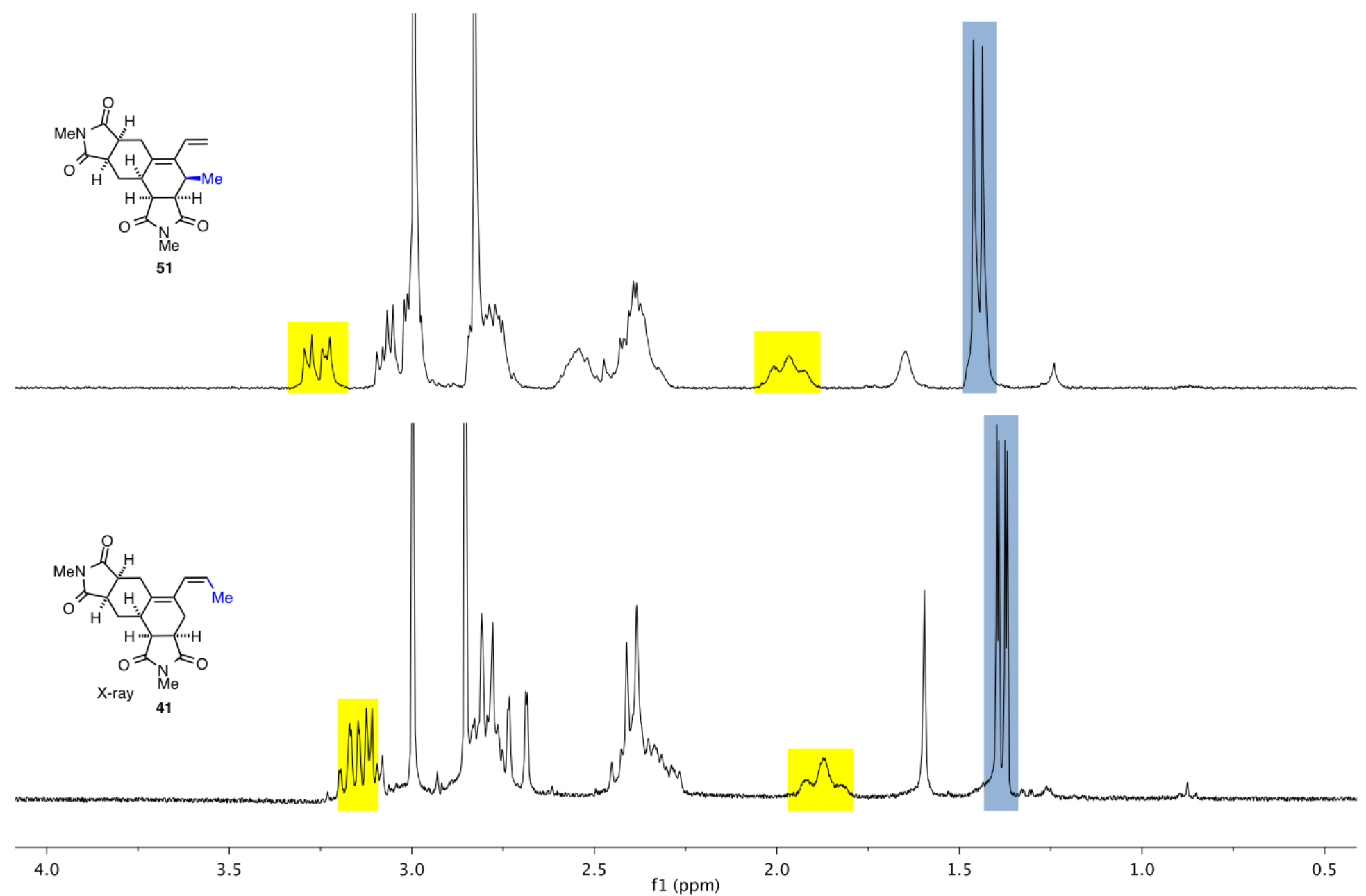

Figure S22: ${ }^{1} \mathrm{H}$ NMR spectra $\left(300 \mathrm{MHz}\right.$, in $\left.\mathrm{CDCl}_{3}\right)$ of $\mathbf{5 1}$ and $\mathbf{4 1}$. 
Similarities between ${ }^{1} \mathrm{H}$ NMR spectra of $\mathbf{4 7}$ and parent [6]dendralene terminal-terminal bis-adduct $\mathbf{B 1}{ }^{10}$ are highlighted in Figure S23. Single crystal X-ray analysis of $\mathbf{4 7}$ (see Figure S6) and $\mathbf{B} \mathbf{1}^{10}$ secured the stereochemical assignments of these compounds.
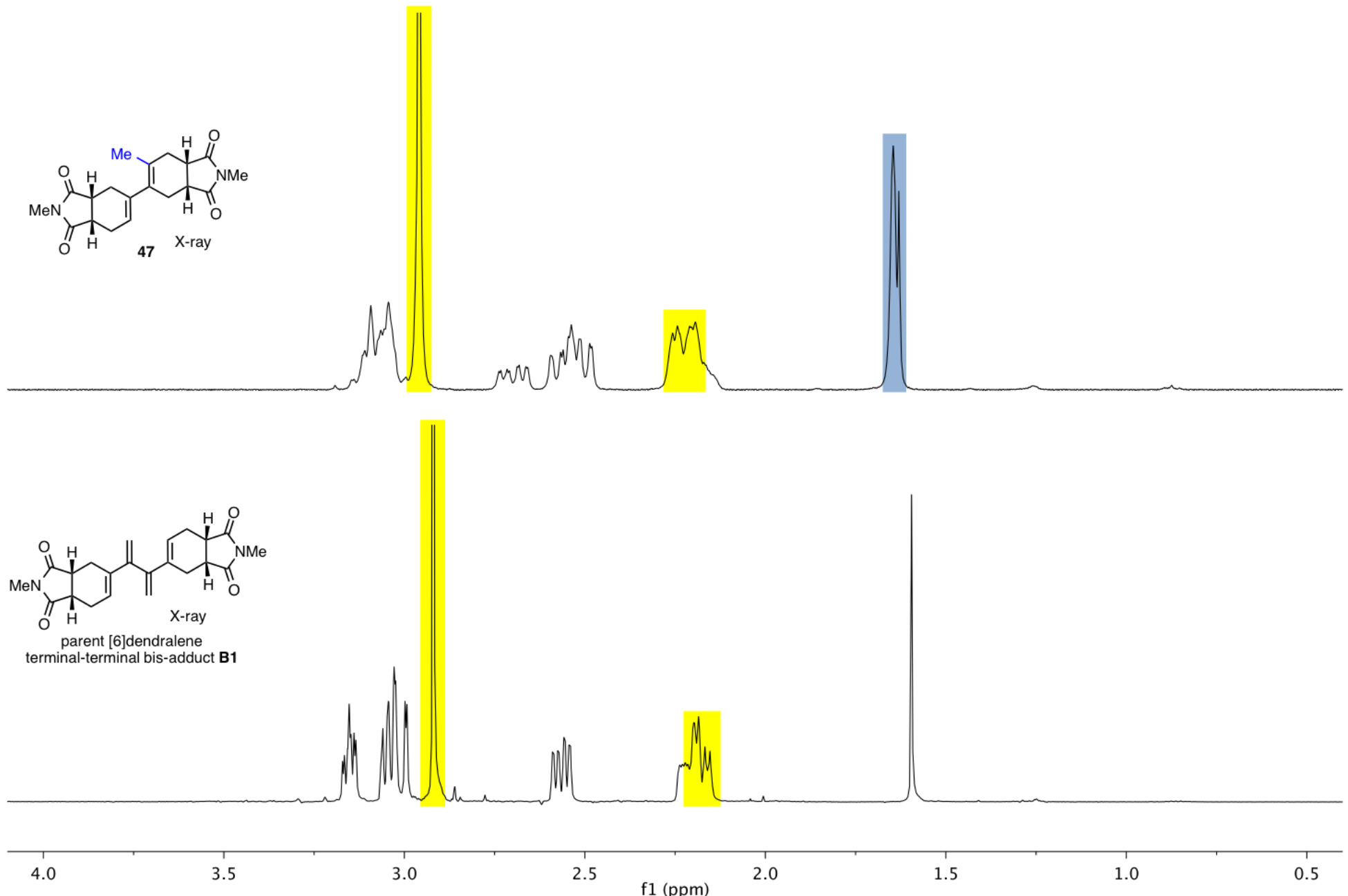

Figure S23: ${ }^{1} \mathrm{H}$ NMR spectra of $47\left(300 \mathrm{MHz}\right.$, in $\left.\mathrm{CDCl}_{3}\right)$ and $\mathbf{B} 1^{10}\left(500 \mathrm{MHz}\right.$, in $\left.\mathrm{CDCl}_{3}\right)$. 
Similarities between ${ }^{1} \mathrm{H}$ NMR spectra of $\mathbf{4 6}$ and parent [6]dendralene terminal-terminal bis-adduct $\mathbf{B 2}{ }^{10}$ are highlighted in Figure S24. Tentative stereochemical assignment of compound $\mathbf{4 6}$ was made by ${ }^{1} \mathrm{H}$ NMR in analogy to similar compound B2.

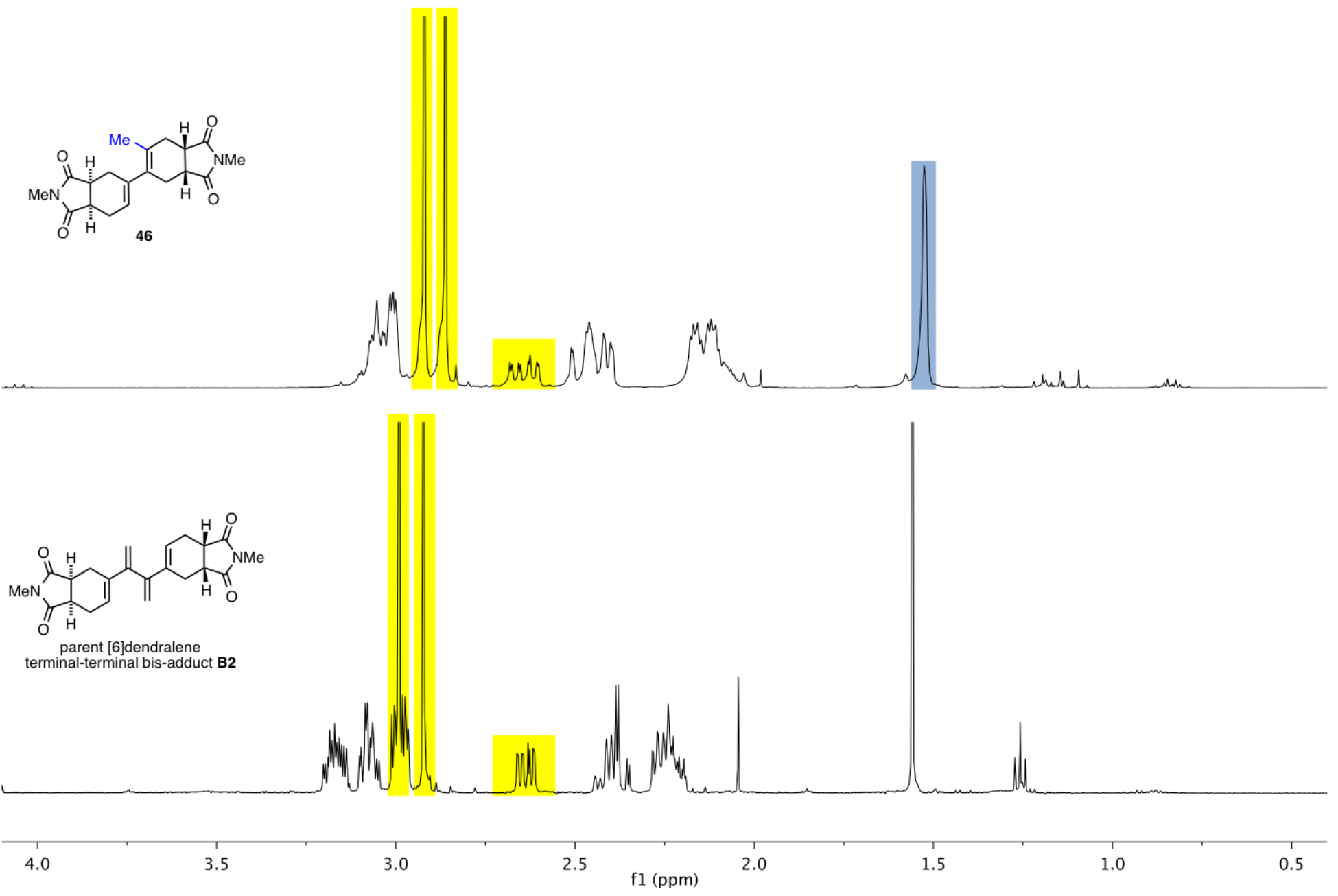

Figure S24: ${ }^{1} \mathrm{H}$ NMR spectra of $46\left(300 \mathrm{MHz}\right.$, in $\left.\mathrm{CDCl}_{3}\right)$ and $\mathbf{B 2}^{10}\left(500 \mathrm{MHz}\right.$, in $\left.\mathrm{CDCl}_{3}\right)$. 
The stereochemistry of tris-adduct 37 was assigned by comparison of ${ }^{1} \mathrm{H}$ NMR spectra with tris-adduct 9. Similarities between ${ }^{1}$ H NMR spectra of $\mathbf{3 7}$ and $\mathbf{9}$ are highlighted in Figure S25. Single crystal X-ray analysis of $\mathbf{9}^{9}$ secured the stereochemical assignments of compound 37 .

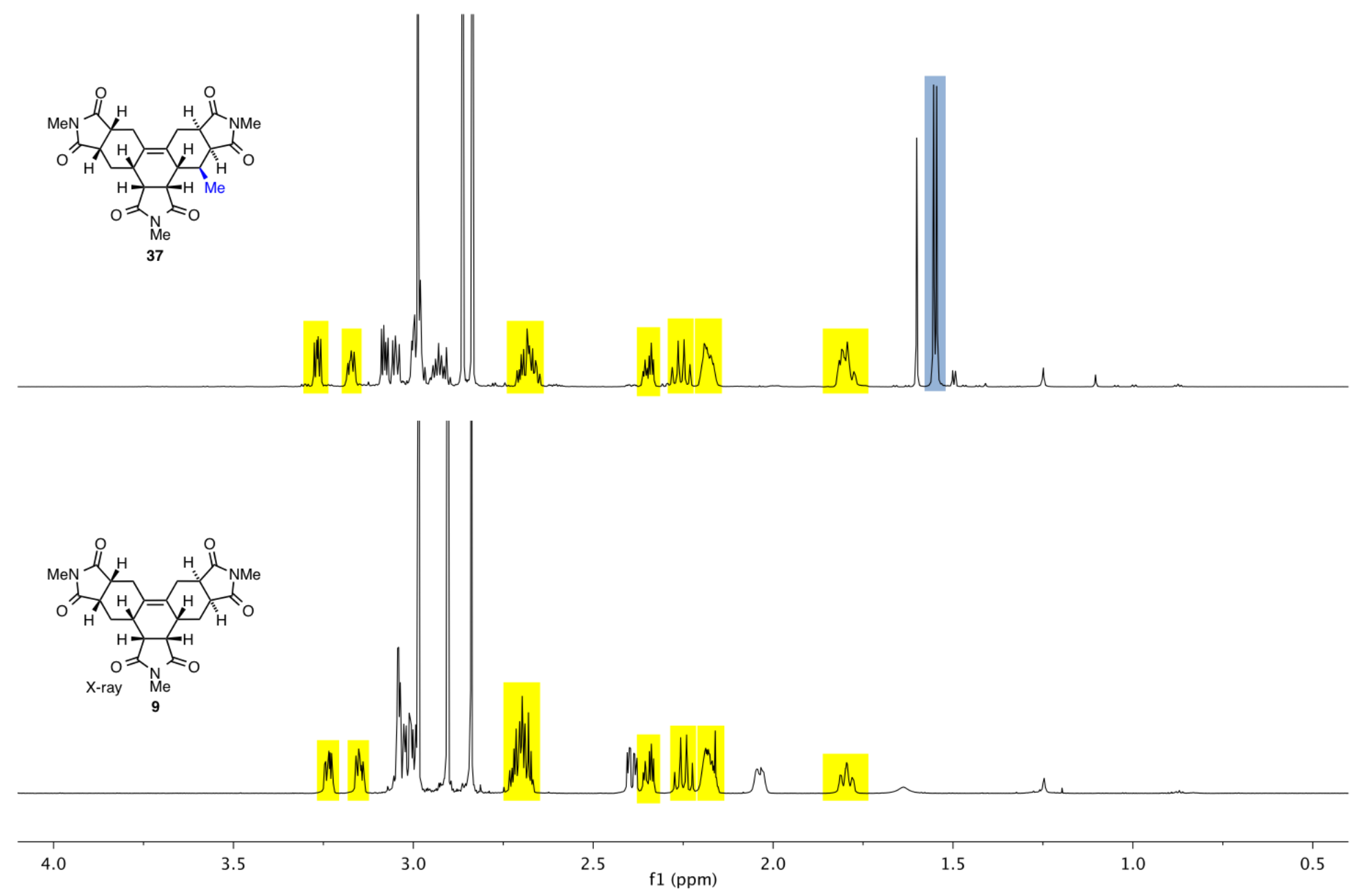

Figure S25: ${ }^{1} \mathrm{H}$ NMR spectra $\left(800 \mathrm{MHz}\right.$, in $\left.\mathrm{CDCl}_{3}\right)$ of 37 and parent [4]dendralene tris-adduct 9. 9 


\section{References}

(1 ) Pangborn, A. B.; Giardello, M. A.; Grubbs, R. H.; Rosen, R. K.; Timmers, F. J. Organometallics 1996, 15, 1518-1520.

(2) Armarego, W. L. F.; Chai, C. L. L. in Purification of Laboratory Chemicals - $5^{\text {th }}$ Edn. (Butterworth-Heinemann, Cornwall, 2003).

(3) Love, B. E.; Jones, E. G. J. Org. Chem. 1999, 64, 3755-3756.

(4) Fringuelli, F.; Girotti, R.; Pizzo, F.; Vaccaro, L. Org. Lett. 2006, 8, 2487-2489.

(5) Hu, Z.; Lakshmikantham, M. V.; Cava, M. P. J. Org. Chem. 1992, 57, 3988-3990.

(6) DENZO-SMN. Otwinowski, Z.; Minor, W. Processing of X-ray diffraction data collected in oscillation mode. In Methods in Enzymology, Volume 276: Macromolecular Crystallography, Part A; Carter Jr., C. W.; Sweet, R. M., Eds.; Academic Press: New York, 1997; pp. 307-326.

(7) SIR92. Altomare, A.; Cascarano, G.; Giacovazzo, C.; Guagliardi, A.; Burla, M. C.; Polidori, G.; Camalli, M. J. Appl. Crystallogr. 1994, 27, 435.

(8) Betteridge, P. W.; Carruthers, J. R.; Cooper, R. I.; Prout, K.; Watkin, D. J. J. Appl. Crystallogr. 2003, 36, 1487.

(9) Payne, A. D.; Willis, A. C.; Sherburn, M. S. J. Am. Chem. Soc. 2005, 127, 12188-12189.

(10) Bojase, G. P. PhD Thesis, The Australian National University, 2009. 